NBER WORKING PAPER SERIES

\title{
WHAT IS WRONG WITH TAYLOR RULES? \\ USING JUDGMENT IN MONETARY \\ POLICY THROUGH TARGETING RULES
}

\author{
Lars E. O. Svensson \\ Working Paper 9421 \\ http://www.nber.org/papers/w9421 \\ NATIONAL BUREAU OF ECONOMIC RESEARCH \\ 1050 Massachusetts Avenue \\ Cambridge, MA 02138 \\ December 2002
}

I thank Jon Faust, Dale Henderson, Bennett McCallum, Anders Vredin and Michael Woodford for many general discussions on issues related to this paper, and Claes Berg, Hans Dillén, Giovanni Favara, Mark Gertler, Kai Leitemo, Bennett McCallum, Edward Nelson, Glenn Rudebusch, Christopher Sims, Frank Smets, Robert Tetlow, Edwin Truman, David Vestin, Michael Wickens, Michael Woodford, participants in conferences at the Bank of England and Insead and in the NBER Summer Institute, and the editors and referees for specific comments on previous versions of this paper. I also thank Annika Andreasson and Kathleen DeGennaro for editorial and secretarial assistance. Financial support from Princeton University's Center for Economic Policy Studies is gratefully acknowledged. Remaining errors and expressed views are my own. The views expressed herein are those of the authors and not necessarily those of the National Bureau of Economic Research.

(C) 2002 by Lars E. O. Svensson. All rights reserved. Short sections of text not to exceed two paragraphs, may be quoted without explicit permission provided that full credit including, (C) notice, is given to the source. 
What is Wrong with Taylor Rules? Using Judgment in

Monetary Policy through Targeting Rules

Lars E. O. Svensson

NBER Working Paper No. 9421

December 2002

JEL No. E42, E52, E58

\begin{abstract}
It is argued that inflation targeting is best understood as a commitment to a targeting rule rather than an instrument rule, either a general targeting rule (explicit objectives for monetary policy) or a specific targeting rule (a criterion for (the forecasts of) the target variables to be fulfilled), essentially the equality of the marginal rates of transformation and substitution between the target variables. Targeting rules allow the use of judgment and extra-model information, are more robust and easier to verify than optimal instrument rules, and they can nevertheless bring the economy close to the socially optimal equilibrium.
\end{abstract}

\author{
Lars E. O. Svensson \\ Department of Economics \\ Fisher Hall \\ Princeton University \\ Princeton, NJ 08544-1021 \\ and NBER \\ svensson@princeton.edu
}




\section{Introduction}

What are the rules for good monetary policy? Here, "good monetary policy" is used in the conventional meaning of successfully stabilizing inflation around a low average level, with some concern for stabilizing output around potential output, what has been called "flexible inflation targeting" in the literature (see, for instance, the contributions to the influential Jackson-Hole symposium organized by Federal Reserve Bank of Kansas City 1999). ${ }^{1}$ What answer does the large literature on monetary-policy rules supply? Most of that literature uses a very narrow interpretation of "policy rule." According to this interpretation, a policy rule expresses the central bank's instrument (usually a short interest rate, the instrument rate; the federal funds rate in the U.S., for instance) as an explicit function of information available to the central bank. Such a policy rule can be called an instrument rule. In particular, most of the literature focuses on simple instrument rules, where the instrument is a function of a small subset of the information available to the central bank. The best-known simple instrument rule is the Taylor rule (John Taylor 1993), where the instrument rate responds only to the inflation and output gaps according to

$$
i_{t}=\bar{f}+f_{\pi}\left(\pi_{t}-\pi^{*}\right)+f_{x} x_{t}
$$

where $i_{t}$ is the instrument rate in period $t, \bar{f}$ is a constant, $\pi_{t}-\pi^{*}$ is the "inflation gap," where $\pi_{t}$ is (the rate of) inflation and $\pi^{*} \geq 0$ is a given inflation target, $x_{t} \equiv y_{t}-y_{t}^{*}$ is the output gap, where $y_{t}$ is $(\log )$ output and $y_{t}^{*}$ is $(\log )$ potential output, and the coefficients $f_{\pi}$ and $f_{x}$ are positive. The constant $\bar{f}$ equals the sum of the average short real interest rate and the inflation target. In the original Taylor (1993) formulation, the coefficients $f_{\pi}$ and $f_{x}$ are 1.5 and .5 , respectively; the inflation target $\pi^{*}$ is $2 \%$ (per year), the average short real interest rate is $2 \%$, and the coefficient $\bar{f}$ is hence $4 \%^{2}$

Much research during the last two decades has examined simple instrument rules (mostly variants of the Taylor rule), both from a descriptive and a prescriptive perspective (see, for instance, McCallum 1999 and the contributions in Ralph Bryant, Peter Hooper and Catherine

\footnotetext{
${ }^{1}$ A noncontroversial objective of monetary policy would be to contribute to the welfare of the representative citizen. This is not an operational objective, though. An increasing number of countries have instead announced "price stability" (meaning low and stable inflation) as the primary objective for monetary policy, with some implicit or explicit concern also for the stability of the real economy, with the view that this is the best contribution monetary policy can make to citizens' welfare.

${ }^{2}$ Knut Wicksell (1898) and Dale Henderson and Warwick McKibbin (1993) have suggested other simple instrument rules with the interest rate as the instrument. Allan Meltzer (1987) and Bennett McCallum (1988) have suggested simple instrument rules with the monetary base as the instrument. The first empirical estimates of interest-rate reaction functions may have been in the 1960s by William Dewald and Harry Johnson (1963) and James Christian (1968). Recent general discussions of Taylor rules include Richard Clarida, Jordi Galí and Mark Gertler (1999), Robert Hetzel (2000), Sharon Kozicki (1999) and Michael Woodford (2001).
} 
Mann 1993 and Taylor 1999c). The introduction by Taylor (1999a) gives a summary of the standard approach of specifying a model, a class of simple instrument rules and a loss function for evaluating alternative simple instrument rules in the class. From a descriptive perspective, it has been examined to what extent simple instrument rules are good empirical descriptions of central-bank behavior (see, for instance, Clarida, Galí and Gertler 1998 and John Judd and Glenn Rudebusch 1998). From a prescriptive perspective, it has been examined how simple instrument rules perform (in the sense of stabilizing inflation around an inflation target without causing unnecessary output-gap variability) in different macro models.

The research on instrument rules has contributed many important insights. These insights include that stability of inflation and determinacy (that is, uniqueness) of equilibria in stickyprice models require the long-run response of the short interest rate to inflation to be larger than one-to-one, the so-called "Taylor principle" (see Taylor 1999b and Woodford 2001), ${ }^{3}$ and that interest-rate smoothing, in the sense of responding to the lagged instrument rate, may improve performance by introducing desirable "history-dependence" that beneficially influences private-sector inflation expectations (see Julio Rotemberg and Woodford 1997 and Woodford 1999c). Other insights are that it is better that the instrument responds to the determinants of the target variables than to the target variables themselves (for instance, even if inflation is the only target variable (the only variable in the loss function), it is generally better to respond to both current inflation and the output gap, since both of these are determinants of future inflation; see for instance, Lars Svensson 1997a and Rudebusch and Svensson 1999), and that the response coefficients in the optimal reaction function depend on the weights in the loss function on different target variables in sometimes nonintuitive and complex ways (see, for instance, Svensson 1997a). One line of research has examined to what extent a given simple instrument rule is "robust," in the sense of performing reasonably well in different macro models. Given the uncertainty about which model is the best representation of reality, little would then be lost if central banks would apply a robust simple instrument rule. Results to date, although arguably from not too different models of closed economies, indicate that variants of the Taylor rule can be quite robust in this sense. ${ }^{4}$

\footnotetext{
${ }^{3}$ Several recent papers, for instance, Jess Benhabib, Stephanie Schmitt-Grohé and Martín Uribe (2001), Charles Carlstrom and Timothy Fuerst (2000) and Lawrence Christiano and Christopher Gust (1999), examine determinacy and multiplicity of equilibria under the assumption that the central bank follows Taylor-type instrument rules.

${ }^{4}$ McCallum has in several papers, for instance, (1988), examined robustness properties of a simple instrument rule for the monetary base. Andrew Levin, Volker Wieland and John Williams (1999) and Rudebusch (2002a) examine the robustness properties of Taylor-type rules.
} 
Thus, the answer from most of the literature on monetary-policy rules to the question posed above seems to be that central banks should commit to following a specific simple instrument rule. Indeed, Federal Reserve Board Governor Yellen, in a discussion of inflation targeting at the FOMC meeting in January, 1995, (Federal Reserve Board 1995, p. 43-44), seems to prefer a Taylor-type rule as a suitable policy rule for the Federal Reserve System:

[I]t seems to me that a reaction function in which the real funds rate changes by roughly equal amounts in response to deviations of inflation from a target of 2 percent and to deviations of actual from potential output describes tolerably well what this Committee has done since 1986. This policy... is an example of the type of hybrid rule that would be preferable [to inflation targeting] in my view, if we wanted a rule. I think the Greenspan Fed has done very well following such a rule, and I think that is what sensible central banks do.

Thus, if a central bank wants to commit itself to a simple instrument rule, it should announce the simple instrument rule and then mechanically follow it. This has the further implication that once the decision about the instrument rule is made, the decision process of the bank is exceedingly simple and mechanical. For the Taylor rule, it just consists of regularly collecting data on inflation and output, collecting either external estimates of potential output or constructing internal estimates, and then calculating the output gap. (Estimating potential output is a nontrivial matter, though, and a major challenge in practical monetary policy.) Once these inputs in the Taylor rule are available, calculating the instrument-setting is completely mechanical. In particular, there is no room for judgment (except that judgment may enter in the estimation of potential output). As McCallum (2000) has expressed it, policy decisions could be turned over to "a clerk armed with a simple formula and a hand calculator."

However, another possible answer from the literature on policy rules is that the instrument rules proposed should not be followed mechanically. Thus, a firm commitment to the instrument rules is not desirable. Instead, the instrument rules should be seen as mere "guidelines" for monetary policy. This is the view expressed by Taylor, for instance in Taylor (1993) and, in more detail, in Taylor (2000). A problem with this answer and use of simple instrument rules is that the rule is then incomplete: some deviations are allowed, but there are no rules for when deviations from the instrument rulse are appropriate. As discussed further below, this arguably makes the idea of simple instrument rules as mere guidlines for monetary policy too vague to be operational.

The contrast between these two alternative answers from most of the literature on monetarypolicy rules and actual monetary-policy practice is striking. First, monetary-policy reform in a 
number of countries during the 1990s has to a large extent focused on (1) formulating explicit and increasingly precise objectives for monetary policy and (2) creating an institutional setting where the central bank is strongly committed to achieving those objectives (see, for instance, Ben Bernanke, Thomas Laubach, Frederic Mishkin and Adam Posen 1999). Thus, there has been commitment to objectives rather than to simple instrument rules. Second, central banks have developed very elaborate and complex decision-making processes, where large amounts of information are collected, processed and analyzed, and where considerable judgment is exercised (see, for instance, Donald Brash 2001). Third, any simple rules of thumb actually used are conditions for target variables or forecasts of target variables, rather than explicit formulas for the instrument rate. This is the case, for instance, for the rule of thumb expressed by the Bank of England and Sveriges Riksbank (the central bank of Sweden), that normally, the interest rate should be adjusted such that the resulting inflation forecast at an appropriate horizon (usually about two-years ahead) is on target. ${ }^{5}$ No central bank has so far made a commitment to a simple instrument rule like the Taylor rule or variants thereof. Neither has any central bank announced a particular instrument rule as a "guideline."

Thus, there appears to be a substantial gap between the research on instrument rules and the practice of monetary policy. This paper discusses and proposes a way to bridge that gap. From a descriptive perspective, it argues that, in order to be useful for discussing real-world monetary policy, the concept of monetary-policy rules has to be broadened and defined as "a prescribed guide for monetary-policy conduct," including "targeting rules" as well as "instrument rules." 6 Furthermore, it argues that the monetary-policy practice is better discussed in terms of targeting rules than instrument rules. A general targeting rule specifies the objectives to be achieved, for instance, by listing the target variables, the targets (target levels) for those variables, and the

${ }^{5}$ This rule furthermore refers to constant-interest-rate forecasts, since both the Bank of England and the Riksbank mainly rely on such forecasts.

The rule has been stated by Charles Goodhart (2000), former member of the Bank of England Monetary Policy Committee, as: "When I was a member of the MPC I thought that I was trying, at each forecast round, to set the level of interest rates, on each occasion, so that without the need for future rate changes prospective (forecast) inflation would on average equal the target at the policy horizon. This was, I thought, what the exercise was supposed to be."

The rule has been stated by Lars Heikensten, First Deputy Governor of the Riksbank, as: "Monetary policy is normally conducted so as to be on target, defined in terms of the CPI, one to two years ahead." Furthermore, any departures from this general rule, due to transitory disturbances to inflation or real costs from a quick return of inflation to target, will be announced by the Riksbank in advance (Lars Heikensten 1999, p. 16). Heikensten and Anders Vredin (1998) provide more discussion of the application of the rule. Claes Berg (1999) gives an extensive account and discussion of the Riksbank's implementation of inflation targeting.

6 Target(ing) rules have previously been discussed by Christopher Sims (1980) (see footnote 38 below), Kenneth Rogoff (1985), Carl Walsh (1998), Svensson (1997a, 1999b), Rudebusch and Svensson (1999), Stephen Cecchetti (1998, 2000), Clarida, Gali and Gertler (1999) and Svensson and Woodford (2002a). After the first versions of this paper were written, Marc Giannoni and Woodford have provided a derivation of an optimal targeting rule in a general linear-quadratic model in (2002a) and a detailed discussion of optimal targeting rules in the basic New-Keynsian model in (2002b). 
(explicit or implicit) loss function to be minimized. A specific targeting rule specifies conditions for the target variables (or forecasts of the target variables), for instance, like the above rule of thumb of the Bank of England and the Riksbank. From a prescriptive perspective, this paper argues that a commitment to targeting rules has a number of advantages, for instance, in allowing the use of all relevant information, in particular, allowing the use of judgment, being more robust to both disturbances and model variation than instrument rules, and likely leading to better monetary-policy outcomes than instrument rules. Presumably, this is why real-world monetary policy and monetary-policy reform have shunned commitment to instrument rules.

Before the rational-expectations revolution in macroeconomics, the behavior of firms and households was frequently represented by simple ad hoc reaction functions, for instance, consumption and investment functions. The rational-expectations revolution led to an emphasis on optimizing and forward-looking behavior by private agents, and their behavior being represented by first-order conditions, Euler conditions, derived from their objectives and constraints. Still, the pioneers of the rational-expectations revolution continued to represent economic policy by mechanical reaction functions, which ignores that under optimizing policy those reaction functions would be as much subject to the essence of the Lucas critique (that reaction functions are endogenous) as mechanical reaction functions for private agents.

Monetary policy by the world's more advanced central banks these days is at least as optimizing and forward-looking as the behavior of the most rational private agents. I find it strange that a large part of the literature on monetary policy still prefers to represent central bank behavior with the help of mechanical instrument rules. The concept of general and specific targeting rules is designed to provide a discussion of monetary policy rules that is fully consistent with the optimizing and forward-looking nature of modern monetary policy. From this point of view, general targeting rules essentially specify operational objectives for monetary policy and specific targeting rules essentially specify operational Euler conditions for monetary policy. In particular, an optimal targeting rule expresses the equality of the marginal rates of transformation and the marginal rates of substitution between the target variables in an operational way. ${ }^{7}$

\footnotetext{
${ }^{7}$ Much monetary-policy reform during the last decade can be interpreted in terms of achieving a trinity of (1) a mandate in the form of clear objectives for monetary policy, (2) operational independence for the central bank, and (3) accountability of the central bank for fulfilling the mandate. Operational independence (also called instrument-independence) protects the central bank from short-term political pressure to stray from its objectives and accountability structures strengthens the bank's commitment to fulfilling the mandate. This trinity can be seen as directed towards making monetary policy goal-directed and therefore optimizing, systematic and rule-like. New Zealand since the passing of the Reserve Bank Act in 1989, provides a good example and has been a source of inspiration for reform in many other countries. In May 2000, I was asked by the Minister of Finance of the New Zealand Government to conduct a review of monetary policy in New Zealand. The evaluation of the goal-directed and forward-looking monetary policy in New Zealand raised many interesting issues and is discussed in Svensson
} 
The rest of the paper is outlined as follows. Section 2 presents the monetary-policy problem facing an inflation-targeting central bank, namely, to stabilize inflation around an inflation target with (under realistic "flexible" inflation targeting) some weight also on stabilizing the output gap. The central-bank objective is expressed as a conventional intertemporal loss function to be minimized, subject to the central bank's information about the state of the economy and its view of the transmission mechanism. For concreteness, two simple examples of models of the transmission mechanism are presented, one backward-looking and one forward-looking. Section 3 discusses a direct optimal-control approach: to solve the optimization problem for the optimal reaction function once and for all and then make a commitment to follow that reaction function. It is shown that even in the simple examples of the transmission mechanism used here, the optimal reaction functions are too complex to be practicable, not to mention verifiable (further specified in section 3). For this and a number of other reasons discussed, the direct optimal-control approach must be judged infeasible. Section 4 discusses a commitment to a simple instrument rule, which, although in principle verifiable, is found to be inadequate as a positive description of real-world inflation targeting and likely to be unsuitable as a normative recommendation for monetary policy. This section also discusses the alternative weaker proposal that simple instrument rules should be used as mere "guidelines," from which deviations sometimes are called for; this proposal is however found incomplete, since it doesn't specify when deviations are appropriate. Section 5 defines targeting rules and argues that a commitment to a targeting rule is both an appropriate description of real-world inflation targeting and a suitable normative recommendation for future monetary-policy developments. This section, as well as the previous two sections to some extent, also responds to recent discussion by McCallum (2000), McCallum and Edward Nelson (2000) and Woodford (1999a) regarding the positive and normative role of commitment to instrument rules and targeting rules. Section 6 summarizes and presents some conclusions. Appendices A-C contain technical and other details.

\section{The monetary-policy problem}

In order to induce sufficient precision and clarity in the discussion, and to avoid the confusion and misunderstanding in some of the literature on monetary-policy rules, it is necessary to provide a bit of formal notation. Inflation targeting involves stabilizing inflation around an inflation target. In practice, as discussed in a number of recent contributions (see, for instance, Federal (2001a). 
Reserve Bank of Kansas City 1996, 1999), inflation targeting is "flexible" inflation targeting, in the sense that it also involves some concern about the stability of the real economy. ${ }^{8}$ These objectives are conventionally and conveniently expressed as an intertemporal loss function to be minimized in each period $t, t=\ldots,-1,0,1, \ldots$, consisting of the expected sum of discounted current and future losses,

$$
\mathrm{E}\left[(1-\delta) \sum_{\tau=0}^{\infty} \delta^{\tau} L_{t+\tau} \mid I_{t}, z^{t}\right] .
$$

Here $\mathrm{E}\left[\cdot \mid I_{t}, z^{t}\right]$ denotes rational expectations conditional on the central bank's information, $I_{t}$, in period $t$ about the state of the economy and the transmission mechanism of monetary policy, and the bank's "judgment," $z^{t}$, to be further specified below. Furthermore, $\delta(0<\delta<1)$ is a discount factor and $L_{t}$ denotes the period loss in period $t$. The scaling by $1-\delta$ is practical, since then the scaled discount factors sum to unity, so the intertemporal loss is a weighted average of the expected period loss and hence of the same order of magnitude. The period loss is a weighted sum of the squared inflation gap and the squared output gap,

$$
L_{t}=\frac{1}{2}\left[\left(\pi_{t}-\pi^{*}\right)^{2}+\lambda x_{t}^{2}\right]
$$

where $\lambda>0$ is a given weight on output-gap stabilization relative to inflation stabilization. Since the implicit output target in (2.2) is not subject to choice but given by potential output, the output target is not "overambitious", so there is no conspicuous reason for an inflation bias (average inflation above the inflation target) as in the literature on the time-consistency problem following Finn Kydland and Edward Prescott (1977) and Robert Barro and David Gordon (1983). "Strict" inflation targeting would be the (unrealistic) special case of $\lambda=0$. Thus, for $\lambda>0$, we have flexible inflation targeting and both inflation and the output gap are target variables (target variables in the sense of entering the loss function). (The abovementioned FOMC discussion of inflation targeting in January 1995, Federal Reserve Board1 995, p. 38-59, is very interesting but somewhat surprising, since all FOMC members seem to interpret inflation targeting as strict inflation targeting, and no member seems aware of the fact that real-world inflation targeting is flexible inflation targeting. $)^{9}$

Many papers assume a loss function of the form

$$
\frac{1}{2}\left(\operatorname{Var}\left[\pi_{t}\right]+\lambda \operatorname{Var}\left[x_{t}\right]\right)
$$

\footnotetext{
${ }^{8} \mathrm{I}$ thus here abstract from any separate objective to stabilize or smooth interest rates, an objective which is difficult to rationalize. Such objectives and their consequences are discussed separately in section 5.6.

${ }^{9}$ Note that, since the intertemporal loss function is the expected discounted future losses, this formulation includes the realistic case when potential output, $y_{t}^{*}$, is unobservable and has to be estimated.
} 
the weighted unconditional variances of inflation and the output gap. This loss function can be seen as the limit of (2.1): The limit when the discount factor approaches unity, $\delta \rightarrow 1$, can be shown to equal ${ }^{10}$

$$
\frac{1}{2}\left\{\left(\mathrm{E}\left[\pi_{t}\right]-\pi^{*}\right)^{2}+\lambda \mathrm{E}\left[x_{t}\right]^{2}\right\}+\frac{1}{2}\left\{\operatorname{Var}\left[\pi_{t}\right]+\lambda \operatorname{Var}\left[x_{t}\right]\right\}
$$

Thus, if the unconditional means fulfill $\mathrm{E}\left[\pi_{t}\right]=\pi^{*}$ and $\mathrm{E}\left[x_{t}\right]=0$, the limit of the intertemporal loss function is $(2.3)$.

The monetary-policy problem for the central bank is then to set its monetary-policy instrument each period $t, i_{t}$ (usually a short interest rate, the "instrument rate"), so as to minimize the intertemporal loss function (2.1), subject to the central bank's information, $I_{t}$, about the state of the economy (including its view of the transmission mechanism for monetary policy, that is, how the instrument affects the target variables) and the central bank's judgment, $z^{t}$ (see below).

For concreteness, I will use two simple examples of standard models of the transmission mechanism, one "backward-looking" and one "forward-looking".

\subsection{Example 1: A simple backward-looking model of the transmission mechanism}

This example of a simple backward-looking model of a closed economy is a variant of that in Svensson (1997a) and Rudebusch and Svensson (1999). ${ }^{11}$ The model has a one-period control lag for the output gap, and a two-period control lag for inflation. For reasons explained below in section 5.4.1, it is practical (and not unrealistic) to let the period be some 3 quarters (the period in Svensson 1997a is taken to be about a year). The main simplification of the backward-looking model is that private-sector expectations are implicitly treated as adaptive expectations, which simplifies the discussion considerably.

Suppose aggregate supply (the Phillips curve) is given by

$$
\pi_{t+1}=\pi_{t}+\alpha_{x} x_{t}+\alpha_{z} z_{t+1}+\varepsilon_{t+1}
$$

where the coefficient $\alpha_{x}$ is positive, $z_{t+1}$ is a column vector exogenous variables discussed below, $\alpha_{z}$ is a corresponding row vector of coefficients multiplying the elements of $z_{t+1}$, so $\alpha_{z} z_{t+1}$ is the scalar product of the two vectors, and $\varepsilon_{t}$ is an iid "cost-push" shock with zero mean and

\footnotetext{
${ }^{10}$ The scaling by $1-\delta$ in (2.1) keeps the limit finite.

11 Laurence Ball (1999) has later used the same model as Svensson (1997a).
} 
variance $\sigma_{\varepsilon}^{2}$. Let aggregate demand (in terms of the output gap) be given by

$$
x_{t+1}=\beta_{x} x_{t}+\beta_{z} z_{t+1}-\beta_{r}\left(r_{t}-\bar{r}\right)+\eta_{t+1},
$$

where the coefficients $\beta_{x}$ and $\beta_{r}$ are positive, $\beta_{z}$ is a row vector of coefficients multiplying the elements of $z_{t+1}, r_{t}$ is a short real interest rate given by

$$
r_{t} \equiv i_{t}-\pi_{t+1 \mid t}
$$

where $i_{t}$ is a short nominal interest rate and the central bank's instrument, $\bar{r}$ is the average real interest rate, and $\eta_{t}$ is an iid "excess demand" shock with zero mean and variance $\sigma_{\eta}^{2}{ }^{12}$ Furthermore, $q_{t+\tau \mid t}$ for any variable $q$ denotes $\mathrm{E}_{t} q_{t+\tau \mid t} \equiv \mathrm{E}\left[q_{t+\tau} \mid I_{t}\right]$, the rational expectation of $q_{t+\tau}$ conditional on the information available in period $t, I_{t}$. Under the assumption of symmetric information, the private sector has the same information as the central bank, so $\pi_{t+1 \mid t}$ is oneperiod-ahead private-sector inflation expectations, and hence $i_{t}-\pi_{t+1 \mid t}$ is the short real interest rate. Potential output, $y_{t}^{*}$, is assumed to be an exogenous stochastic process.

Let $z_{t+1}$ be a vector of exogenous variables in period $t+1$ that are not known in period $t$ and earlier periods (and potentially unobservable also on period $t+1$ and later periods). It is called the deviation. The idea is that it represents additional determinants of future inflation (when the corresponding elements of the vector $\alpha_{z}$ are nonzero) and the output gap (when the corresponding elements of $\beta_{z}$ are nonzero) than current inflation and the output gap, or the deviation of the true model of inflation and output-gap determination from the simple model with the deviation equal to zero. Thus, the sequence of deviations, $\left\{z_{t+\tau}\right\}_{\tau=-\infty}^{\infty}$ can be interpreted as potentially unobservable model perturbations, as in the literature on robust control. ${ }^{13}$ The central bank's estimate of $z_{t+\tau}$ in period $t$ is denoted by $z_{t+\tau, t}$. The sequence $z^{t} \equiv\left\{z_{t+\tau, t}\right\}_{\tau=-\infty}^{\infty}$ of the bank's estimate in period $t$ of past and future deviations is identified with the bank's judgment in period $t$. It represents the unavoidable judgment (almost) always applied in monetary policy. Any explicit model is always taken as, at best, an approximation of the true model of the economy, and monetary-policy makers always find it necessary to make some judgmental adjustments to the results of any given model. The so-called "add factors" applied to model equations in central-bank projections are one aspect of central-bank

\footnotetext{
12 A slightly more complex variant of the backward-looking model would replace the constant average real interest rate, $\bar{r}$, with an exogenous stochastic time-varying Wicksellian real natural interest rate, $r_{t}^{*}$, as in the forward-looking model below.

${ }^{13}$ See, for instance, Lars Hansen and Thomas Sargent (1998) and Alexei Onatski and James Stock (2000). However, that literature deals with the more complex case when the model perturbations are endogenous and chosen by nature to correspond to a worst-case scenario.
} 
judgment, see David Reifschneider, David Stockton and David Wilcox (1997). The general notation obviously allows for judgement affecting both future inflation and output as well as estimates of potential output.

One possibility is that the period- $t$ deviation, $z_{t}$, is observable in period $t$ and later periods, that only future deviations are not known and need to be estimated. Another possibility is that also the current and past deviations are unobservable and need to be estimated.that future. One simple information structure consistent with the latter case is when inflation $\pi_{t}$, output $y_{t}$, potential output $y_{t}^{*}$, and the short real rate $r_{t}$ are all observable in period $t$, but the shocks $\varepsilon_{t}$ and $\eta_{t}$ are unobservable. A somewhat more complex (but very realistic) information structure would make a time-variable component of potential output unobservable and affected by the deviation. Since what enters in the intertemporal loss function is expected current and future period losses, the intertemporal loss function is consistent with potential output and the output gap being unobservable. In the aggregate demand equation, the deviation could be interpreted as an unobservable time-variable component of a Wicksellian natural real interest rate.

Given this interpretation of the deviation $z_{t+1}$, it would be completely misleading to make a simplifying assumption like it being an exogenous autoregressive process. ${ }^{14}$ Thus, I will refrain from such an assumption and instead leave the dynamic properties of $z_{t+1}$ unspecified (except assuming that the unconditional mean of the deviation is zero, $\left.\mathrm{E}\left[z_{t+1}\right]=0\right)$. Instead, the focus will be on the central bank's judgment $z^{t}$ in period $t$ of the whole sequence of future (and current and past) deviations. For simplicity, I assume that the central bank's judgment is exogenous in any period $t$. For simplicity, I also assume that there is symmetric information in that the private sector has the same information about the economy and the transmission mechanism, and that the private sector's rational expectation in period $t$ of the sequence $\left\{z_{t+\tau}\right\}_{\tau=-\infty}^{\infty}$, denoted $z_{\mid t} \equiv\left\{z_{t+\tau \mid t}\right\}_{\tau=-\infty}^{\infty}$ (the private-sector judgment), coincides with the central-bank judgment, $z^{t}$. $^{15}$

Thus, I assume that $\pi_{t}$ and $x_{t}$ are observable and known in the beginning of period $t$. Furthermore, I assume that the central bank's instrument $i_{t}$ is then set for the duration of

\footnotetext{
${ }^{14}$ For instance, assuming that the deviation follows $z_{t+1}=\Gamma z_{t}+\theta_{t+1}$, where $\Gamma$ is a matrix with eigenvalues inside the unit circle and $\theta_{t+1}$ is a vector of zero-mean iid shocks with constant covariance matrix.

15 Thus, under the assumption of observable inflation and output gaps and unobservable shocks $\varepsilon_{t}$ and $\eta_{t}$, the central bank's and the private sector's estimates in period $t+1$ of the unobservable cost-push and excess-demand shocks are by (2.4) and (2.5) trivially given by

$$
\varepsilon_{t+1, t+1}=\varepsilon_{t+1 \mid t+1}=\pi_{t+1}-\pi_{t}-\alpha_{y}\left(y_{t}-y_{t}^{*}\right)-\alpha_{z} z_{t+1, t+1}
$$
}

and

$$
\eta_{t+1, t+1}=\eta_{t+1 \mid t+1}=y_{t+1}-y_{t+1}^{*}-\beta_{y}\left(y_{t}-y_{t}^{*}\right)-\beta_{z} z_{t+1, t+1}+\beta_{r}\left(r_{t}-\bar{r}\right)
$$


period $t$. Note that one-period-ahead inflation expectations, $\pi_{t+1 \mid t}$, are predetermined,

$$
\pi_{t+1 \mid t}=\pi_{t}+\alpha_{x} x_{t}+\alpha_{z} z_{t+1 \mid t}
$$

in the sense that they do not depend on the instrument setting in period $t, i_{t}$, and only depend on $\pi_{t}, x_{t}$ and $z_{t+1 \mid t}$, which in turn are predetermined because of $(2.4),(2.5)$ and the assumption that $z_{t}$ is exogenous. ${ }^{16}$

Thus, the setup implies that inflation and the output gap in the current period $t$ are predetermined by previous decisions and current exogenous shocks (the shocks include the difference between the deviation and the previous private-sector judgment, $\left.z_{t+1}-z_{t+1 \mid t}\right)$. Current inflation expectations for the next period, $\pi_{t+1 \mid t}$, are also predetermined by current inflation, the output gap and the deviation according to (2.7). Actual inflation in the next period, $\pi_{t+1}$, will then equal these inflation expectations plus next period's unobservable cost-push shock, $\varepsilon_{t+1}$, and the effect of any unanticipated shock to the deviation, $z_{t+1}-z_{t+1 \mid t}$. Next period's output gap, $x_{t+1}$, will be determined by the current variables, current inflation expectations, the current instrument setting, $i_{t}$, next period's deviation, $z_{t+1}$, and next period's output-gap shock, $\eta_{t+1}$. Thus, the central bank can affect the output gap in the next period, but it cannot affect inflation until two periods ahead. That is, the control lags for the output gap and inflation are one and two periods (3 and 6 quarters), respectively. As shown in Rudebusch and Svensson (1999), a variant of this simple backward-looking model fits U.S. data quite well.

\subsection{Example 2: A simple forward-looking model of the transmission mechanism}

As another example of a standard model of the transmission mechanism, consider the so-called New-Keynesian model with forward-looking aggregate-supply and aggregate-demand relations, similar to the one used in Clarida, Galí and Gertler (1999). I use the variant in Svensson and Woodford (2002a), where current inflation and output gap is not forward-looking but predetermined one period (which is easily motivated as a minimum move towards realism). Instead, the one-period-ahead inflation and output-gap expectations (or "plans", see below), $\pi_{t+1 \mid t}$ and $x_{t+1 \mid t}$, are forward-looking. ${ }^{17}$ Furthermore, I use a variant, as in Tack Yun (1996), which allows firms to index prices to the average inflation rate rather than, somewhat arbitrary, only allowing

\footnotetext{
${ }^{16}$ Intuitively, a variable is predetermined if it only depends on lagged variables and current exogenous shocks. Formally, a variable is predetermined if it has exogenous one-period-ahead forecast errors.

${ }^{17}$ Intuitively, a variable is forward-looking (non-predetermined, or a jump variable) if it depends on expectations of future variables. Formally, a variable is forward-looking if it has endogenous one-period-ahead forecast errors.
} 
constant prices between opportunities for price adjustment, as in Guillermo Calvo (1983). ${ }^{18}$ The aggregate-supply and aggregate-demand equations are

$$
\begin{aligned}
\pi_{t+1}-\pi & =\delta\left(\pi_{t+2 \mid t}-\pi\right)+\alpha_{x} x_{t+1 \mid t}+\alpha_{z} z_{t+1}+\varepsilon_{t+1} \\
x_{t+1} & =x_{t+2 \mid t}-\beta_{r}\left(i_{t+1 \mid t}-\pi_{t+2 \mid t}-r_{t+1}^{*}\right)+\beta_{z} z_{t+1}+\eta_{t+1}
\end{aligned}
$$

where $\pi \equiv \mathrm{E}\left[\pi_{t}\right]$ is the average inflation rate, $\varepsilon_{t+1}$ and $\eta_{t+1}$ are iid "cost-push" and "excessdemand" shocks, and $r_{t}^{*}$ is an exogenous Wicksellian natural interest rate corresponding to a "neutral" real interest rate consistent with a zero output gap in the absence of deviations (see Woodford 2000b for further discussion of the Wicksellian natural interest rate). (For simplicity, the private-sector discount factor $\delta$ in $(2.8)$ is taken to be the same as in the monetary-policy loss function (2.1).) Again, the exogenous deviation $z_{t+1}$ enters both equations, to emphasize the approximative nature of the simple model and the unavoidability of central-bank judgment.

In this model, private-sector one-period-ahead "plans" for inflation and the output gap, $\pi_{t+1 \mid t}$ and $x_{t+1 \mid t}$, are determined in period $t$ by

$$
\begin{aligned}
\pi_{t+1 \mid t}-\pi & =\delta\left(\pi_{t+2 \mid t}-\pi\right)+\alpha_{x} x_{t+1 \mid t}+\alpha_{z} z_{t+1 \mid t} \\
x_{t+1 \mid t} & =x_{t+2 \mid t}-\beta_{r}\left(i_{t+1 \mid t}-\pi_{t+2 \mid t}-r_{t+1 \mid t}^{*}\right)+\beta_{z} z_{t+1 \mid t} .
\end{aligned}
$$

Thus, the one-period-ahead inflation plan depends on expected future inflation, $\pi_{t+2 \mid t}$, the output-gap plan, $x_{t+1 \mid t}$, and the private-sector judgment, $z_{t+1 \mid t}$. The one-period-ahead outputgap plan depends on the expected future output gap, $x_{t+2 \mid t}$, the expected one-period-ahead real interest-rate gap, $i_{t+1 \mid t}-\pi_{t+2 \mid t}-r_{t+1 \mid t}^{*} \equiv r_{t+1 \mid t}-r_{t+1 \mid t}^{*}$, and the private-sector judgment, $z_{t+1 \mid t}$. Actual inflation and output gap in period $t$ will then differ from the plans because of the unanticipated shocks,

$$
\begin{aligned}
& \pi_{t+1}=\pi_{t+1 \mid t}+\alpha_{z}\left(z_{t+1}-z_{t+1 \mid t}\right)+\varepsilon_{t+1}, \\
& x_{t+1}=x_{t+1 \mid t}+\beta_{r}\left(r_{t+1}^{*}-r_{t+1 \mid t}^{*}\right)+\beta_{z}\left(z_{t+1}-z_{t+1 \mid t}\right)+\eta_{t+1} .
\end{aligned}
$$

Thus, in this model, the period- $t$ expectation of the instrument in period $t+1, i_{t+1 \mid t}$, is what affects future inflation and the output gap. I will assume that the central bank in period

\footnotetext{
18 The assumption that firms can index prices to average inflation between price adjustment opportunities has the advantage that the long-run Phillips curve becomes vertical rather than positively sloped (see also the appendix of the working-paper version of Benhabib, Schmitt-Grohé and Uribe (2001)). In the common formulation, used for instance in Clarida, Galí and Gertler (1999), the Phillips curve is instead (without the assumption of prices predetermined one period)

$$
\pi_{t}=\delta \pi_{t+1 \mid t}+\alpha_{x} x_{t}
$$

which implies that the long-run Phillips curve (when $\delta<1$ ) fulfills $\pi=\alpha_{x} x /(1-\delta)$, where $\pi$ and $x$ is the average inflation and output gap, respectively.
} 
$t$ announces what interest rate it will set in period $t+1, i_{t+1, t}$. Since the central bank has no incentive to stray ex post from any such announcement (since the interest rate does not enter the period loss function (2.2)), I assume that it will set the actual interest rate $i_{t+1}$ according to its previous announcement and that the announcement hence will be credible and equal to the private-sector expectations, ${ }^{19}$

$$
i_{t+1}=i_{t+1, t}=i_{t+1 \mid t}
$$

\section{A direct optimal-control approach: Commitment to an optimal instrument rule}

A direct optimal-control approach to the monetary-policy problem would be to solve the monetarypolicy problem once-and-for-all for the optimal reaction function (for a given model, or, more generally, for a given probability distribution of models). This would result in an optimal reaction function, where the instrument in period $t$ would be a function of the information available in period $t, I_{t}$, and the central bank's judgment, $z^{t}$,

$$
i_{t}=F\left(I_{t}, z^{t}\right)
$$

The optimal reaction function referred to here is the "explicit" reaction function, in the sense that the instrument is written as a function of current and lagged predetermined variables and judgment only. In a linear model with predetermined and forward-looking variables and a quadratic loss function, there is a unique form of the explicit reaction function (see David Currie and Paul Levine 1993, Paul Söderlind 1999 and Svensson 1999b). (This is for a given minimum set of linearly independent predetermined variables; a model can of course trivially be expressed in terms of alternative sets of linearly independent predetermined variables). Since, in equilibrium, the forward-looking variables will be linear functions of the predetermined variables, the instrument can of course be written as a continuum of linear functions of both the forward-looking and the predetermined variables. ${ }^{20}$ In the literature, it is quite common to discuss such reaction functions where the instrument responds not to predetermined variables but

\footnotetext{
${ }^{19}$ Formally, we could say that the central bank instrument in period $t$ is really the announcement, $i_{t+1, t}$, of the future interest rate, rather than the current interest rate, $i_{t}$.

${ }^{20}$ Let $X_{t}$ and $Z_{t}$ denote the column vectors of predetermined and forward-looking variables, respectively. Disregard judgment, for simplicity. Let $i_{t}=F X_{t}$ be the unique explicit reaction function (for simplicity, under optimization under discretion; under commitment the optimal reaction function also involves Lagrange multipliers of the forward-looking equations and thereby lags of the predetermined variables, see below) where $F$ is a unique row vector or a matrix, depending on whether there are one or several instruments. In equilibrium (under discretion), the forward-looking variables will be given by $Z_{t}=G X_{t}$, where $G$ is a unique matrix. For any matrix $K$ of appropriate dimension, the instrument fulfills the implicit reaction function $i_{t}=K Z_{t}+(F-K G) X_{t}$.
} 
to forward-looking variables. These can be called "implicit" reaction functions, since they express a functional relation between the instrument and another endogenous non-predetermined variable. They are indeed equilibrium conditions, which need to be solved together with the rest of the model in order to determine the instrument setting. Thus, explicit and implicit reaction functions, and corresponding explicit and implicit instrument rules, are conceptually distinct. In particular, implicit instrument rules are not directly operational, since they involve an endogenous variable that depends on the instrument setting. In any realistic model, current inflation and the output gap are predetermined, also in the intuitive sense that they cannot be affected by current monetary-policy decisions. Then a Taylor rule (with the current instrument rate responding to current inflation and the current output gap) is an explicit reaction function. In many (unrealistic) models, current inflation and the output gap are forward-looking variables. Then a Taylor rule is an implicit reaction function, an equilibrium condition. McCallum, in (1999), for instance, has emphasized a related point; that a Taylor rule in a quarterly setting is not operational, since output and inflation in the current quarter is reported with a lag and therefore not known in the current quarter. However, in such a setting, as discussed in Rudebusch and Svensson (1999), a Taylor rule can be reformulated in terms of responding to the current estimates of current, yet unreported, output and inflation. As long as these estimates rely on predetermined information, such a Taylor rule would still be an explicit instrument rule. $^{21}$ Since, in practice, data on economic variables are revised several times, all published data, also of past economic variables, are imperfect estimates of underlying variables. However, verification of a particular instrument rule is of course easier if it relies on published data.

Once the above optimization problem is solved and the optimal (explicit) reaction function is determined, the central bank would then make a commitment to follow the optimal reaction function, and follow it mechanically ever after. Thus, once the commitment is made, there is no more optimizing. This can be called a commitment to the optimal instrument rule.

There are many problems with this approach. For a model with forward-looking variables, the optimal reaction function is generally not time-consistent, in the sense that the central bank has an incentive to depart from it in the future. This is the case even if the output target is equal to potential output and not overambitious, as is the case in the period loss function (2.2). This is because, even if there is no problem with an average inflation bias, there is a problem with "stabilization bias" and a lack of "history-dependence," to be further discussed below.

\footnotetext{
${ }^{21}$ Svensson and Woodford (2002b) discuss problems when these estimates depend on forward-looking observable variables.
} 
Therefore the commitment to the optimal instrument rule in a forward-looking variable requires a commitment mechanism, a mechanism by which the central bank can be bound to follow the optimal reaction function in the future. This in turn requires the optimal instrument rule to be verifiable. By this I mean that it can be objectively and unequivocally established whether the central bank is diverging from the reaction function in question or not. ${ }^{22}$

In any realistic model, the technical problem of deriving the optimal reaction function is overwhelmingly difficult, and the resulting optimal reaction function overwhelmingly complex. Thus, even if the optimal reaction function could be calculated, it would be far too complex to ever be verifiable. In fact, the optimal reaction function is overwhelmingly complex even for the simple models presented above, once the optimal response to judgment is taken into account.

\subsection{The backward-looking model}

For the backward-looking model, (2.4) and (2.5), appendix A, equation (A.11), shows that the optimal reaction function is given by

$$
\begin{aligned}
i_{t}= & \bar{r}+\pi^{*}+\left(1+\frac{1-c}{\alpha_{x} \beta_{r}}\right)\left(\pi_{t+1, t}-\pi^{*}\right)+\frac{\beta_{x}}{\beta_{r}} x_{t} \\
& +\frac{\beta_{z}}{\beta_{r}} z_{t+1, t}+\frac{1-c}{\alpha_{x} \beta_{r}} \alpha_{z} \tilde{z}_{t+2, t},
\end{aligned}
$$

where it is practical to define, for $\tau \geq 0$,

$$
\tilde{z}_{t+\tau, t} \equiv \sum_{s=0}^{\infty}(\delta c)^{s} z_{t+\tau+s, t},
$$

the discounted sum (with the discount factor $\delta c$ ) of judgments of future deviations in period $t$, starting $\tau$ periods ahead (in this case, $\tau=2$ ). Furthermore, the coefficient $c$, given by equations (A.10) and (A.7), depends on the parameters of the model, ${ }^{23}$ is an increasing function $c(\lambda)$ of $\lambda$, the relative weight on output-gap variability in the loss function $(2.2)$, and fulfills $0 \leq c(\lambda)<1$, with $c(0)=0$ and $c(\infty) \equiv \lim _{\lambda \rightarrow \infty} c(\lambda)=1$. Moreover, $\pi_{t+1, t}$ denotes the central bank's one-period-ahead forecast of inflation, given by

$$
\pi_{t+1, t}=\pi_{t}+\alpha_{x} x_{t}+\alpha_{z} z_{t+1, t}
$$

This inflation forecast is predetermined in period $t$, so it is independent of the instrument $i_{t}$ in period $t$. (Under the assumption of symmetric information, the central-bank inflation forecast, $\pi_{t+1, t}$, coincides with private-sector inflation expectations, $\left.\pi_{t+1 \mid t}.\right)$

\footnotetext{
${ }^{22}$ See Oliver Hart (1995) and Jean Tirole (1999) for discussion of the role of verifiability for commitment and incomplete contracts.

${ }^{23}$ The coefficient $c$ is the smaller root of the characteristic equation of the difference equation, (A.9), resulting from the model and the first-order conditions.
} 
The first row of (3.1) is not so complex, being a simple Taylor-type rule, with intercept $\bar{r}+\pi^{*}$, a positive response to the (predetermined) one-period-ahead forecast of the inflation gap, $\pi_{t+1, t}-\pi^{*}$, with a coefficient above unity $\left(\right.$ since $\left.1+(1-c) / \alpha_{x} \beta_{r}>1\right)$, and a positive response to the output gap, with the coefficient $\beta_{x} / \beta_{r}$. Given (3.3), this can also be expressed as a response to the current inflation gap, $\pi_{t}-\pi^{*}$, with a coefficient above unity, which is in line with the Taylor principle mentioned above.

However, the second row of (3.1) shows the optimal response to judgment, which is quite complex even for this simple model. Of course, with the simplifying assumption that the deviation is an $\mathrm{AR}(1)$ process, the second row would be simpler and consist of a response to the vector $z_{t, t}$, still with a rather complex coefficient. But, as argued above, such a simplifying assumption is totally unwarranted for any realistic form of judgment. ${ }^{24}$

\subsection{The forward-looking model}

For the forward-looking model, appendix B, equation (B.15), shows that the optimal interestrate decision and announcement in period $t$ for the interest rate in period $t+1, i_{t+1, t}$, is given by

$$
\begin{aligned}
i_{t+1, t}= & r_{t+1, t}^{*}+\pi^{*}+\left(1-\frac{\alpha_{x}}{\lambda \beta_{r}}\right) \frac{\lambda}{\alpha_{x}} c(1-c) x_{t, t-1} \\
& +\frac{\beta_{z}}{\beta_{r}} z_{t+1, t}+\left(1-\frac{\alpha_{x}}{\lambda \beta_{r}}\right) c\left\{[1-\delta c(1-c)] \alpha_{z} \tilde{z}_{t+2, t}-(1-c) \alpha_{z} z_{t+1, t}\right\} .
\end{aligned}
$$

where As shown in appendix B, equation (B.7), the optimal policy has no average inflation bias, so average inflation equals the inflation target,

$$
\pi=\pi^{*}
$$

The coefficient $c$ in (3.5), given by (A.10) and (B.11), although not identical to that in (3.1), is still also an increasing function of $\lambda, c(\lambda)$, that fulfills $0 \leq c(\lambda)<1$, with $c(0)=0$ and $c(\infty) \equiv \lim _{\lambda \rightarrow \infty} c(\lambda)=1$. Furthermore, $\tilde{z}_{t+2, t}$ is defined as in (3.2) (for $\tau=2$ ), although with the new coefficient $c(\lambda)$.

\footnotetext{
${ }^{24}$ In the unrealistic case of strict inflation targeting, $\lambda=0$, we have $c(\lambda)=c(0)=0$, and the optimal reaction function becomes

$$
i_{t}=\bar{r}+\pi^{*}+\left(1+\frac{1}{\alpha_{x} \beta_{r}}\right)\left(\pi_{t+1, t}-\pi^{*}\right)+\frac{\beta_{x}}{\beta_{r}} x_{t}+\frac{\beta_{z}}{\beta_{r}} z_{t+1, t}+\frac{\alpha_{z}}{\alpha_{x} \beta_{r}} z_{t+2, t}
$$

(which corresponds to (3.1) with $c(\lambda)=0$, when we use the convention that $0^{0}=1$ ). Thus, we see how the optimal instrument rate should respond to the one-period-ahead forecast of the inflation gap, $\pi_{t+1, t}-\pi^{*}$, the current output gap, $x_{t}$, the one- and two-period-ahead forecasts of the exogenous variable, $z_{t+1, t}$ and $z_{t+2, t}$. Even in the simple case of strict inflation targeting, judgment matters (in the form of the one- and two-period-ahead forecasts of the deviation).
} 
Thus, for the forward-looking model, the optimal reaction function is different from a Taylor rule. Instead, it corresponds to a response to the central bank's forecast of the Wicksellian real interest rate, $r_{t+1, t}^{*}$, with a unit coefficient, a response to the lagged forecast of the output gap, $x_{t, t-1}$, and a quite complex response to judgment. The response to the lagged forecast of the output gap illustrates that the optimal reaction function under commitment involves responses to lagged states of the economy, what is called "history dependence" in Woodford (1999c). ${ }^{25}$ In a forward-looking model, such history-dependence has a beneficial impact on private-sector expectations.

Appendix B, equation (B.16), shows that the lagged forecast of the output gap fulfills

$$
x_{t, t-1}=-\frac{\alpha_{x} c}{\lambda} \sum_{j=0}^{\infty} c^{j} \alpha_{z} \tilde{z}_{t-j, t-1-j} .
$$

Thus, (3.7) can be substituted into (3.5), in which case the optimal reaction function can be written as a complex response to current and previous judgment, in addition to the one-to-one response to the forecast of the Wicksellian real interest rate. ${ }^{26}$

With forward-looking variables, the optimal reaction function is not time-consistent, and each period the central bank has an incentive to temporarily depart from it. Thus, a commitment mechanism and corresponding verifiability of the reaction function is necessary. However, even in this exceedingly simple model of the transmission mechanism, the optimal reaction function is quite complex, especially with regard to judgment, and certainly impossible to verify. ${ }^{27}$

\footnotetext{
${ }^{25}$ We note that the response to the lagged output-gap forcast can be of either sign, depending on whether $\lambda$ is greater or smaller than $\alpha_{x} / \beta_{r}$.

${ }^{26}$ The lagged central-bank output-gap forecast, $x_{t, t-1}$, is in equilibrium equal to the lagged private-sector output-gap expectation/plan, $x_{t \mid t-1}$, since the central bank and the private sector are assumed to have the same information. For the purpose of this paper, since we do not discuss the issue of determinacy of equilibrium, it does not matter whether it is the central-bank forecast or the private-sector expectation/plan that enters the reaction function (3.5). For the issue of determinacy in this forward-looking model, this does matter. More precisely, it matters whether the optimal reaction function is understood as a response to any realized value of an endogenous variable, such as private-sector expectations/plans $x_{t \mid t-1}$, or to the actual values of the exogenous shocks determining the equilibrium values of the endogenous variables, as in (3.7). These issues are discusssed in detail in Svensson and Woodford (2002a). There it is shown how determinacy can be ensured under different implementations of inflation-forecast targeting.

${ }^{27}$ In the unrealistic case of strict inflation targeting, $\lambda=0$, the optimal reaction function is (see (B.17))

$$
i_{t+1, t}=r_{t+1, t}^{*}+\frac{\beta_{z}}{\beta_{r}} z_{t+1, t}-\frac{\alpha_{z}}{\alpha_{x} \beta_{r}}\left(z_{t+2, t}-z_{t+1, t}\right) .
$$

Under strict inflation targeting, there is no problem with time-consistency (because there is no tradeoff between inflation- and output-gap stability). The optimal reaction function still involves response to judgment for one and two periods ahead.
} 


\subsection{A commitment to the optimal instrument rule is impracticable}

For several reasons, the direct optimal-control approach with a once-and-for-all calculation of the optimal reaction function and then a commitment to this reaction function is completely impracticable. Indeed, this conclusion seems to be part of the conventional wisdom, and a commitment to an optimal instrument rule has no advocates, as far as I know. We have already seen that, even in these two very simple models, the optimal reaction functions are quite complex, as soon as there is a role for deviations from the simple model and judgment of those deviations. This complexity makes verifiability impossible, although verifiability is necessary as soon as there is a time-consistency problem and an incentive to temporarily depart from the optimal reaction function. In more realistic models, the complexity increases dramatically further. The optimal reaction function indeed requires that every conceivable contingency can be anticipated, which is clearly impossible.

There are also more fundamental problems with the idea of a once-and-for-all commitment. If this commitment is possible in a particular period, what is special with that period? Why didn't the commitment occur in a previous period, leaving no possibility to recommitment this period? Woodford (1999a) has provided an ingenious solution to that problem, by proposing a more sophisticated kind of commitment, "in a timeless perspective." This involves a commitment to recommit only to reaction functions to which one would have preferred to commit oneself far into the past. This is a commitment not to exploit the possibility of a one-time "surprise" at the time of the recommitment. It allows optimal recommitment, for instance when new information about the transmission mechanism arrives, without the disadvantage of the negative effect on expectations that the possibility of surprises otherwise induces.

But Woodford's ingenious idea does not diminish the already overwhelming problem of enforcement and verifiability of a commitment to a complex instrument rule. For practical purposes, the direct optimal-control approach, with either a once-and-for-all commitment or continuous recommitment in a timeless perspective, will only be a theoretical benchmark for evaluation purposes. It is not a coincidence that no central bank has tried to implement this approach. For a practical monetary-policy rule, we have to look elsewhere. 


\section{Commitment to a simple instrument rule}

Let me start by specifying the idea of a commitment to a simple instrument rule. The first step is to consider a restricted class of reaction functions, namely where the instrument is a function only of a particular small subset, $\bar{I}_{t}$, of the central bank's information, $I_{t}$,

$$
i_{t}=f\left(\bar{I}_{t}\right)
$$

Typically, the instrument is restricted to be a linear function of the target variables (inflation and (estimates of) the output gap) and the lagged instrument, which results in a Taylor-type rule with interest-rate smoothing. Then the reaction function is

$$
i_{t}=\bar{f}+f_{\pi}\left(\pi_{t}-\pi^{*}\right)+f_{x} x_{t}+f_{i} i_{t-1}
$$

where the constant $\bar{f}$ and the coefficients $f_{\pi}, f_{x}$ and $f_{i}$ remain to be determined. The Taylor rule, (1.1), is the best known special case. In the realistic situation when inflation and the output gap are predetermined, (4.1) makes the instrument a simple function of predetermined variables, called an explicit instrument rule in Rudebusch and Svensson (1999), Svensson (1999b) and Svensson and Woodford (2002a).

Once the class of reaction functions is determined, the second step is to determine the numerical values of its parameters; for the case of (4.1), the constant $\bar{f}$ and the coefficients $f_{\pi}$, $f_{x}$ and $f_{i}$ ). The coefficients can either be chosen so that the reaction function minimizes the intertemporal loss function (2.1) for a particular model (is optimal for a given model and the given class of reaction functions), or such that it performs reasonably well for a few alternative models (is "robust" over a class of models). ${ }^{28}$

For the backward-looking model above, one simple instrument rule is just to forget about the judgment part in (3.1) and instead follow the reaction function

$$
i_{t}=\bar{r}+\pi^{*}+\left(1+\frac{1-c}{\alpha_{x} \beta_{r}}\right)\left(\pi_{t+1, t}-\pi^{*}\right)+\frac{\beta_{x}}{\beta_{r}} x_{t} .
$$

As noted, this is a variant of the Taylor rule, with the predetermined one-period ahead forecast of the inflation gap entering instead of the current inflation gap. Using the expression of the inflation forecast in (3.3), but disregarding the judgment part of (3.3), results in the corresponding

\footnotetext{
${ }^{28}$ The contributions to the conference volume edited by Taylor, (1999c), provide many examples on commitment to alternative simple instrument rules; see especially the introduction by Taylor (1999a). The dominance of this approach in current research is indicated by the fact that, in this volume, only Rudebusch and Svensson (1999) also consider targeting rules.
} 
simple reaction function of current inflation and output gaps,

$$
i_{t}=\bar{r}+\pi^{*}+\left(1+\frac{1-c}{\alpha_{x} \beta_{r}}\right)\left(\pi_{t}-\pi^{*}\right)+\left(\alpha_{x}+\frac{1-c}{\beta_{r}}+\frac{\beta_{x}}{\beta_{r}}\right) x_{t} .
$$

For the forward-looking model above, the obvious corresponding reaction function that disregards judgment in (3.5) would be

$$
i_{t+1, t}=r_{t+1, t}^{*}+\pi^{*}+\left(1-\frac{\alpha_{x}}{\lambda \beta_{r}}\right) \frac{\lambda}{\alpha_{x}} c(1-c) x_{t, t-1} .
$$

In this case, the obvious simple reaction function differs from the Taylor rule. Also, arguably it is not so simple, since it responds to the one-period-ahead forecast of the Wicksellian natural interest rate, which may be difficult to estimate in practice. Furthermore, it responds to the previous one-period-ahead output-gap forecast rather than the current output gap (estimate). All this makes it less simple and also less easy to verify. ${ }^{29}$

The third step, finally, is for the central bank to commit to the particular simple instrument rule chosen and then follow it ever after, or at least until there is a recommitment to a new instrument rule. More precisely, once the simple instrument rule has been specified, the central bank's decision process is exceedingly simple.

In the backward-looking model, if the central bank has specified the form (4.3) of the simple instrument rule, the decision-making process thereafter can be described as follows: (1) Collect data on current inflation and current output. (2) Estimate potential output (which as noted above is a nontrivial step) and then subtract from output to get the current output gap. (3) Use (4.3) to calculate $i_{t}$. (4) Announce and implement $i_{t}$. (5) In the next period, start over again.

If the central bank has specified the form (4.2) of the simple instrument rule, the decisionmaking process is somewhat more elaborate after (2): (3) One alternative is to be sophisticated, form the judgment $z_{t+1, t}$, and use this together with current inflation and the output gap to form $\pi_{t+1, t}$ according to (3.3). Another alternative is to be unsophisticated, disregard any judgment, and use only current inflation and the output gap in (3.3) to form $\pi_{t+1, t}$. In the former case, there is still some partial role for judgment, in the latter not. (4) Use $\pi_{t+1, t}$ and $x_{t}$ in (4.2) to calculate $i_{t}$. (5) Announce and implement $i_{t}$. (6) In the next period, start over again.

In the forward-looking model, the steps are as follows: (1) Construct a one-period-ahead forecast of the Wicksellian natural interest rate, $r_{t+1, t}^{*}$. This is a nontrivial step, comparable to estimating potential output. (2) Recall the one-period-ahead output-gap forecast from the

\footnotetext{
${ }^{29}$ Also, recall that the response to the lagged output-gap forcast can be of either sign, cf. footnote 25 .
} 
previous period, $x_{t, t-1}$. (3) Use $r_{t+1, t}^{*}$ and $x_{t+1, t}$ in (4.4) to calculate $i_{t+1, t}$. (4) Construct the one-period-ahead output-gap forecast, $x_{t+1, t}$, to be used in the interest-rate decision next period. This is a nontrivial step; it involves combining (5.5), (5.6) and (4.4) to solve for the resulting output-gap forecast. (5) Announce $i_{t+1, t}$. (6) In period $t+1$, implement $i_{t+1}=i_{t+1, t}$ and start over again.

The fact that the simple instrument rule (4.4) relies on the lagged one-period-ahead outputgap forecast, and the fact that constructing this is not so easy, makes this simple instrument rule still somewhat complex. A simpler instrument rule would be to follow a Taylor-type rule with interest-rate smoothing, (4.1). As discussed in Svensson and Woodford (2002a), as long as $f_{\pi}>1$ so the Taylor principle is upheld, this results in a unique equilibrium in the forwardlooking model, although the Taylor-type rule will result in a worse outcome (a larger value of the loss function (2.1)) than (4.4). In this case, the decision process would be the same simple one as for the backward-looking model with the instrument rule (4.2).

\subsection{Advantages of a commitment to a simple instrument rule}

The advantages of a commitment to a simple instrument rule are that (1) the simplicity of the instrument rule makes commitment technically feasible, and (2) simple instrument rules may be relatively robust.

Sufficient simplicity of the instrument rule, for instance, if it is restricted to be a Taylortype rule with interest-rate smoothing like (4.1), implies that it is easily verifiable. Then, a commitment is, in principle, feasible.

Some research indicates that a Taylor-type rule with interest-rate smoothing is relatively robust, in the sense that it performs tolerably well for a variety of models. This idea of robust simple instrument rules has been promoted and examined in several papers by McCallum and recently restated in McCallum (1999). Results of Levin, Wieland and Williams (1999) for a set of models of the U.S. economy indicate that a Taylor-type reaction function with interestrate smoothing may be relatively robust in this sense. Intuitively, in (almost) closed-economy models where future inflation and the output gap mainly depend linearly on current inflation, the output gap and the instrument rate, a Taylor-type instrument rule with the right coefficients will be optimal or close to optimal (as is for instance the case in the backward-model above, in the absence of any deviations). The models examined by Levin, Wieland and Williams (1999) are all of this type, as is the model used in Rudebusch and Svensson (1999). On the other hand, 
even for such a restricted class of reaction functions (where the Federal funds rate only depends on the inflation gap, the output gap and the lagged Federal funds rate), there is still considerable variation in the suggested magnitudes for the three coefficients, as is apparent from the papers in Taylor (1999c). Thus, there is far from general agreement on what the precise coefficients should be. Furthermore, the simulations providing evidence of robustness of Taylor-type rules all disregard the role of judgment.

\subsection{Problems of a commitment to a simple instrument rule}

The problems with the idea of a commitment to a simple instrument rule include that (1) the simple instrument rule may be far from optimal in some circumstances, (2) there is no room for judgmental adjustments and extra-model information, (3) desired development of the instrument rule due to learning and new information will conflict with the commitment, unless sophisticated and (arguably) unrealistic recommitment "in a timeless perspective", as suggested by Woodford (1999a), is allowed, and (4) in spite of all the academic work and promotion, no central bank has actually chosen to do it, and prominent central bankers scoff at the idea.

A first obvious problem for a Taylor-type rule, with or without interest-rate smoothing, is that, if there are other important state variables than inflation and the output gap, it will not be optimal. For a large and not so open economy as the U.S., inflation and the output gap may be the most important state variables, and the efficiency loss in not responding to other variables may in many cases be moderate (as seems to be the case for the models examined by Levin, Wieland and Williams 1999). For a smaller and more open economy, the real exchange rate, the terms of trade, foreign output and the foreign interest rate seem to be the minimum essential state variables that have to be added (see, for instance, Svensson 2000), increasing the number of response coefficients that must be fixed. I am not aware of any agreed-upon levels of the response coefficients for these variables.

With forward-looking variables, the optimal reaction function is characterized by historydependence, as has been emphasized by Woodford (1999c) and as was demonstrated in (3.5) and (3.7). The lack of history-dependence may seem to be a problem for a simple instrument rule. However, any response to the lagged instrument rate implies some history dependence, since (4.1) can be written

$$
i_{t}=\frac{\bar{f}}{1-f_{i}}+\sum_{j=0}^{\infty} f_{i}^{j}\left[f_{\pi}\left(\pi_{t-j}-\pi^{*}\right)+f_{x} x_{t-j}\right]
$$


Thus, a suitable choice of the coefficient $f_{i}$ may allow some approximation to the optimal history dependence and, as further discussed in Woodford (1999c), partly remedy this problem.

A second problem is that a commitment to an instrument rule does not leave any room for judgmental adjustments and extra-model information, made explicit by the inclusion of the deviation $z_{t}$ and the central-bank judgment $z^{t}$ above. As I believe most students of practical monetary policy would agree with, practical monetary policy cannot (at least not yet) rely on models only. As further discussed in Svensson (2001c), the use of judgmental adjustments and extra-model information is both desirable in principle and unavoidable in practice. For instance, when a rare event, like a stock market crash, an Asian crisis or the floating of the Brazilian real occurs, central bankers may have to use their judgments rather than their models in assessing its likely effect on future inflation and output. Given the lags in the effects of monetary policy, it will be efficient to respond to such an event before it shows up in the variables that enter the simple instrument rule, like current GDP and inflation. Indeed, Taylor (1993) to a large extent discusses the Fed's departures from the Taylor rule and their reasons. Put differently, a commitment to a simple instrument rule does not provide any rules for when discretionary departures from the simple instrument rule are warranted.

A third problem with simple instrument rules would seem to be that a once-and-for-all commitment to an instrument rule would not allow any improvement of the instrument rule when new information about the transmission mechanism, the variability of shocks, or the source of shocks arrives. ${ }^{30}$ A once-and-for-all commitment also faces the problem of an incentive to exploit the initial situation, for instance, by temporarily increasing output by an initial surprise inflation, and letting the simple reaction function apply only in the future. As a solution to the problem of once-and-for-all commitments, Woodford (1999a) has, as discussed above in section 3.3, suggested repeated recommitment "in a timeless perspective" to new revised instrument rules when new information arrives. The timeless perspective is a self-imposed restriction to consider only long-run instrument rules that do not depend on the period when the commitment is made, and by construction it eliminates any exploitation of the initial situation. ${ }^{31}$ Presumably, though, such recommitment to a new instrument rule would have to occur relatively infrequently and only after substantial accumulated information has arrived. Nevertheless, recommitment to

\footnotetext{
${ }^{30}$ For a linear model of the transmission mechanism and a quadratic loss function, certainty-equivalence applies for the optimal reaction function. That is, the reaction function does not depend on the variance of the shocks. Certainty-equivalence does not apply for simple reaction functions, so the coefficients of the optimal simple reaction function do depend on the variance of the shocks (see Currie and Levine 1993).

31 The idea of commitment in a timeless perspective is worked out by Woodford (1999a) for optimal reaction functions rather than simple ones (the model used is so simple that the optimal reaction function is quite simple).
} 
new long-run instrument rules is at least a logically possible (and theoretically elegant) solution to the problem of once-and-for-all commitment.

Of course, along the lines of Woodford's recommitment in a timeless perspective, the central bankers faced with an Asian crisis could ask: Suppose that in the past, when we designed our current instrument rule, we had anticipated the possibility of a future Asian crisis. What response to the crisis would we then have committed ourselves to? Answering this question would amount to revising the simple instrument rule by incorporating this particular event. Undertaking a substantial revision of the instrument rule may not make much sense unless the same event is expected to occur reasonably frequently in the future, though. It would also seem to require that the event is somehow incorporated in the models used to derive the optimal simple instrument rule. However, if the central bank tries to incorporate too many possible events, the instrument rule would no longer be simple, and verification of the bank's adherence to the rule becomes increasingly difficult. Furthermore, there could be times when a relatively swift response is called for, without leaving much time for a thorough revision of the instrument rule. It seems that we still lack rules for when departures from the simple instrument rule are called for, without which the simple rule is either incomplete or inefficient.

Suppose a central bank went ahead and wanted to implement a commitment to a simple instrument rule? How would it actually commit itself to the instrument rule? One extreme possibility would be to have the Central Bank Act (or, in New Zealand, the Policy Targets Agreement (PTA), see Svensson 2001a) include the instrument rule in a verifiable way (and also specify suitable sanctions for departures from the rule), with revisions of the law when new information calls for revisions of the instrument rule. A less extreme possibility would be an Instrument-Rule Report (rather than the Inflation Reports issued by many inflationtargeting central banks), where the central bank presents its derivation and motivation of the current instrument rule, solemnly commits itself to follow it, and invites external scrutiny of its adherence to the rule (and criticism and embarrassment if it departs from the rule). The rule would then be in effect until a new issue of the Instrument-Rule Report presents and motivates a new revision of the rule. Revisions would probably have to be rather infrequent to limit the amount of discretion.

The decision-making process inside the central bank would then be quite uneven. The infrequent revisions of the rule would be highly active and demanding periods, using all the bank's intellectual capacity. During the presumably long periods in-between, monetary policy 
could be conducted by a clerk with a hand calculator, or even a pre-programmed computer. Furthermore, the central bank would be forward-looking only at the time when it reconsiders and recommits to a new instrument rule; in-between it would not be forward-looking but behave in a completely mechanical way.

Thus, an obvious fourth problem is that commitment to a simple instrument rule is far from an accurate description of current monetary policy, inflation targeting or other. Such a monetary-policy setup does not exist in the current inflation-targeting countries, nor has it ever existed before. No central bank has (to my knowledge) announced and committed itself to an explicit instrument rule. No central bank has issued anything similar to an Instrument-Rule Report. Nor does there seem to be any attempt to construct a commitment mechanism, whereby a central bank would be obliged to follow a mechanical instrument rule. In spite of the impressive academic work on a commitment to a simple instrument rule, I doubt that we will ever see such an arrangement materialize. Certainly, prominent current and previous central bankers seem skeptical and maintain that some amount of discretion is inevitable. As Alan Blinder (1998) puts it,

Rarely does society solve a time-consistency problem by rigid precommitment... Enlightened discretion is the rule.

As stated by Mervyn A. King (1999),

Mechanical policy rules are not credible... No rule could be written down that describes how policy would be set in all possible outcomes. Some discretion is inevitable. But that discretion must be constrained by a clear objective to which policy is directed...

As expressed by Bernanke and Mishkin (1997):

Inflation targeting does not represent [a commitment to] an ironclad policy rule... Instead, inflation targeting is better understood as a policy framework...

But do not simple instrument rules fit actual central-bank behavior well? Several researchers, for instance, Clarida, Galí and Gertler (1998) and Judd and Rudebusch (1998), have found that variants of Taylor-type rules with interest-rate smoothing fit U.S. data reasonably well. The interpretation of this finding is not obvious, though. First, the similarity of the outcome of policy decisions with a simple instrument rule is completely consistent with the forwardlooking goal-directed behavior by the central bank, say in the form of discretionary periodby-period optimization, in a situation where inflation and the output gap are important state 
variables. That is, the simple instrument rule is a reduced form rather than a primitive, the endogenous end point rather than the exogenous starting point of monetary policy. Second, even the best empirical fits leave one third or more of the variance of changes in the federal funds rate unexplained. ${ }^{32}$ Thus, departures from the simple instrument rules are substantial and ask for an explanation.

\subsection{A simple instrument rule as a "guideline"}

As discussed above, a firm commitment to a simple instrument rule is associated with a number of problems, and it has, for apparently good reasons, never been tried out in the real world. However, another interpretation of the role of simple instrument rules is as a much looser commitment: An instrument rule should not be followed mechanically; instead it should be seen as a "benchmark" or a "guideline" for assessing instrument-rate decisions. This is the interpretation and use of policy rules that Taylor himself has proposed for the Taylor rule, for instance in the classic article (1993) proposing the Taylor rule, and, in more detail, in (2000).

Taylor (2000, p. 443) defines a "monetary policy rule" as "simply a contingency plan that specifies as clearly as possible the circumstances under which a central bank should change the instruments of monetary policy" and mentions the Taylor rule as an example. Thus, his definition of monetary policy rules is restricted to include instrument rules only. Furthermore, as to the use of such monetary policy rules, he states, (2000, p. 445-446):

$[\mathrm{J}]$ ust because monetary policy rules can be written down as a mechanical-looking mathematical equation does not imply that central banks should follow them mechanically.

To the contrary, most proposals for monetary policy rules suggest that the rules be used as guidelines, or general policy frameworks... Because some discretion is needed to implement the policy rule, the mathematical form becomes an approximation, much like the simplifying assumptions that underlie the models that are used for policy evaluation... [D] espite the mathematical form, I proposed this rule [the Taylor rule] in the early 1990s as a benchmark or guideline for assessing interest rate decisions. At a minimum, discretion is needed to assess monthly data on commodity prices, employment, industrial production and other variables, in order to estimate (or predict) the current quarterly inflation rate and the output gap.

Moreover, there will, on occasion, be a need to change the interest rate because of some special factor that cannot be included in the policy rule. Liquidity crises in financial markets will usually require such discretion. The 1987 stock market break

\footnotetext{
32 Judd and Rudebusch (1998), for instance, estimate reaction functions for the Federal Reserve System during the terms of Arthur Burns, Paul Volcker and Alan Greenspan. The best fit is for Greenspan's term (sample 1987:1-1997:4) and the partial-adjustment form $\Delta i_{t}=\gamma\left(i_{t}^{*}-i_{t-1}\right)+\rho \Delta i_{t-1}$, where $i_{t}^{*}$ is given by a Taylor-type rule, $i_{t}^{*}=\bar{f}+f_{\pi}\left(\pi_{t}-\pi^{*}\right)+f_{y}\left(y_{t}-y^{*}\right)$. The best adjusted $R^{2}$ is 0.67 .
} 
in the United States is one example. Before the stock market break of 1987, the Fed was increasing the federal funds rate, apparently because inflation and the output gap were increasing. But when liquidity became a concern after the break in the market, the Fed lowered the interest rate and thereby provided more liquidity. After the liquidity concerns dissipated, the Fed returned to its tightening mode. By doing so it was able to contain the rise in inflation much earlier than in similar periods in the 1970s. It is important to point out that such discretionary actions are relative to the benchmark policy rule - the Taylor rule in this example. Hence, even with these discretionary actions the policy rule has substantive content for the decisions.

I believe this quote leads to some hard questions about the idea of a simple instrument rule as a guideline. First, the discretion mentioned about using available information to estimate current quarterly inflation and output gap concerns constructing the given arguments of the Taylor rule, not the Taylor rule itself, the reaction function. Thus, this is not actually an example of a deviation from the instrument rule. Second, the quote states that deviations from the instrument rule will be needed "on occasion" because of some special factor (other than the inflation and output gap included in the rule). The one example given in this quote is liquidity crises in financial markets, more precisely the 1987 stock market break. In Taylor (1993), two other examples of reasons for deviation from the rule is given: the oil-price shock after Iraq's invasion of Kuwait in late 1990, and the increase in long interest rates in early 1990, possibly related to anticipations of German unification and related increased fiscal expenditure and investment in Germany. These examples seems to refer to rather big and rare events. Does this mean that the instrument rule should be followed mechanically except when similar big events occur? If so, this would seem to imply that it should be followed mechanically most of the time, since such big events (fortunately) are relatively rare.

More generally, I find the idea of a simple instrument rule as a mere guideline not sufficiently specific to be operational. When shall the rule be followed, and when not? More precisely, there are no rules for when deviations from the instrument rule are appropriate. This seems to create an inherent lack of transparency. How can outside observers then judge whether a deviation is appropriate or not?

Nevertheless, one could possibly imagine a central bank announcing that "we are going to use the following explicit instrument rule as our guideline, and we will carefully explain and motivate any deviation from the rule." But so far, no central bank has announced any instrument rule as a guideline.

Still, the fact that historical examples of successful policy are similar to variants of simple 
instrument rules, the fact that variants of simple instrument rules perform reasonably well in a variety of different models, together with the fact that they can be derived as optimal in some circumstances (for instance, in the backward-looking model above in the absence of any deviation) imply that these simple instrument rules can serve a useful role as rough guidelines, in that large departures from them have better to have good explanations. But they are not more than very rough guidelines. They are not sufficient as rules for good monetary policy.

Thus, although alternative instrument rules can serve as very rough guidelines, ${ }^{33}$ and decisions ex post may sometimes be similar to those prescribed by the simple instrument rules, a commitment to a simple instrument rule (even with Woodford's recommitment in a timeless perspective) does not seem to be a realistic substitute for the forward-looking decision framework applied by inflation-targeting central banks. Indeed, instead of making infrequent forwardlooking decisions at the time of the infrequent recommitment to a new simple instrument rule, it seems that central banks instead choose to be continuously forward-looking and have a regular cycle of decision-making. To quote Alan Greenspan (1994),

Implicit in any monetary policy action or inaction, is an expectation of how the future will unfold, that is, a forecast.

The belief that some formal set of rules for policy implementation can effectively eliminate that problem is, in my judgment, an illusion. There is no way to avoid making a forecast, explicitly or implicitly. ${ }^{34}$

Therefore, I will turn, in section 5, to a, in my mind, better way of describing current inflation targeting, namely as a commitment to a targeting rule, more precisely, a "forecast-targeting rule." Before that, I will comment on a particular instrument rule that has been suggested as an alternative to Taylor-type rules, namely so-called "forecast-based" instrument rules, which sometimes is considered (misleadingly, in my mind) corresponding to "inflation-forecast targeting".

\footnotetext{
${ }^{33}$ See, for instance, the contributions in Taylor (1999c) and, with regard to the performance of a Taylor rule for the Eurosystem, Stefan Gerlach and Gert Schnabel (1998), Gert Peersman and Frank Smets (1998) and Taylor (1999d).

34 Alan Budd (1998), which alerted me to this quote, contains an illuminating and detailed discussion of the advantages of explicitly considering forecasts rather than specifying reaction functions from observed variables to the instrument.
} 


\subsection{A commitment to a "forecast-based" instrument rule}

A particular class of reaction functions involves the instrument rate responding to a $T$-periodahead inflation forecast, of the form

$$
i_{t}=\bar{f}+f_{\pi}\left(\pi_{t+T, t}-\pi^{*}\right)+f_{i} i_{t-1} .
$$

This class of reaction functions has been referred to as forecast-based (instrument) rules and is promoted by, for instance, Nicoletta Batini and Andrew Haldane (1999). Variants of it are used in the Quarterly Projection Model (QPM) of Bank of Canada, (Donald Coletti, Benjamin Hunt, David Rose, and Robert Tetlow 1996), Richard Black, Tiff Macklem and Rose (1997), and the Forecasting and Policy System (FPS) of the Reserve Bank of New Zealand, (Black, Vincenzo Cassino, Aaron Drew, Eric Hansen, Hunt, Rose, and Alasdair Scott 1997). For a forecast-horizon $T$ sufficiently long, the inflation forecast is no longer predetermined but depends on the instrument. For such a horizon, the forecast in most applications have been taken to be an equilibrium, or "rule-consistent," forecast, meaning that it is an endogenous rationalexpectations forecast conditional on an intertemporal equilibrium of the model. Thus, this reaction function is really an equilibrium condition that has to be satisfied by simultaneously determined variables. This is called an implicit instrument rule in Rudebusch and Svensson (1999), Svensson (1999b) and Svensson and Woodford (2002a).

The reaction function (4.6) is sometimes said to represent "inflation-forecast targeting"; a more precise and consistent terminology is "responding to an inflation forecast." In this paper, as in Rogoff (1985), Walsh (1998), Svensson (1997a, 1999b), Rudebusch and Svensson (1999), Cecchetti (1998, 2000), Clarida, Galí and Gertler (1999) and Svensson and Woodford (2002a), "targeting variable $Y_{t}$ " means minimizing a loss function that is increasing in the deviation between the variable and a target. ${ }^{35}$ In contrast, in some of the literature "targeting variable $Y_{t}$ " refers to a reaction function where the instrument responds to the same deviation. As discussed in Svensson (1999b, section 2.4), these two meanings of "targeting variable $Y_{t}$ " are not equivalent. The reason is that it is generally better (in the sense of minimizing the loss function) that the instrument responds to the determinants of the target variables than to the target variables themselves (for instance, even if inflation is the only target variable (the only variable in the loss function), it is generally better to respond to both current inflation

\footnotetext{
${ }^{35}$ This is completely in line with Jan Tinbergen's (1952) classic treatment, where a "target variable" is defined as a variable that enters the objective function and a "target" is the value of a target variable that optimizes the objective function.
} 
and the output gap, when both these are determinants of future inflation; see, for instance, Svensson (1997a), Rudebusch and Svensson (1999), and the optimal reaction function under strict inflation targeting (3.4) in footnote 24). Note also that, in the forward-looking model, the optimal reaction function (3.5) does not respond to any of the current target variables but to their determinants. Thus, it seems advisable not to confuse "responding to variable $Y_{t}$ " with "targeting variable $Y_{t} . "$

Above, simple instrument rules were criticized for, among other things, not taking judgment into account. However, the forecast-based instrument rule of the form (4.6) seems less sensitive to criticism on this point. The equilibrium forecast that enters the rule can in principle incorporate all relevant information, in particular, the judgment, $z^{t}$. Nevertheless, it is unsuitable for other reasons. A first reason, as already noted, is that it is (when responding to equilibrium forecasts) an equilibrium condition rather than an operational explicit reaction function of predetermined variables. Still, it could be a desirable equilibrium condition. More precisely, it could be a desirable specific targeting rule, a reformulated first-order condition for optimal policy. ${ }^{36}$ A second reason is then that, unfortunately, the forecast-based instrument rule of the form (4.6) is not an optimal targeting rule for the conventional loss function (2.1) with (2.2). As explained in some detail in Svensson (2001d), one can work backwards and find the intertemporal loss function in period $t$ for which (4.6) is an optimal first-order condition. It is of the form

$$
\mathcal{L}_{t}=\frac{1}{2}\left[\delta^{T}\left(\pi_{t+T, t}-\pi^{*}\right)^{2}+\lambda_{i}\left(i_{t}-\bar{\imath}\right)^{2}+\lambda_{\Delta i}\left(i_{t}-i_{t-1}\right)^{2}\right] .
$$

This loss function is such that, in each period, the central bank puts weight on both instrumentrate stabilization and instrument-rate smoothing, $\lambda_{i}>0$ and $\lambda_{\Delta i}>0$ (that is, the instrument rate has to be a separate target variable and enter the loss function directly, which, as noted in section 5.6, is difficult to rationalize). Furthermore, the central bank must be concerned with stabilizing the inflation gap at a fixed horizon $T$ only. Thus, in contrast with the conventional intertemporal loss function (2.1) with (2.2), the central bank does not consider any tradeoff between inflation gaps at different horizons. Indeed, the implied loss function for the forecastbased instrument rule does not fulfill the minimum requirement of being time-consistent in the classical sense of Robert Strotz (1955-56), and in any period the central bank will, with this

\footnotetext{
${ }^{36}$ Indeed, when (4.6) is used in in the QPM of the Bank of Canada (Coletti, Hunt, Rose, Tetlow 1996) and the FPS of the Reserve Bank of New Zealand (Black, Cassino, Drew, Eric Hansen, Hunt, Rose, Scott 1997), the interest rate is a 3-month interest rate, which is strictly speaking not an instrument rate but a market interest rate over which the central bank has less than perfect control. In that case, strictly speaking, (4.6) is not an "instrument" rule or a "reaction function," but a "targeting" rule.
} 
loss function, regret previous decisions made. In addition, the implied loss function does not incorporate any concern for output-gap stability (except indirectly through the horizon $T$ ).

A third reason is that, in line with the above, as demonstrated by Levin, Wieland and Williams (2001), in simulations on different macro models, the performance of this particular forecast-based instrument rule, as long as it does not utilize quite short forecast horizons (making the forecast virtually predetermined), is inferior and nonrobust, when evaluated according to (2.1) with (2.2) or the special case (2.3). All together, the forecast-based instrument rule of the form (4.6) is quite problematic, in spite of its entrenched position in the QPM of the Bank of Canada (Coletti, Hunt, Rose and Tetlow 1996) and the FPS of the Reserve Bank of New Zealand (Black, Cassino, Drew, Eric Hansen, Hunt, Rose, and Scott 1997). (See also the discussion in section 5.5 below.)

However, arguably a reaction function when the instrument responds to the unchangedinterest-rate forecasts (of both inflation and the output gap) make more sense and can be seen as a first-order Taylor expansion (around an unchanged interest rate) of the optimal specific targeting rules to be discussed below, even if the central bank does not have a separate instrumentrate stabilization and/or smoothing objective, see appendix C below, equations (C.1) and (C.2), as well as Per Jansson and Vredin (2000) and Rudebusch and Svensson (1999).

\section{Commitment to a targeting rule}

\subsection{Generalizing monetary-policy rules}

Thus, I find that a commitment to a simple instrument rule is not a good description of current inflation targeting, nor does the concept of instrument rules seem sufficient to discuss monetarypolicy rules. Instead, as argued in Svensson (1999b), the concept of monetary-policy rules needs to be broadened.

In order to discuss alternative decision frameworks for monetary policy, it is practical to have a consistent classification of such decision frameworks. To repeat, as in Rudebusch and Svensson (1999), Svensson (1999b) and Svensson and Woodford (2002a), a "monetary-policy rule" is interpreted broadly as a "prescribed guide for monetary-policy conduct." 37 This allows not only the narrow "instrument rules" but also the broader, and arguably more relevant, "targeting rules". In line with Tinbergen (1952), "target variables" are operational goal variables and

\footnotetext{
${ }^{37}$ Indeed, the first definition of "rule" in Merriam-Webster (1996) is "a prescribed guide for conduct or action."
} 
variables that enter a loss function, a function that is increasing in the distance of the target variables from prescribed "targets" (target levels). "Targeting" is minimizing such a loss function.

A "general targeting rule" is a high-level specification of a monetary-policy rule that specifies operational objectives, that is, the target variables, the targets and the loss function to be minimized. A "specific targeting rule" is instead expressed directly as an operational condition for the target variables (or for forecasts of the target variables). ${ }^{38}$

\subsection{Forecast targeting}

"Forecast targeting" refers to using forecasts of the target variables effectively as intermediate target variables, as in King's (1994) early characterization of inflation targeting, and means minimizing a loss function where forecasts enter as arguments. Monetary policy affects the economy with considerable lags. Current inflation and output are, to a large extent, determined by previous decisions of firms and households. Normally, current monetary-policy actions can only affect the future levels of inflation and the output gap, in practice with substantial lags and with the total effects spread out over several quarters. This makes forecasts of the target variables crucial in practical monetary policy.

Assume that the transmission mechanism is approximately linear, in the sense that the future target variables depend linearly on the current state of the economy and the instrument (as in

\footnotetext{
38 Sims (1980), while discussing the implications of the Robert Lucas (1976) critique for VAR studies, provides an early endorsement of targeting rules rather than instrument rules (although without using these names). As an example of monetary policy, Sims first (1980, p.13) specifies assumptions, under which "... the optimal form for macropolicy will be stabilization of the price level." He then continues (brackets denote my comments): "If we could agree on a stable model in which all forms of shock to the aggregate price level were specified a priori, then it would be easy in principle to specify an appropriate function mapping past values of observed macrovariables into current levels of policy variables in such a way as to minimize price variance [that is, to specify the optimal instrument rule]. However, if disturbances in the economy can originate in a variety of different ways, the form of this policy reaction function may be quite complicated. It is much easier simply to state that [the] policy rule is to minimize the variance of the price level [that is, as a general targeting rule]. Furthermore, if there is uncertainty about the structure of the economy, then even with a fixed policy objective function, widely understood, the form of the dependence of policy on observed history will shift over time as more is learned about (or as opinions shift about) the structure of the economy. One could continually re-estimate the structure and, each period, re-announce an explicit relation of policy variables to history [that is, re-announce the instrument rule]. However it is simpler to announce the stable objective function once [that is, the general targeting rule] and then each period solve only for this period's policy variable values instead of computing a complete policy reaction function [that is, the instrument rule need not be explicitly stated]. This is done by making conditional projections from the best existing reduced from model, and picking the best-looking projected future time path [that is, by general forecast targeting]. Policy choice is then most easily and reliably carried out by comparing the projected effects of alternative policies and picking the policy which most nearly holds the price level constant [that is, fulfills the specific targeting rule]."

Summarizing the argument, Sims (1980, p.14) again states: “... an optimal policy regime and the present regime in most countries are both most naturally specified in terms of the effects of policy on the evolution of the economy [that is, in terms of the targeting rule], rather than in terms of the nature of the dependence of policy on the economy's history [that is, in terms of the instrument rule]."

In consistency with this, reviewing the Taylor (1999c) conference volume, Sims also concludes (2001, p.566): "It seems to me that the call by RS [Rudebusch and Svensson 1999] for thinking about rules this way [as targeting rules instead of instrument rules] is one of the most important ideas in the book."
} 
the above examples of the two simple backward- and forward-looking models). Furthermore, assume that any uncertainty about the transmission mechanism and the state of the economy shows up as "additive" uncertainty about future target variables, in the sense that the degree of uncertainty about future target variables only depends on the horizon but not on the current state of the economy and the instrument setting. (This is the way the deviation enters in the backward- and forward-looking models used above.) Finally, let the intertemporal loss function be quadratic. It is then a standard result in optimal-control theory that so-called certaintyequivalence applies, and that optimal policy need only focus on conditional mean forecasts of the future target variables, forecasts conditional on the central bank's current information and a particular future path for the instrument. ${ }^{39}$ Since this means treating the forecasts as (intermediate) target variables (that is, putting forecasts of the target variables in the loss function), the procedure can be called "forecast targeting."

This decision-making process in the central bank then involves making conditional forecasts of inflation and the output gap, conditional on different paths of the central bank's instrument rate, using all relevant information about the current and the future state of the economy and the transmission mechanism. ${ }^{40}$ Then, the instrument-rate path is chosen, for which the corresponding conditional forecasts minimize the intertemporal loss function, which, in practice, means that the inflation forecast returns to the inflation target and that the corresponding conditional output-gap forecast returns to zero at an appropriate pace. If the inflation forecast is too high relative to the inflation target at the relevant horizon (but the output-gap forecast is acceptable), the instrument-rate path needs to be raised; if the conditional inflation forecast is too low, the instrument-rate path needs to be lowered. The chosen instrument-rate path is then the basis for the current instrument setting. In regular decision cycles, the procedure is then repeated. If no new significant information has arrived, the forecasts and the instrumentrate path are the same, and instrument-rate setting follows the same instrument-rate path. (The time-consistency problem that arises when there are forward-looking variables is further discussed below.) If new significant information has arrived, the forecasts and the instrumentrate path are updated. This is essentially the procedure recommended by Blinder (1998) and referred to as "dynamic programming" and "proper dynamic optimization." Compared to many

\footnotetext{
${ }^{39}$ For proof of the certainty-equivalence theorem for optimal-control theory, see Gregory Chow (1975) for models with predetermined variables only and Currie and Levine (1993) for models with both predetermined and forward-looking variables.

40 See Brash (2001) and Svensson (2001a) for a discussion of the decision-making process of the Reserve Bank of New Zealand, which provides a prime example of forecast targeting.
} 
other intertemporal decision problems that households, firms and investors solve one way or another (usually without the assistance of a sizeable staff of PhDs in economics), this particular decision problem is, in principle, not overly complicated or difficult.

Forecast targeting requires that the central bank has a view of what the policy multipliers are, that is, how instrument-rate adjustments affect the conditional inflation and output-gap forecasts. But it does not imply that forecasts must be exclusively model-based. Instead, it allows for extra-model information and judgmental adjustments, as well as very partial information about the current state of the economy. It basically allows for any information that is relevant for the inflation and output-gap forecasts.

\subsection{A commitment to a general forecast-targeting rule}

Let me be more specific. Let $i^{t}=\left\{i_{t+\tau, t}\right\}_{\tau=0}^{\infty}$ denote an instrument plan in period $t$. Conditional on the central bank's information in period $t, I_{t}$ (including its view of the transmission mechanism, etc.), and its judgment, $z^{t}$, and conditional on alternative instrument plans $i^{t}$, consider alternative (mean) forecasts for inflation, $\pi^{t}=\left\{\pi_{t+\tau, t}\right\}_{\tau=0}^{\infty}$, and the output gap, $x^{t}=\left\{x_{t+\tau, t}\right\}_{\tau=0}^{\infty}$ (consisting of the difference between $y^{t}$, the (mean) output forecast, and $y^{* t}$, the (mean) potential-output forecast). That is, $\pi_{t+\tau, t}=\mathrm{E}\left[\pi_{t+\tau} \mid i^{t}, I_{t}, z^{t}\right]$, etc. ${ }^{41}$ Furthermore, consider the intertemporal loss function in period $t$ applied to the forecasts of the target variables, that is, when the forecasts are substituted into the intertemporal loss function (2.1) with $(2.2)$,

$$
\mathcal{L}_{t}=\sum_{\tau=0}^{\infty} \delta^{\tau} \frac{1}{2}\left[\left(\pi_{t+\tau, t}-\pi^{*}\right)^{2}+\lambda x_{t+\tau, t}^{2}\right] .
$$

By a commitment to a general forecast-targeting rule, I mean a commitment to minimize a loss function over forecasts of the target variables. For an intertemporal quadratic loss function like (5.1), in principle this requires that the inflation target, $\pi^{*}$, the relative weight on outputgap stabilization, $\lambda$, and the discount factor, $\delta$, are specified. In practice, the loss function is not specified in this detail, and the central bank has some discretion over the translation of the stated objectives into a loss function, for instance, how the Reserve Bank of New Zealand interprets the

\footnotetext{
${ }^{41}$ Constructing conditional forecasts in a backward-looking model (that is, a model without forward-looking variables) is straightforward. Constructing such forecasts in a forward-looking model raises some specific difficulties, which are explained and resolved in the appendix of the working-paper version of Svensson (1999b). The conditional forecasts for an arbitrary interest-rate path derived there assume that the interest-rate paths are "credible", that is, anticipated and allowed to influence the forward-looking variables. Eric Leeper and Tao Zha (1999) present an alternative way of constructing forecasts for arbitrary interest-rate paths, by assuming that these interest-rate paths result from unanticipated deviations from a normal reaction function.
} 
PTA (see Svensson 2001a). ${ }^{42}$ Each period $t$, conditional on the central bank's forecasting model, information $I_{t}$ and judgment $z^{t}$, the bank then finds the combination of forecasts and instrument plan that minimizes (5.1), the optimal forecasts and instrument plan, denoted $\left(\hat{\pi}^{t}, \hat{x}^{t}, \hat{\imath}^{t}\right)$, and then makes the current instrument decision according to the current optimal instrument plan (the current instrument decision will be given by $\hat{\imath}_{t, t}$ in the backward-looking model and $\hat{\imath}_{t+1, t}$ in the forward-looking model).

As stated, this decision-making process implies discretionary minimization each period of a well-defined intertemporal loss function. The process will result in an endogenous reaction function for the current instrument decision, a function $F\left(I_{t}, z^{t}\right)$ of the central bank's information and judgment. This reaction function need not be specified explicitly, and it need not be followed mechanically. For a model without forward-looking variables, the resulting endogenous instrument-setting will follow the optimal reaction function derived under the direct optimalcontrol approach discussed above. For a model with forward-looking variables, this decisionmaking process will result in a different reaction function than the optimal one, to be further discussed below.

More precisely, how does the central bank find the optimal forecasts and instrument plan? One possibility is that, conditional on the information $I_{t}$ and the judgment $z^{t}$, the central bank staff generates a set of alternative forecasts $\left(\pi^{t}, x^{t}\right)$ for a set of alternative instrument plans $i^{t}$. This way, the staff constructs the "feasible set" of forecasts and instrument plans. The decisionmaking body of the central bank then selects the combination of forecasts that "looks best," in the sense of achieving the best compromise between stabilizing the inflation gap and stabilizing the output gap, that is, implicitly minimizes (5.1).

\subsubsection{The backward-looking model}

In the backward-looking model, the central bank's forecasting model in period $t$ will be given by (2.4)-(2.6), where the corresponding forecasts are substituted for actual values (and forecasts of the shocks are set equal to zero),

$$
\begin{aligned}
& \pi_{t+\tau+1, t}=\pi_{t+\tau, t}+\alpha_{x} x_{t+\tau, t}+\alpha_{z} z_{t+\tau+1, t}, \\
& x_{t+\tau+1, t}=\beta_{x} x_{t+\tau, t}+\beta_{z} z_{t+\tau+1, t}-\beta_{r}\left(i_{t+\tau, t}-\pi_{t+\tau+1, t}-\bar{r}\right),
\end{aligned}
$$

\footnotetext{
${ }^{42}$ In Svensson (2001b, 2002a), I argue that the time has come for central banks to announce explicit loss functions, including the relative weight $\lambda$ on output-gap stabilization.
} 
for $\tau \geq 0$. Thus, the forecasts fulfilling (5.2) and (5.3) are conditional on the central bank's judgment, $z^{t} \equiv\left\{z_{t+\tau, t}\right\}_{\tau=-\infty}^{\infty}$, and alternative instrument plans, $i^{t}$. As is shown in appendix A, equation (A.5), a central bank minimizing the intertemporal loss function will implicitly be satisfying the first-order condition

$$
\pi_{t+\tau+1, t}-\pi^{*}=\frac{\lambda}{\delta \alpha_{x}}\left(\delta x_{t+\tau+1, t}-x_{t+\tau, t}\right)
$$

for $\tau \geq 1$. This is the implicit condition for forecasts of the inflation and output gaps "looking good." Combining (5.4) with (5.2) and (5.3) leads to the optimal forecasts and instrument path, $\left(\hat{\pi}^{t}, \hat{x}^{t}, \hat{\imath}^{t}\right)$, and to the instrument-rate decision, $\hat{\imath}_{t, t}$, each period $t$. This instrument-rate decision will be consistent with (3.1), the complex optimal reaction function for this model. However, the commitment to the general targeting rule means that the central bank never need to make this reaction function explicit; instead it just repeatedly solves its optimization problem each period and implements its instrument-rate decision. In particular, the instrument setting incorporates the central bank's judgment in an optimal way.

\subsubsection{The forward-looking model}

In the forward-looking model, the central bank's forecasting model will be

$$
\begin{aligned}
\pi_{t+\tau+1, t}-\pi & =\delta\left(\pi_{t+\tau+2, t}-\pi\right)+\alpha_{x} x_{t+\tau+1, t}+\alpha_{z} z_{t+\tau+1, t} \\
x_{t+\tau+1, t} & =x_{t+\tau+2, t}-\beta_{r}\left(i_{t+\tau+1, t}-\pi_{t+\tau+2, t}-r_{t+\tau+1, t}^{*}\right)+\beta_{z} z_{t+\tau+1, t}
\end{aligned}
$$

for $\tau \geq 0$, given the central bank's forecast of the natural real interest rate, $r^{* t} \equiv\left\{r_{t+\tau, t}^{*}\right\}_{\tau=0}^{\infty}$, and its judgment $z^{t}$. With forward-looking variables, straight-forward discretionary optimization each period $t$ of the loss function (5.1) encounters the time-consistency problem: Even in the absence of any new information in period $t+1$, the optimal instrument-rate setting in period $t+1$ will deviate from the optimal instrument-rate plan in period $t$.

Under the assumption that the central bank instead anticipates the result of future optimization each period, time-consistency is assured. Appendix B then shows (equation (B.18) for $\tau=0$ ), that the central bank will each period $t$ set the instrument rate so as to implicitly achieve the first-order condition

$$
\pi_{t+1, t}-\pi^{*}=-\frac{\lambda}{\alpha_{x}} x_{t+1, t}
$$

Combining this first-order condition with (5.5) will result in optimal forecasts, $\left(\hat{\pi}^{t}, \hat{x}^{t}\right)$. Combining these forecasts with (5.6) will result in the optimal instrument path, $\hat{\imath}^{t}$. The optimal 
instrument-rate decision, $i_{t+1, t}$, is then given by $i_{t+1, t}=\hat{\imath}_{t+1, t}$, which follows from combining (5.6) for $\tau=0$ with $\hat{x}_{t+1, t}, \hat{x}_{t+2, t}, \hat{\pi}_{t+2, t}, r_{t+1, t}^{*}$ and $z_{t+1, t}$. The implied reaction function need never be made explicit. It is shown in appendix B, equation (B.21), that the implied reaction function is given by

$$
i_{t+1, t}=r_{t+1, t}^{*}+\pi^{*}+\frac{\tilde{c}}{\beta_{r} \lambda}\left[\beta_{r} \lambda-\alpha_{x}(1-\delta \tilde{c})\right] \alpha_{z} \tilde{z}_{t+2, t}+\frac{\alpha_{x} \tilde{c} \alpha_{z} z_{t+1, t}+\lambda \beta_{z} z_{t+1, t}}{\beta_{r} \lambda} .
$$

This reaction function is clearly different from the optimal reaction function, (3.5), although there is still no average inflation bias (under the assumption that the unconditional mean of the deviation is zero), so average inflation equals the inflation target and (3.6) holds. ${ }^{43}$ The coefficient $\tilde{c}$ is different from the coefficient $c$ of the optimal reaction function. It is still a function of the relative weight $\lambda$ on output gap stabilization, fulfills $0 \leq \tilde{c}(\lambda)<1$, and is now given by

$$
\tilde{c}(\lambda) \equiv \frac{\lambda}{\lambda+\alpha_{x}^{2}}
$$

(see (B.20)). Moreover, $\tilde{z}_{t+2, t}$ is defined as in (3.2), but with the coefficient $\tilde{c}$ substituted for $c$.

Thus, under discretionary forecast-targeting in the forward-looking model, the resulting instrument setting described by (5.8) will differ from the optimal reaction function (3.5). This illustrates that discretionary optimization results in stabilization bias (the response to shocks in (5.8) is different from that in (3.5)) and a lack of history-dependence (since there is no response to previous shocks in (5.8)).

The reason why discretionary optimization does not result in the optimal outcome is that, in the decision-period $t-1$, an increase in the two-period-ahead inflation forecast for $t+1$, $\pi_{t+1, t-1}$, increases the one-period-ahead forecast, $\pi_{t, t-1}$, via (5.5) when $t-1$ is substituted for $t$ and $\tau=1$. However, in the decision-period $t$, the inflation forecast for $t+1, \pi_{t+1, t}$, can be increased without any effect on inflation in period $t$, since the latter is now predetermined. Therefore, the tradeoff (the marginal rate of transformation) involved in adjusting the inflation forecast for $t+1$ is different between decision periods $t-1$ and $t$.

\subsubsection{A "commitment to continuity and predictability"}

As discussed in Svensson and Woodford (2002a), a commitment to a modified general targeting rule can solve the time-consistency problem and avoid the loss from discretionary optimization.

\footnotetext{
${ }^{43}$ If the unconditional mean of the deviation is zero, it follows from (2.8) that the unconditional mean of the output gap is zero, $\mathrm{E}\left[x_{t}\right]=0$. Using this and taking the unconditional mean of (5.7) results in $\mathrm{E}\left[\pi_{t+1, t}\right]=\pi^{*}$.
} 
More precisely, let $\Xi_{t, t-1}$ denote the shadow price (the Lagrange multiplier of (5.5) in (B.1), appendix B) of the one-period ahead aggregate-supply relation in period $t-1$. That is, $\Xi_{t, t-1}$ measures the increase in value of the intertemporal loss function resulting from an increase in the one-period-ahead inflation forecast in period $t-1, \pi_{t, t-1}$, due, for instance, to a change in judgment or an anticipated shock. Modify the general targeting rule by adding the term $\Xi_{t, t-1}\left(\pi_{t+1, t}-\pi^{*}\right)$ to the loss function (5.1) each period $t$, which results in

$$
\sum_{\tau=0}^{\infty} \delta^{\tau} \frac{1}{2}\left[\left(\pi_{t+\tau, t}-\pi^{*}\right)^{2}+\lambda x_{t+\tau, t}^{2}\right]+\Xi_{t, t-1}\left(\pi_{t+1, t}-\pi^{*}\right) .
$$

This can be interpreted as a commitment to a general targeting rule that involves "continuity and predictability," in that the previous cost in period $t-1$ of adjusting the forecast for period $t+1$ is taken into account. It internalizes the cost of disappointing private-sector expectations in period $t-1$ of inflation in period $t+1$, by incorporating the cost of the resulting effect on inflation in period $t$, had the change in $\pi_{t+1, t}$ been anticipated in period $t-1$. It is very much in line with the transparency, predictability and continuity emphasized in actual inflation targeting (see, for instance, King 1997). ${ }^{44} 45$

As shown in Svensson and Woodford (2002a), the central bank will then each period $t$ choose the instrument-rate plan $i_{t+1, t}$ so as to implicitly achieve the first-order condition

$$
\pi_{t+1, t}-\pi^{*}=-\frac{\lambda}{\alpha_{x}}\left(x_{t+1, t}-x_{t, t-1}\right) .
$$

According to this first-order condition, the one-period-ahead inflation-gap forecast shall be proportional to the negative of the change in the current one-period-ahead output-gap forecast from the previous period, with the proportionality factor $\lambda / \alpha_{x}$. As shown in appendix B, equation (B.9), this is the optimal first-order condition, and combining it with the forecasting model (5.5) and (5.6) will result in the optimal forecasts and instrument plan. Consequently, the implied instrument decision will fulfill (3.5) and be consistent with the optimal reaction function. ${ }^{46}$

\footnotetext{
${ }^{44}$ An increase $d \pi_{t+1, t-1}>0$ of the two-period-ahead inflation forecast in period $t-1$ would, everything else equal, also increase the one-period-ahead inflation forecast in period $t-1$, by $d \pi_{t, t-1}=\delta d \pi_{t+1, t}$, by $(5.5)$ for $\tau=0$ in period $t-1$ (since expectations of inflation in period $t+1$ affects inflation in period $t$ ). The present-value cost of this in period $t-1$ is $\varphi_{t, t-1} \delta d \pi_{t+1, t}$, the Lagrange multiplier of the same (5.5) for $\tau=0$ in period $t-1$. The present-value in period $t$ of this is then $\varphi_{t, t-1} d \pi_{t+1, t}$. Thus, the second term in (5.10) amounts to internalizing in period $t$ the consequences for the inflation forecast for period $t$ of adjusting the inflation forecast for period $t+1$, had such an adjustment been anticipated in period $t-1$.

45 Adding a linear term to the loss function is similar to the linear inflation contracts discussed in Walsh (1995) and Torsten Persson and Guido Tabellini (1993). Indeed, the term added in (5.10) corresponds to a statecontingent linear inflation contract, which, as discussed in Svensson (1997b), can remedy both stabilization bias and average-inflation bias.

46 The observant reader notes that the modified loss function making the discretion equilibrium optimal is related to the idea of recursive contracts by Albert Marcet and Ramon Marimon (1999).
} 


\subsubsection{Advantages and problems of a commitment to a general targeting rule}

A commitment to a general targeting rule means specifying clear objectives for monetary policy. Clear objectives in the form of a well-specified loss function is often taken for granted in research on monetary policy. Nevertheless, in practical monetary policy, specifying clear objectives is a substantial achievement. In practice, discretion in monetary policy has often meant discretion also with respect to the objectives, as is still the case to some extent for the Federal Reserve System. Specifying explicit objectives, together with operational independence and effective accountability structures is rightly considered essential in an effective monetary-policy setup (see Bernanke, Laubach, Mishkin and Posen 1999 and Svensson 2001a).

A major advantage with a commitment to a general targeting rule is also that the central bank is free to use all information deemed essential to achieve its objective. In particular, it allows the central bank to exercise its judgment and extra-model information, as demonstrated in the backward- and forward-looking models used in the examples above.

What are the problems with a commitment to a general targeting rule? One problem is that the objectives may still not be sufficiently well specified not to be open to interpretation. For instance, the relative weight on output-gap stabilization in flexible inflation targeting, the $\lambda$ in (2.2), is not directly specified by any inflation-targeting central bank (as mentioned, I argue in Svensson 2001b, 2002a that it should be specified.) In practice, evaluation of inflationtargeting monetary policy is left with examining reported forecasts of the inflation and output gaps and assessing whether they "look good" and provide a reasonable compromise between keeping inflation close to target and the output-gap movements necessary for this (as was the case for me in Svensson 2001a).

A second potential problem, emphasized by Woodford (1999a), is the potential consequences of the discretionary optimization under a commitment to a general targeting rule, more precisely that such discretionary optimization is not fully optimal in a situation with forward-looking variables. As we have seen, discretionary optimization results in stabilization bias and a lack of history dependence. ${ }^{47}$ The practical and empirical importance of the inefficiency caused by discretionary optimization is not obvious, though. It is perfectly possible that, in realistic models with considerable inertia and strong backward-looking elements, this inefficiency is overwhelmed by benefits from both specifying clear objectives for monetary policy and allowing all relevant

\footnotetext{
${ }^{47}$ The remedies Woodford (1999a) suggests are actually commitments to alternative specific targeting rulesalthough they are not called so.
} 
information and judgment to bear on monetary-policy decisions. Simulations by McCallum and Edward Nelson (2000) and David Vestin (2001) do not reject the hypotheses that the inefficiency is relatively small.

Furthermore, the discretion involved in a commitment to a general targeting rule may be constrained by a few more sophisticated mechanisms. The emphasis in inflation targeting on predictability and transparency may be interpreted as a commitment to not surprising the private sector, effectively similar to the "commitment to continuity and predictability" introduced above which enforces the commitment equilibrium. As discussed in Jon Faust and Svensson (2000), increased transparency may increase the reputational costs of deviating from announced goals and this way enforce a policy closer to the optimal commitment. ${ }^{48}$

Remaining problems with a commitment to a general targeting rule can potentially be solved by a commitment to a specific targeting rule, though.

\subsection{A commitment to a specific forecast-targeting rule}

A specific targeting rule specifies a condition for the forecasts of the target variables, which can formally be written as

$$
G\left(\pi^{t}, x^{t}\right)=0
$$

where $G(\cdot, \cdot)$ is a vector-valued function (possibly). This condition may be an optimal first-order condition, or an approximate first-order condition. Indeed, the optimal specific targeting rule expresses the equality of the marginal rates of transformation and the marginal rates of substitution between the forecasts of the target variables in an operational way. Then, the monetary-policy problem consists of finding the combination of forecasts and instrument path, $\left(\hat{\pi}^{t}, \hat{x}^{t}, \hat{\imath}^{t}\right)$, that is consistent with the central bank's forecasting model and fulfills the specific targeting rule, (5.12). Thus, in contrast to a commitment to a general targeting rule, once the condition (5.12) has been specified, finding the optimal forecasts and instrument plan is not a matter of minimizing a loss function but finding the solution to a system of difference equations. ${ }^{49}$

\footnotetext{
${ }^{48}$ Indeed, both these mechanisms arguably provide some foundations for McCallum's (1997) loosely specified idea of "just do it."

49 Alternatively, we can say that the central bank has a new (intermediate) intertemporal loss function to mimimize in period $t$, namely the inner product $G\left(\pi^{t}, x^{t}\right)^{\prime} G\left(\pi^{t}, x^{t}\right)$, the minimum of which occurs for (5.12). Thus, to each specific targeting rule, we can assign a trivial general targeting rule.
} 


\subsubsection{The backward-looking model}

In the backward-looking model, the optimal specific targeting rule for the forecasts $\pi^{t}$ and $x^{t}$ in period $t$ is the first order condition for an optimum, (5.4) for $\tau \geq 1$, derived in appendix A, equation (B.5). When the discount factor is close to unity, $\delta \approx 1$, the specific targeting rule can be written approximately as

$$
\pi_{t+\tau+1, t}-\pi^{*}=\frac{\lambda}{\alpha_{x}}\left(x_{t+\tau+1, t}-x_{t+\tau, t}\right)
$$

That is, the inflation-gap forecast should be proportional, with the factor $\lambda / \alpha_{x}$, to the forecast of the change in the output gap.

This specific targeting rule follows directly from the equality of the marginal rate transformation of the output gap into inflation (following from the aggregate-supply relation, (5.2)) and the marginal rate of substitution of inflation for the output gap (following from the intertemporal loss function, (5.1)). More precisely, in order to specify the relevant marginal rate of transformation from the output gap into inflation, consider the output-gap changes necessary for an increase in the two-period-ahead inflation forecast, $d \pi_{t+2, t}>0$, while holding the inflation forecast at all other horizons constant, $d \pi_{t+j, t}=0, j \neq 2$. From the aggregate-supply relation, (5.2), for $\tau=1$, we realize that the one-period-ahead output-gap forecast has to be increased, $d x_{t+1, t}>0$, resulting in an increase of the two-period-ahead forecast, fulfilling

$$
d \pi_{t+2, t}=\alpha_{x} d x_{t+1, t}>0
$$

Furthermore, in order to keep the three-period-ahead inflation forecast unchanged, $d \pi_{t+3, t}=0$, we realize from (5.2) for $\tau=2$, that the two-period-ahead output-gap forecast must be reduced,

$$
d x_{t+2, t}=-d \pi_{t+2, t} / \alpha_{x}=-d x_{t+1, t}<0
$$

where I have used (5.14). Thus, we need a combination of an increase in the one-period-ahead and reduction in the two-period-ahead output-gap forecasts to get a change in the two-periodahead inflation forecast only. It is practical to have a compact notation for such combinations, so I let them be denoted by the vector

$$
\tilde{x}_{t+1, t} \equiv\left(x_{t+1, t}, x_{t+2, t}\right) \equiv(1,-1) x_{t+1, t} .
$$

Now, let $\operatorname{MRT}\left(\pi_{t+2, t}, \tilde{x}_{t+1, t}\right)$ denote the marginal rate of transformation of the combination of output-gap forecasts $\tilde{x}_{t+1, t}$ into the two-period-ahead inflation forecast, $\pi_{t+2, t}$. By (5.14), it 
obviously fulfills

$$
\left.\operatorname{MRT}\left(\pi_{t+2, t}, \tilde{x}_{t+1, t}\right) \equiv \frac{d \pi_{t+2, t}}{d x_{t+1, t}}\right|_{d x_{t+2, t}=-d x_{t+1, t}}=\alpha_{x} .
$$

Thus we have found the relevant marginal rate of transformation. It is a generalization of the standard marginal rate of transformation since it involves the transformation of a combination of variables, rather than a single variable, into another variable.

It remains to find the corresponding marginal rate of substitution. Let $\operatorname{MRS}\left(\pi_{t+j, t}, x_{t+k, t}\right)$ denote the (standard) marginal rate of substitution of inflation in period $t+j, \pi_{t+j, t}$, for the output gap in period $t+k, x_{t+k, t}$. By (5.1), it fulfills

$$
\left.\operatorname{MRS}\left(\pi_{t+j, t}, x_{t+k, t}\right) \equiv \frac{d \pi_{t+j, t}}{d x_{t+k, t}}\right|_{d \mathcal{L}_{t}=0}=-\frac{\delta^{k} \lambda x_{t+k, t}}{\delta^{j}\left(\pi_{t+j, t}-\pi^{*}\right)}
$$

Let $\operatorname{MRS}\left(\pi_{t+2, t}, \tilde{x}_{t+1, t}\right)$ denote the (generalized) marginal rate of substitution of $\pi_{t+2, t}$ for the combination of output-gap forecasts $\tilde{x}_{t+1, t}$. It will be given by the sum of the marginal rates of substitution of $\pi_{t+2, t}$ for the separate changes in the output-gap forecasts (an increase one period ahead, an equal decrease two periods ahead), hence

$$
\begin{aligned}
\operatorname{MRS}\left(\pi_{t+2, t}, \tilde{x}_{t+1, t}\right) & \left.\equiv \frac{d \pi_{t+2, t}}{d x_{t+1, t}}\right|_{d \mathcal{L}_{t}=0, d x_{t+2, t}=-d x_{t+1, t}} \\
& =\operatorname{MRS}\left(\pi_{t+2, t}, x_{t+1, t}\right)+\operatorname{MRS}\left(\pi_{t+2, t}, x_{t+2, t}\right)(-1)
\end{aligned}
$$

Combining this with (5.17) gives

$$
\operatorname{MRS}\left(\pi_{t+2, t}, \tilde{x}_{t+1, t}\right)=\frac{\lambda\left(\delta x_{t+2, t}-x_{t+1, t}\right)}{\delta\left(\pi_{t+2, t}-\pi^{*}\right)} .
$$

Thus, we have found the relevant marginal rates of transformation and substitution between the target variables. Equalizing these,

$$
\operatorname{MRT}\left(\pi_{t+2, t}, \tilde{x}_{t+1, t}\right)=\operatorname{MRS}\left(\pi_{t+2, t}, \tilde{x}_{t+1, t}\right),
$$

gives (5.4) for $\tau=1$. Repeating the argument above for $\pi_{t+3, t}$, etc., results in (5.4) for $\tau \geq 1$.

Once the optimal specific targeting rule has been specified, the decision-making process of the central bank each period $t$ is then to find inflation- and output-gap forecasts that are consistent with the specific targeting rule. This means combining (5.4) (or its approximation (5.13)) with the forecasting model, (5.2) and (5.3) for the judgment $z^{t}$, and finding the appropriate inflationand output-gap forecasts and the corresponding instrument path. In particular, this can be done in a two-step procedure. First, the specific targeting rule is combined with the Phillips curve, (5.2), and the optimal inflation- and output-gap forecasts, $\left(\hat{\pi}^{t}, \hat{x}^{t}\right)$, are determined. Then 
these forecasts are used in the aggregate-demand relation, (5.3), to infer the corresponding instrument path, $\hat{\imath}^{t}$. Again, the optimal instrument setting in period $t$ is then given by $i_{t}=\hat{\imath}_{t, t}$. This instrument setting will be consistent with the optimal reaction function, (3.1), but this reaction function need not be made explicit. Indeed, given (5.3) for $\tau=0$, the judgment $z^{t}$ and the optimal forecasts $\hat{\pi}^{t}$ and $\hat{x}^{t}$, the optimal instrument-rate setting in period $t$ is given by

$$
\hat{\imath}_{t, t}=\bar{r}+\pi_{t+1, t}-\frac{1}{\beta_{r}} \hat{x}_{t+1, t}+\frac{\beta_{x}}{\beta_{r}} x_{t}+\frac{\beta_{z}}{\beta_{r}} z_{t+1, t} .
$$

The specific targeting rule can be formulated, using the approximation (5.13), as: "Select the instrument path so that the marginal rate of transformation of the output gap into inflation and the marginal rate of substitution of inflation for the output gap are equal, more specifically, that the inflation-gap forecast equals the proportion $\lambda / \alpha_{x}$ of the change in the output-gap forecast." The central bank then need not optimize but just solve difference equations.

We note that the targeting rule (5.4) only depends on the parameters $\delta$ (the discount factor), $\lambda$ (the relative weight on output-gap stabilization) and $\alpha_{x}$ (the effect of the output gap on inflation, the slope of the short-run Phillips curve). In particular, the targeting rule is independent of the coefficients in the vectors $\alpha_{z}$ and $\beta_{z}$. That is, it is independent of how the deviation affects inflation and output, and hence also of the judgment, the forecast of the deviations. Furthermore, the targeting rule (5.4) is independent of all the parameters of the aggregate-demand relation, (5.3). Indeed, the targeting rule only depends on the loss function, (5.1), via the marginal rate of substitution between inflation and the output gap (hence on the parameters $\delta$ and $\lambda$ ), and the aggregate-supply relation, the Phillips curve (5.2), via the marginal rate of transformation between inflation and the output gap (hence on the parameter $\alpha_{x}$ ). Since the marginal rates of transformation only depend on the derivatives of the aggregate-supply relation with respect to inflation and the output gap, the additive judgement (the "add factors") do not appear in the optimal targeting rule. This illustrates the relative robustness of targeting rules (relative to optimal reaction functions and instrument rules) suggested in Svensson (1997a) and further examined and confirmed in Svensson and Woodford (2002a). ${ }^{50}$

${ }^{50}$ For the case of strict inflation targeting, $\lambda=0$, the specific targeting rule (5.4) simplifies to the trivial

$$
\pi_{t+2, t}=\pi^{*} .
$$

That is, the two-period-ahead inflation should equal the inflation target. From (5.2) for $\tau=1$, it follows that the optimal one-period-ahead output-gap forecast, $\hat{x}_{t+1, t}$, must fulfill

$$
\hat{x}_{t+1, t}=-\frac{1}{\alpha_{x}}\left(\pi_{t+1, t}-\pi^{*}+\alpha_{z} z_{t+2, t}\right) .
$$

Using this in (5.18) will result in the desired instrument setting, $\hat{\imath}_{t, t}$, which will be consistent with the reaction function (3.4). Again, this reaction function need never be made explicit. 
A simple specific targeting rule As noted above and in footnote 5, the Bank of England and Sveriges Riksbank have formulated a simple specific targeting rule, "set the instrument rate so that a constant-interest-rate inflation forecast about two-years ahead equals the inflation target." This can be seen as an attempt to formulate an operational and simple targeting rule, not necessarily optimal but hopefully not far from being optimal. If the two-year horizon is seen as longer than the minimum horizon at which inflation can be affected, it can be interpreted as corresponding to flexible rather than strict inflation targeting. Since it takes a minimum of two periods to affect inflation in the simple model, and since I have assumed above that the period is 3 quarters, let me interpret the approximate two-year horizon as three periods (9 quarters). Thus, this simple rule can be interpreted as

$$
\pi_{t+3, t}=\pi^{*}
$$

where the 3 -period-ahead inflation forecast, $\pi_{t+3, t}$, is taken to be conditional on a constant interest rate, in this case corresponding to $i_{t+1, t}=i_{t, t}=i_{t}$. The implied reaction function resulting from this simple targeting rule is derived in appendix A.1, equation (A.17).

Clearly, the simple targeting rule (5.19) is generally different from the optimal specific targeting rule (5.4) or (5.13). Consequently, the implied reaction function derived in appendix A.1 is different from the optimal reaction function (3.1), corresponding to this simple targeting rule not being optimal. In addition to not being optimal, there are a number of additional problems with using constant-interest-rate forecasts, as discussed in Donald Kohn (2000).

A special case: Aggregate supply independent of judgment Consider the unrealistic special case when the aggregate-supply relation, (2.4) and (5.2), is independent of judgment, $\alpha_{z} \equiv 0$, so judgment only affects the aggregate-demand relation, $\beta_{z} \neq 0$. Combination of the optimal targeting rule (5.4) with the aggregate-supply relation (5.2) then results in a difference equation for the inflation forecast that fulfills (see (A.8) in appendix A)

$$
\pi_{t+\tau+1, t}-\pi^{*}=c^{\tau}\left(\pi_{t+1, t}-\pi^{*}\right)
$$

for $\tau \geq 1$. Here the coefficient $c=c(\lambda), 0 \leq c(\lambda)<1$, is an increasing function of the relative weight $\lambda$ on output-gap stabilization, as reported in section 3.1 and derived in appendix A. This specific targeting rule has been emphasized in Svensson (1997a, 1999b). It shows that, under flexible inflation targeting $(\lambda>0$ and $0<c(\lambda)<1)$, the inflation forecast should be brought back to the inflation target gradually and exponentially (if the predetermined one-period-ahead 
inflation forecast, $\pi_{t+1, t}$, deviates from the inflation target). Furthermore, the higher the relative weight on output-gap stabilization, the larger the coefficient $c(\lambda)$, and the slower the approach towards the inflation target.

But this simple and intuitive specific targeting rule for the backward-looking model is only valid under the special and unrealistic assumption of aggregate supply independent of judgment. (Therefore, in retrospect, I wish that I had not emphasized this particular targeting rule, (5.20), that much, for instance, in Svensson 1997a, 1999b.) Without that assumption, the judgment enters in a complicated way in (5.20), as seen in (A.8). Thus, the still simple (5.4) is the more general form of the specific targeting rule for the backward-looking model, valid also when judgment affects the aggregate-supply relation.

\subsubsection{The forward-looking model}

For the forward-looking model, appendix B, equation (B.5), shows that the optimal specific targeting rule is

$$
\pi_{t+\tau+1, t}-\pi^{*}=-\frac{\lambda}{\alpha_{x}}\left(x_{t+\tau+1, t}-x_{t+\tau, t}\right)
$$

for $\tau \geq 0$. For $\tau=0$, as discussed briefly in appendix B, equation (B.10), $x_{t, t}$ is interpreted as given by

$$
x_{t, t} \equiv x_{t, t-1}
$$

the one-period-ahead output-gap forecast in the previous period, $x_{t, t-1}$ (and not the current output gap, $x_{t}$ ), in order to be optimal in a timeless perspective. ${ }^{51}$

Again, this specific targeting rule can be derived directly from the equality of the marginal rate transformation of the output gap into inflation (following from the aggregate-supply relation,

${ }^{51}$ Expressed in terms of one-period-ahead private-sector expectations/plans, the consolidated first-order condition for an optimum in a timeless perspective is

$$
\pi_{t+1 \mid t}-\pi^{*}=-\frac{\lambda}{\alpha_{x}}\left(x_{t+1 \mid t}-x_{t \mid t-1}\right)
$$

If the optimal specific targeting rule is seen as a forecast of this first-order condition in period $t$, it can be written

$$
\pi_{t+1, t}-\pi^{*}=-\frac{\lambda}{\alpha_{x}}\left(x_{t+1, t}-x_{t \mid t-1}\right)
$$

under the assumption that the lagged private-sector outputput-gap forecast $x_{t \mid t-1}$ is directly observable by the central bank in period $t$. In line with this, $x_{t, t}$ in (5.21) should be interpreted as given by

$$
x_{t, t} \equiv x_{t \mid t-1}
$$

instead of (5.22). Since, as noted in section 3.2, in equilibrium, the one-period-ahead central-bank forecast and the one-period-ahead private-sector expecation/plan will be equal, this distinction does not matter for the purpose of this paper. It does matter for determinacy issues in the forward-looking model, as discusssed in detail in Svensson and Woodford (2002a). 
(5.5)) and the marginal rate of substitution of inflation for the output gap (following from the intertemporal loss function, (5.1)). Again, because the marginal rate of transformation depends on the derivatives of the aggregate-supply relation with respect to inflation and the output gap, the judgment part and the aggregate-demand relation do not appear.

The relevant marginal rates of transformation and substitution can thus be found with a similar argument as above for the backward-looking model in section 5.4.1. Consider the sequence of output-gap forecast changes required to increase the two-period-ahead inflation forecast, $d \pi_{t+2, t}>0$, while holding the inflation forecast at other horizons constant, $d \pi_{t+j, t}=0$, $j \neq 2$. From (5.5) for $\tau=0$, we see that any increase in the two-period-ahead inflation forecast, $d \pi_{t+2, t}>0$, everything else equal, will increase the one-period-ahead inflation forecast, $\pi_{t+1, t}$, since one-period-ahead inflation depends on expectations of two-period-ahead inflation. Keeping $\pi_{t+1, t}$ constant then requires a fall in the one-period-ahead output gap forecast, $d x_{t+1, t}=-\delta d \pi_{t+2, t} / \alpha_{x}<0$. Thus, we have

$$
d \pi_{t+2, t}=-\frac{\alpha_{x}}{\delta} d x_{t+1, t}>0
$$

Furthermore, from (5.5) for $\tau=1$, we see that constancy of $\pi_{t+3, t}$ then requires an increase in the two-period-ahead output-gap forecast, $d x_{t+2, t}=-d \pi_{t+2, t} / \alpha_{x}=-d x_{t+1, t} / \delta$. Thus, the relevant combination, $\tilde{x}_{t+1, t}$, of one- and two-period-ahead output-gap forecasts is $\tilde{x}_{t+1, t} \equiv$ $\left(x_{t+1, t}, x_{t+2, t}\right) \equiv(1,-1 / \delta) x_{t+1, t}$. By (5.23), it follows that the relevant marginal rate of transformation of this combination $\tilde{x}_{t+1, t}$ into $\pi_{t+2, t}$ is given by

$$
\left.\operatorname{MRT}\left(\pi_{t+2, t}, \tilde{x}_{t+1, t}\right) \equiv \frac{d \pi_{t+2, t}}{d x_{t+1, t}}\right|_{d x_{t+2, t}=-d x_{t+1, t} / \delta}=-\frac{\alpha_{x}}{\delta} .
$$

By a similar argument as for the backward-looking model in section 5.4.1, the relevant marginal rate of substitution of $\pi_{t+2, t}$ for this combination $\tilde{x}_{t+1, t}$ will be

$$
\begin{aligned}
\operatorname{MRS}\left(\pi_{t+2, t}, \tilde{x}_{t+1, t}\right) & \left.\equiv \frac{d \pi_{t+2, t}}{d x_{t+1, t}}\right|_{d \mathcal{L}_{t}=0, d x_{t+2, t}=-d x_{t+1, t} / \delta}= \\
& =\operatorname{MRS}\left(\pi_{t+2, t}, x_{t+1, t}\right)+\operatorname{MRS}\left(\pi_{t+2, t}, x_{t+2, t}\right)\left(-\frac{1}{\delta}\right) \\
& =\frac{\lambda\left(x_{t+2, t}-x_{t+1, t}\right)}{\delta\left(\pi_{t+2, t}-\pi^{*}\right)}
\end{aligned}
$$

with the use of (5.17). Equality of the marginal rate of transformation and the marginal rate of substitution then results in (5.21) for $\tau=1$. Repeating the same argument for $\pi_{t+3, t}$, etc., results in (5.21) for $\tau \geq 1$. Repeating the same argument for $\pi_{t+1, t}$, taking into account the 
hypothetical effect on $\pi_{t, t-1}$ if this had been anticipated (that is, considering optimality in the time-less perspective), results in (5.21) for $\tau=0$ with (5.22).

Thus, the central bank should find the inflation and output-gap forecasts that fulfill the specific targeting rule (5.21) with (5.22). This is done by combining the specific targeting rule with the forward-looking Phillips curve, (5.5), which results in the optimal forecasts, $\hat{\pi}^{t}$ and $\hat{x}^{t}$. From the aggregate-demand relation, (5.6), for $\tau=0$, the optimal instrument decision is given by

$$
\hat{\imath}_{t+1, t}=r_{t+1, t}^{*}+\pi^{*}+\left(\hat{\pi}_{t+2, t}-\pi^{*}\right)+\frac{1}{\beta_{r}}\left(\hat{x}_{t+2, t}-\hat{x}_{t+1, t}\right)+\frac{\beta_{z}}{\beta_{r}} z_{t+1, t} .
$$

The resulting instrument decision will be consistent with the optimal reaction function, (3.5). Again, the optimal reaction function need never be made explicit.

We note that the optimal specific targeting rule for the forward-looking model, (5.21) with (5.22), is different from the optimal specific targeting rule for the backward-looking model, (5.4). Comparing (5.21) to the approximation (5.13) for $\delta \approx 1$, we see that the right side is the same but have opposite signs. This is because the marginal rate of transformation between inflation and the output gap, the dynamic tradeoff between the target variables, is different for the two aggregate-supply relations, cf. (5.16) and (5.24). As has been observed in the literature, the dynamics of the backward-looking and the forward-looking Phillips curves (5.2) and (5.5) are quite different. A steady increase in inflation corresponds to a positive output gap in the backward-looking Phillips curve but a negative output gap in the forward-looking one (see Ball 1994 and Gregory Mankiw 2001).

The simple specific targeting rule like (5.19) raises additional issues and problems in a forward-looking model, as discussed in appendix B.2 and by Kai Leitemo (2000).

A commitment to a specific price-level targeting rule Consider a commitment to an alternative specific targeting rule, related to price-level targeting. First, let $p_{t}$ denote (the $\log$ of) the price level in period $t$ (so $\pi_{t} \equiv p_{t}-p_{t-1}$ ) and define a (log) price-level target path in period $t, p^{* t}=\left\{p_{t+\tau, t}^{*}\right\}_{\tau=0}^{\infty}$, according to

$$
\begin{aligned}
p_{t, t}^{*} & \equiv p_{t, t-1}^{*}+\pi^{*}+p_{t}-p_{t \mid t-1}, \\
p_{t+\tau, t}^{*} & \equiv p_{t, t}^{*}+\pi^{*} \tau .
\end{aligned}
$$

This price-level target path starts from $p_{t, t}^{*}$ and then increases at a rate equal to the inflation target. Since the starting point is adjusted by the unanticipated shock to the price level, $p_{t}-$ 
$p_{t \mid t-1}=\varepsilon_{t}+\alpha_{z}\left(z_{t}-z_{t \mid t-1}\right)$, some base drift is allowed to occur. Second, specify the specific price-level targeting rule as

$$
p_{t+\tau+1, t}-p_{t+\tau+1, t}^{*}=-\frac{\lambda}{\alpha_{x}} x_{t+\tau+1, t}
$$

for $\tau \geq 0$. That is, the price-level-gap forecast should be proportional to the negative of the output-gap forecast. By first-differencing (5.27) with respect to $\tau$ for $\tau \geq 1$ and a given $t$ and using (5.26), we directly get (5.21) for $\tau \geq 1$. By first-differencing (5.27) with respect to $t$ for $\tau=0$ and using (5.25) and (5.26) and the fact that, in equilibrium, $p_{t, t-1}=p_{t \mid t-1}$, we get (5.21) for $\tau=0$ and (5.22). Thus, the price-level targeting rule (5.27) implies the inflation targeting rule $(5.21)$ and $(5.22)$.

It is easy to show that (5.27) will result if the central bank minimizes a loss function corresponding to flexible price-level targeting under discretion. This illustrates the close relation between optimal inflation targeting under commitment and price-level targeting under discretion previously discussed by Svensson (1999c), Vestin (2000), Svensson and Woodford (2002a) and Smets (2000).

\subsubsection{Advantages and problems of a commitment to a specific targeting rule}

A commitment to a specific targeting rule has the obvious advantage of providing a more specific, more operational, and more easily verifiable commitment than a commitment to a general targeting rule. This way it provides stronger accountability. The optimal specific targeting rule can also overcome any inefficiency caused by discretionary optimization, while retaining the flexibility in allowing all relevant information and judgment to bear on the monetary-policy decision. Compared to the benchmark of a commitment to the optimal instrument rule, it is more robust, in the sense of only depending on part of the model of the transmission mechanism, namely the marginal rate of transformation between the target variables.

A potential disadvantage, however, is that a specific targeting rule, in order to be optimal, depends on the precise marginal rate of transformation, the dynamic tradeoff between the target variables. Therefore, it is not robust to different models of the aggregate-supply relation, as is apparent in the examples of the backward-looking and forward-looking models used above. Thus, it is clearly less robust than a commitment to a general targeting rule.

The simple specific targeting rule of the Bank of England and Sveriges Riksbank discussed above is at most a rather preliminary attempt to formulate an operational specific targeting rule 
and raises a number of problems, as discussed in Kohn (2000) and Leitemo (2000).

\subsection{Some criticism}

McCallum, for instance in (2000), and McCallum and Nelson, for instance in (2000), have several times criticized various aspects of and defended alternatives to ideas presented in this paper. First, as a defense of instrument rules involving responses to target variables only, they have suggested that there is a benefit to discussing monetary policy without reference to explicit loss functions. At the same time, the results of these instrument rules have been evaluated in terms of the resulting variances of inflation and the output gap. But this is equivalent to using a loss function consisting of a weighted sum of the variances of inflation and the output gap, (2.3), for different values of the weight $\lambda$. It seems more transparent to me, then, to be explicit about such a loss function. ${ }^{52} 53$

Second, McCallum and Nelson have also argued that targeting rules can be replaced by obvious instrument rules, thereby implying that targeting rules are redundant. Consider, for instance, the targeting rule (5.21) with (5.22) with $\tau=0$ for the forward-looking model above, which can be written

$$
\pi_{t+1, t}-\pi^{*}+\frac{\lambda}{\alpha_{x}}\left(x_{t+1, t}-x_{t, t-1}\right)=0 .
$$

The idea is that this can be replaced by an instrument rule of, for instance, the form

$$
i_{t}=\left(1-f_{i}\right)\left\{\bar{r}+\pi_{t}+\gamma\left[\pi_{t+1, t}-\pi^{*}+\frac{\lambda}{\alpha_{x}}\left(x_{t+1, t}-x_{t, t-1}\right)\right]\right\}+f_{i} i_{t-1}
$$

where the response coefficient, $\gamma$, is very large (McCallum and Nelson 2000 in simulations suggest $\gamma \geq 50)$ and in the limit approaches infinity. Such an instrument rule would ensure that the term within the square brackets is arbitrarily close to zero and hence fulfills the targeting rule (5.28). However, as discussed in detail in Svensson and Woodford (2002a), this is a dangerous

\footnotetext{
52 A common way of evaluating the outcome of alternative instrument rules is to plot the result in a graph with unconditional inflation variance on the horisontal axis and unconditional output-gap variance on the vertical axis and then examine the result in relation to the "Taylor curve" (see Taylor 1979) of efficient combinations of the two variances. This is of course equivalent to using a loss function of the form (2.3), with different relative weights $\lambda \geq 0$. Indeed, a common way to find the Taylor curve is to optimize over a class of reaction functions for values of $\lambda$ from zero to infinity. See, for instance, Rudebusch and Svensson (1999) and several other papers in Taylor $(1999 \mathrm{c})$.

Taylor (1979) plotted the standard deviations along the axes; plotting the variances has the advantage that the (negative) slope at a preferred point on the Taylor curve can be interpreted as revealing $1 / \lambda$ in the loss function above, since indifference curves for the loss function (2.3) correspond to straigth lines with (negative) slope $1 / \lambda$.

53 Another problem with restricting simple rules to respond to target variables only is, as noted above, that the general principle is that it is best to respond to the main determinants of the (forecasts) of the target variables. The set of these main determinants is likely to include more variables than the current target variables; indeed, the current target variables may not be among the determinants at all (which is the case when the target variables are forward-looking variables).
} 
and completely impracticable idea. It is completely inconceivable in practical monetary policy to have reaction functions with very large response coefficients, since the slightest mistake in calculating the argument of the reaction function would have grave consequences and result in extreme instrument-rate volatility. (Such interest-rate volatility does not arise in McCallum and Nelson's 2000 simulations because no mistakes are allowed for.) The fact that McCallum has long argued for robust instrument rules makes this idea even more surprising. ${ }^{54}$

Third, McCallum and Nelson have also argued that the Reserve Bank of New Zealand provides an example of a central bank that is committed to an instrument rule, as an argument in favor the practical relevance of instrument rules. It is true that the Reserve Bank uses a reaction function of the form (4.6) in its Forecasting and Policy System (FPS) in order to generate an endogenous future interest-rate path. However, for the first few quarters of this interest-rate path, the interest rate is set by discretion and judgment, and the reaction function is only used further into the future. Hence, it is not the case that the current interest-rate decision, or even the first few quarters of the interest-rate path, is given by the reaction function. Brash (2001) and Svensson (2001a) provide some further details on the decision-making process of the Reserve Bank. ${ }^{55}$

\subsection{Interest-rate stabilization and smoothing and exchange-rate smoothing}

The discussion of instrument rules and targeting rules here has, except briefly in the discussion of the forecast-based instrument rule (4.6) in section 4.4, been under the assumption of no separate monetary-policy objectives of interest-rate stabilization and/or smoothing. That is, only inflation and the output gap has been considered target variables and hence entered the loss function, and only (forecasts of) inflation and the output gap have entered the specific targeting rules discussed.

I find the case for explicit instrument-rate stabilization and/or smoothing objectives quite weak (see Brian Sack and Wieland 1999 for further discussion and empirical evidence). Such objectives would correspond to adding the term $\lambda_{i}\left(i_{t}-\bar{\imath}\right)^{2}+\lambda_{\Delta i}\left(i_{t}-i_{t-1}\right)^{2}$, where $\lambda_{i}$ and $\lambda_{\Delta i}$ are positive weights and $\bar{\imath}$ denotes the average instrument-rate level, in the period loss function (2.2). Possible adverse consequences for financial markets of interest-rate volatility,

\footnotetext{
${ }^{54}$ Furthermore, on a more technical note and as examined in Svensson and Woodford (2002a), stability properties of the model are not invariant between (5.28) and (5.29).

${ }^{55}$ In my review of the operation of monetary policy in New Zealand, (2001a), I actually criticize the Reserve Bank for its use of this form of a reaction function and suggest that it considers alternatives, with reference to the same problems as those reported in section 4.4.
} 
beyond the real effects represented by output-gap stabilization, are hardly convincing, except in special circumstances with an exceptionally weak financial sector. A desire to avoid too large interest-rate surprises would rather correspond to a term of the form $\lambda_{i}\left(i_{t}-i_{t \mid t-1}\right)^{2}$, where $i_{t \mid t-1}$ denotes previous market expectations of the instrument rate, but with a systematic and transparent monetary policy as in current inflation targeting, instrument-rate surprises are small anyhow. In practical monetary policy, there are recent conspicuous deviations from instrumentrate smoothing, in Fed interest-rate reductions in the first half of 2001 and previously Willem Buiter's voting in the Bank of England MPC. Deviations from Milton Friedman's (1969) optimal quantity of money could motivate a quadratic interest-rate term (cf. Woodford 1999b), but since most money pays some interest these days, the distortion would seem to be minor, and it is difficult to see that such costs could be significant compared to the costs of variability of inflation and the output gap. Woodford (1999c) has shown that an instrument-smoothing objective under discretion can induce a desirable history-dependence of monetary policy. In the perspective of this paper, though, a commitment to an optimal specific targeting rule is a more direct way of achieving such history-dependence. The practical importance of historydependence also remains to be established, as noted above. Rudebusch (2002b) suggests that the high coefficient on the lagged federal funds rate in estimated Fed reaction functions can be explained by the Fed reacting to persistent shocks rather than to some separate interest-rate smoothing objective. ${ }^{56}$

If interest-rate stabilization and/or smoothing nevertheless is a separate monetary policy objective, the interest rate in question is also a target variable. Most of the above-mentioned reason for such objectives would probably apply to something like a 3-month money-market interest rate, rather than the instrument rate (which is typically a repo rate or an overnight rate). Then this market interest rate becomes an additional target variable, separate from, but related to (via the expectations hypothesis, for instance) the instrument rate.

The more target variables, the more complex the specific targeting rules. In particular, if an interest rate is a target variable, the targeting rules not only depend on the loss function and the Phillips curve, but also on the aggregate-demand relation, since the latter involves the tradeoffs between output and interest rates. It would still be the case that additive judgement, as in the backward- and forward-looking example models used here, would not enter explicitly

\footnotetext{
${ }^{56}$ Even though the PTA for the Reserve Bank of New Zealand states that the Reserve Bank "shall seek to avoid unnecessary instability in output, interest rates and the exchange rate," I must confess that I, in my evaluation (2001a), did not much consider stability of interest rates as a separate objective.
} 
in the targeting rules. In this respect, the optimal targeting rule would still be simpler than the optimal instrument rule, since the judgment would enter the latter, in addition in a complex way, as we have seen in the above example models. In case the instrument rate enters the loss function, so the instrument rate rather than a somewhat longer market rate is a target variable, the targeting rule would be indistinguishable from an implicit forecast-based instrument rule (although, for a reasonable loss function, of different form than (4.6)).

As an example, consider the case of instrument-rate stabilization, when the term $\lambda_{i}\left(i_{t+\tau, t}-\bar{\imath}\right)^{2}$ is added within the bracket in the intertemporal loss function (5.1), corresponding to a separate objective to stabilize the instrument rate around its mean, $\bar{\imath}$. Then the instrument rate is also a target variable. For the backward-looking model, in section 5.4.1 above I specified the required changes $\left(d x_{t+1, t}, d x_{t+2, t}\right)=(1,-1) d x_{t+1, t}$ in the output-gap forecast for a change in the twoperiod-ahead inflation forecast only. By the aggregate-demand relation, (5.3), for $\tau=0$ and $\tau=1$, these require changes in the instrument rate that fulfill

$$
\begin{aligned}
d i_{t, t} & =-\frac{1}{\beta_{r}} d x_{t+1, t}<0, \\
d i_{t+1, t} & =d \pi_{t+2, t}-\frac{1}{\beta_{r}}\left(d x_{t+2, t}-\beta_{x} d x_{t+1, t}\right)=\frac{\alpha_{x} \beta_{r}+1+\beta_{x}}{\beta_{r}} d x_{t+1, t}>0, \\
d i_{t+2, t} & =d \pi_{t+3, t}-\frac{1}{\beta_{r}}\left(d x_{t+3, t}-\beta_{x} d x_{t+2, t}\right)=\frac{\beta_{x}}{\beta_{r}} d x_{t+2, t}=-\frac{\beta_{x}}{\beta_{r}} d x_{t+1, t}<0 .
\end{aligned}
$$

Thus, the relevant linear combination of target variables now includes these instrument rates and is given by $\tilde{x}_{t+1, t} \equiv\left(x_{t+1, t}, x_{t+2, t}, i_{t, t}, i_{t+1, t}, i_{t+2, t}\right) \equiv\left[1,-1,-1 / \beta_{r},\left(\alpha_{x} \beta_{r}+1+\beta_{x}\right) / \beta_{r},-\beta_{x} / \beta_{r}\right] x_{t+1, t}$. With this interpretation of $\tilde{x}_{t+1, t}$, the relevant marginal rate of transformation of $\tilde{x}_{t+1, t}$ into $\pi_{t+2, t}$ is still given by (5.16). The calculation of the relevant marginal rate of substitution of $\pi_{t+2, t}$ for this combination $\tilde{x}_{t+1, t}$ must now take into account the required changes in the instrument rate and the marginal rates of substitution of $\pi_{t+j, t}$ for $i_{t+l, t}$,

$$
\operatorname{MRS}\left(\pi_{t+j, t}, i_{t+l, t}\right)=-\frac{\delta^{l} \lambda_{i}\left(i_{t+l, t}-\bar{\imath}\right)}{\delta^{j}\left(\pi_{t+j, t}-\pi^{*}\right)} .
$$

This results in

$$
\begin{aligned}
\operatorname{MRS}\left(\pi_{t+j, t}, \tilde{x}_{t+1, t}\right)= & \frac{\lambda\left(\delta x_{t+2, t}-x_{t+1, t}\right)}{\delta\left(\pi_{t+2, t}-\pi^{*}\right)} \\
& +\frac{\lambda_{i}\left[\left(i_{t, t}-\bar{\imath}\right)-\delta\left(\alpha_{x} \beta_{r}+1+\beta_{x}\right)\left(i_{t+1, t}-\bar{\imath}\right)+\delta^{2} \beta_{x}\left(i_{t+2, t}-\bar{\imath}\right)\right]}{\delta^{2} \beta_{r}\left(\pi_{t+2, t}-\pi^{*}\right)} .
\end{aligned}
$$

Equality of the marginal rate of transformation (5.16) and substitution (5.30), and repeating 
the argument for $\pi_{t+3, t}$, etc., then implies the optimal specific targeting rule

$$
\begin{aligned}
\pi_{t+\tau+1, t}-\pi^{*}= & \frac{\lambda}{\delta \alpha_{x}}\left(\delta x_{t+\tau+, t}-x_{t+\tau, t}\right) \\
& +\frac{\lambda_{i}}{\delta^{2} \alpha_{x} \beta_{r}}\left[\delta^{2} \beta_{x}\left(i_{t+\tau+1, t}-\bar{\imath}\right)-\delta\left(\alpha_{x} \beta_{r}+1+\beta_{x}\right)\left(i_{t+\tau, t}-\bar{\imath}\right)+\left(i_{t+\tau-1, t}-\bar{\imath}\right)\right]
\end{aligned}
$$

for $\tau \geq 1$. The decision problem then consists of combining (5.31) with both the aggregatesupply and aggregate-demand relations, (5.2) and (5.3), and solving for the optimal combination of inflation, output-gap and instrument-rate forecasts, $\left(\hat{\pi}^{t}, \hat{x}^{t}, \hat{\imath}^{t}\right)$, and then implementing $\hat{\imath}_{t, t}$.

For the forward-looking model, similar reasoning results in the relevant linear combination of target variables $\tilde{x}_{t+1, t} \equiv\left(x_{t+1, t}, x_{t+2, t}, i_{t, t}, i_{t+1, t}, i_{t+2, t}\right) \equiv\left[1,-1 / \delta, 1 / \beta_{r},-\left(\alpha_{x} \beta_{r}+1+\delta\right) / \delta \beta_{r}\right.$, $\left.1 / \delta \beta_{r}\right] x_{t+1, t}$ and the optimal specific targeting rule

$$
\begin{aligned}
\pi_{t+\tau+1, t}-\pi^{*}= & -\frac{\lambda}{\alpha_{x}}\left(x_{t+\tau+1, t}-x_{t+\tau, t}\right) \\
& -\frac{\lambda_{i}}{\delta \alpha_{x} \beta_{r}}\left[\left(\alpha_{x} \beta_{r}\right)\left(i_{t+\tau, t}-\bar{\imath}\right)-\delta\left(i_{t+\tau+1, t}-i_{t+\tau, t}\right)+\left(i_{t+\tau, t}-i_{t+\tau-1, t}\right)\right]
\end{aligned}
$$

for $\tau \geq 0$, with (5.22) and $i_{t, t} \equiv i_{t, t-1}, i_{t-1, t} \equiv i_{t-1, t-2}$. The decision problem then consists of combining (5.32) with both the aggregate-supply and aggregate-demand relations, (5.5) and (5.6), and solving for the optimal combination of inflation, output-gap and instrument-rate forecasts, $\left(\hat{\pi}^{t}, \hat{x}^{t}, \hat{\imath}^{t}\right)$, and then implementing $\hat{\imath}_{t+1, t} \cdot{ }^{57}$

Are (5.31) and (5.32) targeting rules or instrument rules? Since the instrument rate appears, they are also "implicit" instrument rules. They are not "explicit" instrument rules, since the relations do not express the instrument as function of predetermined variables only, but as an equilibrium condition for endogenous variables. However, (5.31) and (5.32) are fundamentally targeting rules, in the sense that only variables who are target variables enter there. The instrument rate being a separate target variable is a necessary condition for it to appear in these rules. If we set $\lambda_{i}=0$, so the instrument rate no longer is a separate target variable, the instrument rate no longer appears in the specific targeting rule.

One can conceive of a separate objective of exchange-rate smoothing, meaning the addition to the period loss function of a term $\lambda_{\Delta s}\left(s_{t}-s_{t-1}\right)^{2}$, where $\lambda_{\Delta s}$ is a positive weight and $s_{t}$ is the log of the nominal exchange rate, so $s_{t}-s_{t-1}$ is the rate of currency depreciation (when

57 Note that (5.32) is the same optimal first-order condition as equation (32) in Giannoni (2000). Giannoni assumes a loss function with interest-rate stabilization $\left(\lambda_{i}>0\right)$ and uses the forward-looking model with current inflation and output being forward-looking variables rather than predetermined. Giannoni and Woodford (2002b) have recently provided a detailed discussion of targeting rules when the instrument rate is one of the target variables. 
the exchange rate is measured as units of domestic currency per unit of foreign currency). It is certainly possible for central banks to smooth exchange rates somewhat, at the cost of increased variability in the other target variables, inflation and the output gap. One can also conceive of separate objectives of real-exchange-rate smoothing, or even stabilization of a real-exchange-rate gap between the real exchange rate and a "potential" real exchange rate. Additional separate objectives makes monetary policy more ambitious and the corresponding decision problem, and the corresponding specific targeting rule more complex, in a similar way as interest-rate stabilization causes more complexity. It therefore makes commitment and verification more difficult. I see no good reasons for separate exchange-rate objectives, nominal or real, under flexible inflation targeting in advanced countries. ${ }^{58}$ As discussed in some detail in Svensson (2000), in an open economy with CPI inflation targeting, there may nevertheless be some implicit realexchange-rate smoothing, depending on the share of imported final goods and the degree of exchange-rate pass-through. ${ }^{59}$

\subsection{Distribution forecast targeting}

Under the above assumptions of a quadratic loss function and an essentially linear transmission mechanism, together with additive uncertainty, the certainty-equivalence result implies that the mean forecasts are the relevant target variables, regardless of the degree of uncertainty. When the uncertainty about the transmission mechanism is "nonadditive," that is, there is uncertainty about the policy multipliers, or if the transmission mechanism is characterized by significant nonlinearities, certainty-equivalence no longer applies, and the mean forecasts of the target variables are not sufficient. Instead, the "balance of risks" and indeed the whole probability distribution of the target variables matter. As discussed in Svensson (1999a, 2001c), forecast targeting can then be generalized from mean forecast targeting to distribution forecast targeting.

Distribution forecast targeting would then consist of constructing conditional probability distributions of the target variables instead of mean forecast only. Thus, for a given instrument-rate path, the central bank would construct the joint conditional density function of the random path of inflation and the output gap, conditional upon all information available in period $t$, the judg-

\footnotetext{
${ }^{58}$ In emerging market economies, foreign currency debt, vulnerable balance sheets and related threats to financial stability may arguably motivate some separate weight on exchange-rate smoothing.

${ }^{59}$ For simplicity, assume a unitary immediate exchange-rate pass-through to the CPI of a small open economy. Its CPI inflation, $\pi_{t}^{c}$, can then be written as $\pi_{t}^{c}=\pi_{t}+\omega\left(q_{t}-q_{t-1}\right)$, where $\pi_{t}$ is inflation in domestically produced goods and services in the CPI, $\omega$ is the share of imported goods in the CPI, and $q_{t}$ is the log real exchange rate, so $q_{t}-q_{t-1}$ is real currency depreciation. Then the term $\left(\pi_{t}^{c}-\pi^{*}\right)^{2}$ in the period loss function is equal to $\left(\pi_{t}-\pi^{*}\right)^{2}+\omega^{2}\left(q_{t}-q_{t-1}\right)+2 \omega \pi_{t}\left(q_{t}-q_{t-1}\right)$, so the square of real currency depreciation implicitly enters the loss function.
} 
ment, and a given instrument-rate path. Then, the intertemporal loss function is evaluated with the help of this conditional probability distribution. First, this can be done informally, by the decision-making body of the bank. In this case, the decision-making body could be presented with the probability distributions of the target variables for a few alternative instrument-rate paths and then decide which path and distribution provides the best compromise. This is, in principle, the same problem that any economic agent is assumed to solve in countless applications of decision-making under uncertainty. Second, given a numerical representation of the probability distributions and a specification of the parameters of the loss function, the loss function can easily be evaluated numerically.

Inflation-targeting central banks already seem to consider the whole probability distribution of the forecast, by considering the "balance of risks." Furthermore, the Bank of England and the Riksbank have developed sophisticated methods for constructing confidence intervals for the forecasts published in their Inflation Reports (see Mårten Blix and Peter Sellin 1998 and Erik Britton, Paul Fisher and John Whitley 1998). The Bank of England presents fan charts for both inflation and output, and the Riksbank gives confidence intervals for its inflation forecasts. Furthermore, scrutiny of the motivations for instrument-rate changes (including the minutes from the Bank of England's Monetary Policy Committee and the Riksbank's Executive Board) indicate that both banks occasionally take properties of the whole distribution into account in their decisions, for instance, when the risk is unbalanced and "downside risk" differ from "upside risk."

However, the point forecasts (the center of the confidence intervals) reported and published by the Bank of England and the Riksbank are, by tradition, mode forecasts (that is, the most likely outcome), rather than mean forecasts. When the probability distribution is asymmetric, these two differ. Hence, one interpretation of the adjustment of the mode because of the balance of risk, is that it is just a way of constructing the mean, in which case the procedure is still one of mean forecast targeting rather than true distribution forecast targeting. It would be more transparent to always let the reported point forecasts be the mean forecasts rather than the mode forecasts, and then explicitly report whether the balance-of-risk considerations imply that the banks are deviating from mean forecast targeting. 


\section{Summary and conclusions}

This paper starts from the observation that most recent research on monetary-policy rules is restricted to consider a commitment to a simple instrument rule, where the central-bank instrument is a simple function of available information about the economy, like the Taylor rule. Alternatively, as proposed by Taylor, for instance, in $(1993,2000)$, the proposed simple instrument rules are only to be used as "guidelines" and that deviations from the rules are sometimes called for. The paper argues that a commitment to a simple instrument rule is inadequate as a description of current monetary policy, especially inflation targeting. Furthermore, it argues that the proposal to use simple instrument rules as mere guidelines is incomplete and too vague to be operational. First, monetary-policy reform in the last two decades is better described as the formulation of clear objectives for monetary policy and the creation of institutional commitment to those objectives. Second, inflation-targeting central banks have developed elaborate decision-making processes, in which huge amounts of data are collected and processed, conditional inflation- and output-gap forecasts are constructed with the exercise of considerable judgment and extra-model information, and an instrument decision is reached with the help of those forecasts. This process can to a large extent be seen as inflation-forecast targeting, setting the instrument so that the corresponding conditional inflation forecast, conditional on all relevant information and judgment, is consistent with the inflation target and the output-gap forecast not indicating too much output-gap variability. Third, no central bank has made an explicit commitment to a simple instrument rule. Instead, some prominent current and former central bankers seem highly skeptical about the idea. Neither has any central bank announced that a particular simple instrument rule is used as a guideline. Fourth, the proposal to use instrument rules as guidelines is incomplete and too vague to be operational, since it does not provide any rules for when deviations from the rule are appropriate.

The paper attempts to bridge the gap between the recent literature's focus on simple instrument rules and the actual monetary-policy practice by inflation-targeting central banks. It argues that, in order to be more useful, the concept of monetary-policy rules should be broadened beyond the narrow instrument rules and also include targeting rules. It argues that, both from a descriptive and a prescriptive perspective, inflation targeting is better understood as a commitment to a targeting rule, either a general targeting rule in the form of clear objectives for monetary policy or a specific targeting rule in the form of a condition for (the forecasts of) the target variables. The optimal specific targeting rule is actually an operational specification 
of the equality of the marginal rates of transformation and the marginal rates of substitution between the target variables. Targeting rules have the important advantage that they allow the use of judgment and extra-model information. They are also more robust and easier to verify than optimal instrument rules, but they can nevertheless bring the economy close to the socially optimal equilibrium. These ideas are illustrated with the help of two simple examples of the transmission mechanism. Some recent defense of commitment to simple instrument rules and criticism of forward-looking monetary policy and targeting rules by McCallum, Nelson and Woodford are also addressed.

Whereas simple instrument rules, like variants of the Taylor rule, may to some extent serve as very rough benchmarks for good monetary policy, they are very incomplete rules, because they don't specify when the central bank should or should not deviate from the simple instrument rule. Such deviations, by discretion and judgment, have been and will be frequent, in a descriptive perspective (recall that simple instrument rules at most explain two thirds of the empirical variance of interest-rate changes), and they should be frequent, from a normative perspective (since the simple instrument rules are not optimal and do not take judgement into account). In contrast, targeting rules should be much more complete rules, because there are few good reasons to deviate from them, since they allow the use of judgment and extra-model information.

Macroeconomics long ago stopped modeling private economic agents as following mechanical rules for consumption, saving, production and investment decisions; instead, they are now normally modeled as optimizing agents that achieve first-order conditions, Euler conditions. It is long overdue to acknowledge that modern central banks are, at least when it comes to the inflation targeters, optimizing to at least the same extent time as private economic agents; therefore their behavior can be better modeled with the help of targeting rules than with simple instrument rules.

As stated (several times) above, optimal specific targeting rules simply state the equality of the marginal rates of transformation and the marginal rates of substitution between the target variables in an operational way. Since the marginal rates of transformation depend only on the derivatives of the transmission mechanism with respect to the target variables, the optimal specific targeting rules are inherently simpler and more robust than the optimal instrument rules, which depend on all aspects of the transmission mechanism. In particular, additive judgement and "add factors" do not enter in the formulation of the specific targeting rules, because they do not appear in the derivatives. Still, the optimal specific targeting rules are fully consistent with 
the use of judgment and extra-model information, since these enter into the construction of the forecasts that have to fulfill the specific targeting rule. In contrast, the optimal instrument rules have to include judgment explicitly, making them overwhelmingly complex and, in practice, impossible to verify.

In conclusion, then, what are the rules for good monetary policy, the initial question posed in this paper? My suggestion is: (1) Specify operational objectives, the general targeting rule. That is, specify the target variables, the targets, and the relative weight(s) on stabilizing the target variables around their targets. (2) Estimate the dynamic tradeoffs between the target variables, the marginal rates of transformation. In the standard case when the target variables are inflation and the output gap, this means estimating a Phillips curve. (3) Given these marginal rates of transformation and the marginal rates of substitution from the loss function, calculate a first-order condition for optimal policy, that is, a specific targeting rule. If this specific targeting rule is too complicated to be operational, simplify. In most cases, this will result in an operational condition for the forecasts of the target variables. (4) Estimate the rest of the transmission mechanism, that is, the dynamic impact of the instrument rate on the target variables. (5) Conditional on the estimated transmission mechanism and on current information and judgment, construct a set of forecast paths for the target variables for a set of alternative instrument-rate paths. Select the forecasts and the instrument paths that best fulfill the specific targeting rule, and set the current instrument rate accordingly. (6) When estimates of the marginal rates of transformation between the target variables are updated, revise the specific targeting rule correspondingly. (7) Explain all this in transparent monetarypolicy reports, modeled on the Monetary Policy Statements of the Reserve Bank of New Zealand, or the Inflation Reports of the Bank of England and the Riksbank.

These rules for good monetary policy acknowledge that the specific targeting rules, the Euler conditions of monetary policy, will depend on the transmission mechanism via the marginal rates of transformation between the target variables. Therefore, they allow for revisions of the specific targeting rules when the estimate of these marginal rates of transformation change. This way, the overall rules for good monetary policy are robust, but the specific targeting rule is allowed to change with the estimated marginal rates of transformation.

There may be cases when the dynamic tradeoffs between the target variables are too complex to result in a simple operational specific targeting rule. In such cases, the central bank may have to abandon an attempt to find a specific targeting rule and instead have to rely on the 
general targeting rule, namely selecting the forecasts and the instrument path that best seem to minimize the intertemporal loss function. Although this can be done in more informal and intuitive ways, given numerical representations of the alternative forecasts and a specified loss function, the loss function can always be evaluated numerically for each forecast alternative, in order to assist the decision-making body of the bank in finding the best alternative.

Further research on general and specific targeting rules should both lead to a better understanding of actual monetary-policy practice and also better contribute to the further improvement of that practice: Regarding general targeting rules, how can central banks be more specific about the loss function they (explicitly or implicitly) apply? ${ }^{60}$ Regarding flexible inflation targeting, how can central banks specify the other objective(s) besides stabilizing inflation and the relative weight(s) on this (these) objective(s)? Regarding specific targeting rules, is it possible to provide more optimal, but still operational, targeting rules than the Bank of England's and the Riksbank's "the constant-interest-rate inflation forecast about two years ahead should equal the inflation target?" For instance, given an empirical forward- and backward-looking Phillips curve, is there an operational close-to-optimal specific targeting rule involving inflation- and output-gap forecasts? How robust is such a specific targeting rule to realistic revisions of the Phillips curve? If some fraction of the current research on simple instrument rules were directed towards the study of targeting rules, we would soon know the answers to these questions.

\section{A The backward-looking model}

In period $t$, consider finding the combination of forecasts and instrument plan, $\left(\pi^{t}, x^{t}, i^{t}\right)$, that minimizes (5.1) subject to (5.2), (5.3) and the judgment $z^{t}$.

Given that the only target variables are $\pi_{t}$ and $x_{t}$, this minimization can be simplified into two stages. The first stage is to minimize (5.1), conditional on $\pi_{t}, \pi_{t+1, t}, x_{t}$ and $z^{t}$ and including only the constraint (5.2). This results in optimal forecasts, $\hat{\pi}^{t} \equiv\left\{\hat{\pi}_{t+\tau, t}\right\}_{\tau=0}^{\infty}$ and $\hat{x}^{t} \equiv\left\{\hat{x}_{t+\tau, t}\right\}_{\tau=0}^{\infty}$. The second stage is then to use these optimal forecasts in (5.3), which implies

$$
i_{t+\tau, t}=\bar{r}+\pi_{t+\tau+1, t}-\frac{1}{\beta_{r}} x_{t+\tau+1, t}+\frac{\beta_{x}}{\beta_{r}} x_{t+\tau, t}+\frac{\beta_{z}}{\beta_{r}} z_{t+\tau+1, t},
$$

to infer the optimal instrument plan $\hat{\imath}^{t}=\left\{\hat{\imath}_{t+\tau, t}\right\}_{\tau=0}^{\infty}$. The optimal instrument setting in period $t$ is then $\hat{\imath}_{t}=\hat{\imath}_{t, t}$, and $\hat{\imath}_{t+\tau, t}$ can be seen as a forecast of future instrument setting conditional on current information (and the current judgment).

Consider the Lagrangian corresponding to stage 1,

$$
\mathfrak{L}_{t}=\sum_{\tau=0}^{\infty} \delta^{\tau}\left\{\frac{1}{2}\left[\left(\pi_{t+\tau, t}-\pi^{*}\right)^{2}+\lambda x_{t+\tau, t}^{2}\right]+\delta \Xi_{\tau+1, t}\left(\pi_{t+\tau+1, t}-\pi_{t+\tau, t}-\alpha_{x} x_{t+\tau, t}-\alpha_{z} z_{t+\tau+1, t}\right)\right\},
$$

\footnotetext{
${ }^{60}$ Svensson (2001b, 2002a) provide some suggestions on this point.
} 
where $\Xi_{\tau+1, t}$ is the Lagrange multiplier of the constraint (5.2). Note that $\pi_{t}, x_{t}, \pi_{t+1, t}$ and $z_{t+\tau, t}$ are predetermined for $\tau \geq 1$, and consider the first-order conditions for an optimum, with respect to $\pi_{t+\tau+1, t}$ and $x_{t+\tau, t}$ for $\tau \geq 1$. They are

$$
\pi_{t+\tau+1, t}-\pi^{*}+\Xi_{\tau+1, t}-\delta \Xi_{\tau+2, t}=0
$$

with respect to $\pi_{t+\tau+1, t}$, and

$$
\lambda x_{t+\tau, t}-\delta \alpha_{x} \Xi_{\tau+1, t}=0
$$

with respect to $x_{t+\tau, t}$. From (A.4), we have

$$
\Xi_{\tau+1, t}=\frac{\lambda}{\delta \alpha_{x}} x_{t+\tau, t} .
$$

Using this in (A.3), we can write a consolidated first-order condition as

$$
\pi_{t+\tau+1, t}-\pi^{*}+\frac{\lambda}{\delta \alpha_{x}}\left(x_{t+\tau, t}-\delta x_{t+\tau+1, t}\right)=0 .
$$

In order to find the equilibrium, rewrite (5.2) as

$$
x_{t+\tau, t}=\frac{1}{\alpha_{x}}\left(\pi_{t+\tau+1, t}-\pi_{t+\tau, t}-\alpha_{z} z_{t+\tau+1, t}\right)
$$

and use this to eliminate $x_{t+\tau, t}$ in (A.5). This results in a difference equation for $\pi_{t+\tau+1, t}$,

$$
\pi_{t+\tau+1, t}-\pi^{*}+\frac{\lambda}{\delta \alpha_{x}^{2}}\left[\left(\pi_{t+\tau+1, t}-\pi_{t+\tau, t}-\alpha_{z} z_{t+\tau+1, t}\right)-\delta\left(\pi_{t+\tau+2, t}-\pi_{t+\tau+1, t}-\alpha_{z} z_{t+\tau+2, t}\right)\right]=0 .
$$

For the case of flexible inflation targeting, $\lambda>0$, rewrite the difference equation as

$$
\left(\pi_{t+\tau+2, t}-\pi^{*}\right)-2 a\left(\pi_{t+\tau+1, t}-\pi^{*}\right)+\frac{1}{\delta}\left(\pi_{t+\tau, t}-\pi^{*}\right)=-\frac{\alpha_{z}}{\delta}\left(z_{t+\tau+1, t}-\delta z_{t+\tau+2, t}\right),
$$

where

$$
2 a \equiv 1+\frac{1}{\delta}+\frac{\alpha_{x}^{2}}{\lambda}
$$

(since $\pi_{t+1, t}$ is given, it is natural to express the difference equation in terms of the inflation forecasts).

By standard methods, the solution to this difference equation can be shown to fulfill

$$
\pi_{t+\tau+1, t}-\pi^{*}=c\left(\pi_{t+\tau, t}-\pi^{*}\right)+\alpha_{z} w_{t+\tau+1, t}
$$

for $\tau \geq 1$ (recall that $\pi_{t+1, t}$ is predetermined). Here, the coefficient $c$ fulfills $0<c<1$ and is the smaller root of the characteristic equation,

$$
\mu^{2}-2 a \mu+\frac{1}{\delta}=0
$$

hence given by

$$
c \equiv a-\sqrt{a^{2}-\frac{1}{\delta}} .
$$


Furthermore, $c$ is an increasing function of $\lambda, c(\lambda)$, which fulfills $c(0)=\lim _{\lambda \rightarrow 0} c(\lambda)=0$, $c(\infty) \equiv \lim _{\lambda \rightarrow \infty} c(\lambda)=1$. Finally, the vector $w_{t+\tau+1, t}$ is given by

$$
\begin{aligned}
w_{t+\tau+1, t} & \equiv c \sum_{s=0}^{\infty}(\delta c)^{s}\left(z_{t+\tau+1+s, t}-\delta z_{t+\tau+2+s, t}\right) \\
& =c z_{t+\tau+1, t}-c \delta(1-c) \sum_{s=0}^{\infty}(\delta c)^{s} z_{t+\tau+2+s, t} \\
& =z_{t+\tau+1, t}-(1-c) \tilde{z}_{t+\tau+1, t}
\end{aligned}
$$

where

$$
\tilde{z}_{t+\tau, t} \equiv \sum_{s=0}^{\infty}(\delta c)^{s} z_{t+\tau+s, t} .
$$

For the case of strict inflation targeting, $\lambda=0$, we have $c(0)=0, \tilde{z}_{t+\tau, t} \equiv z_{t+\tau, t}$ and $w_{t+\tau+1, t}=0$, so the (A.8) is replaced by

$$
\pi_{t+\tau+1, t}-\pi^{*}=0
$$

for $\tau \geq 1$.

It follows from (A.6) and (A.8), that the corresponding output-gap forecast is

$$
\begin{aligned}
x_{t+\tau, t} & =\frac{1}{\alpha_{x}}\left[-(1-c)\left(\pi_{t+\tau, t}-\pi^{*}\right)+\alpha_{z}\left(w_{t+\tau+1, t}-z_{t+\tau+1, t}\right)\right] \\
& =-\frac{1-c}{\alpha_{x}}\left[\left(\pi_{t+\tau, t}-\pi^{*}\right)+\alpha_{z} \tilde{z}_{t+\tau+1, t}\right] .
\end{aligned}
$$

By (A.1), the optimal interest setting in period $t$ then follows

$$
\begin{aligned}
i_{t}= & \bar{r}+\pi_{t+1, t}-\frac{1}{\beta_{r}} x_{t+1, t}+\frac{\beta_{x}}{\beta_{r}} x_{t}+\frac{\beta_{z}}{\beta_{r}} z_{t+1, t} \\
= & \bar{r}+\pi_{t+1, t}+\frac{1-c}{\alpha_{x} \beta_{r}}\left[\left(\pi_{t+1, t}-\pi^{*}\right)+\alpha_{z} \tilde{z}_{t+2, t}\right]+\frac{\beta_{x}}{\beta_{r}} x_{t}+\frac{\beta_{z}}{\beta_{r}} z_{t+1, t} \\
= & \bar{r}+\pi^{*}+\left(1+\frac{1-c}{\alpha_{x} \beta_{r}}\right)\left(\pi_{t+1, t}-\pi^{*}\right)+\frac{\beta_{x}}{\beta_{r}} x_{t} \\
& +\frac{\beta_{z}}{\beta_{r}} z_{t+1, t}+\frac{1-c}{\alpha_{x} \beta_{r}} \alpha_{z} \tilde{z}_{t+2, t} .
\end{aligned}
$$

\section{A.1 A constant-interest-rate inflation forecast}

By (5.2) we have that the one-period-ahead inflation forecast, $\pi_{t+1, t}$ is given by

$$
\pi_{t+1, t}=\pi_{t}+\alpha_{x} x_{t}+\alpha_{z} z_{t+1, t}
$$

and cannot be affected by the current instrument. In contrast, by (5.3), the one-period-ahead output-gap forecast, $x_{t+1, t}$, is given by

$$
x_{t+1, t}=\beta_{r} \pi_{t+1, t}+\beta_{x} x_{t}+\beta_{z} z_{t+1, t}-\beta_{r}\left(i_{t}-\bar{r}\right)
$$

and can be affected by the current instrument. 
The two-period-ahead inflation forecast, $\pi_{t+2, t}$, will by (5.2) and (A.13) be given by

$$
\begin{aligned}
\pi_{t+2, t} & =\pi_{t+1, t}+\alpha_{x} x_{t+1, t}+\alpha_{z} z_{t+2, t} \\
& =\pi_{t+1, t}+\alpha_{x}\left[\beta_{r} \pi_{t+1, t}+\beta_{x} x_{t}+\beta_{z} z_{t+1, t}-\beta_{r}\left(i_{t}-\bar{r}\right)\right]+\alpha_{z} z_{t+2, t} \\
& =\left(1+\alpha_{x} \beta_{r}\right) \pi_{t+1, t}+\alpha_{x} \beta_{x} x_{t}+\alpha_{x} \beta_{z} z_{t+1, t}+\alpha_{z} z_{t+2, t}-\alpha_{x} \beta_{r}\left(i_{t}-\bar{r}\right) .
\end{aligned}
$$

Thus, we see that the two-period-ahead inflation forecast depends on the one-period-ahead inflation forecast, $\pi_{t+1, t}$, the current output gap, $x_{t}$, the one- and two-period-ahead forecasts of the deviation, $z_{t+1, t}$ and $z_{t+2, t}$, and the current interest rate relative to the average real interest rate, $i_{t}-\bar{r}$.

Let us also note that the two-period-ahead output-gap forecast, $x_{t+2, t}$, is given by

$$
\begin{aligned}
x_{t+2, t}= & \beta_{r} \pi_{t+2, t}+\beta_{x} x_{t+1, t}+\beta_{z} z_{t+2, t}-\beta_{r}\left(i_{t+1, t}-\bar{r}\right) \\
= & \beta_{r}\left[\left(1+\alpha_{x} \beta_{r}\right) \pi_{t+1, t}+\alpha_{x} \beta_{x} x_{t}+\alpha_{x} \beta_{z} z_{t+1, t}+\alpha_{z} z_{t+2, t}-\alpha_{x} \beta_{r}\left(i_{t}-\bar{r}\right)\right] \\
& +\beta_{x}\left[\beta_{r} \pi_{t+1, t}+\beta_{x} x_{t}+\beta_{z} z_{t+1, t}-\beta_{r}\left(i_{t}-\bar{r}\right)\right]+\beta_{z} z_{t+2, t}-\beta_{r}\left(i_{t+1, t}-\bar{r}\right) \\
= & \left(1+\alpha_{x} \beta_{r}+\beta_{x}\right) \beta_{r} \pi_{t+1, t}+\left(\alpha_{x} \beta_{r}+\beta_{x}\right) \beta_{x} x_{t} \\
& +\left(\alpha_{x} \beta_{r}+\beta_{x}\right) \beta_{z} z_{t+1, t}+\left(\alpha_{z} \beta_{r}+\beta_{z}\right) z_{t+2, t} \\
& -\left(\alpha_{x} \beta_{r}+\beta_{x}\right) \beta_{r}\left(i_{t}-\bar{r}\right)-\beta_{r}\left(i_{t+1, t}-\bar{r}\right)
\end{aligned}
$$

Thus, the two-period-ahead output-gap forecasts depends on the one-period-ahead inflation forecast, $\pi_{t+1, t}$, the current output gap, $x_{t}$, the one- and two-period-ahead forecast of the deviation, $z_{t+1, t}$ and $z_{t+2, t}$, and the current and one-period-ahead forecasts of the interest rate, $i_{t}$ and $i_{t+1, t}$.

Construct the 3-period-ahead inflation forecast,

$$
\begin{aligned}
\pi_{t+3, t}= & \pi_{t+2, t}+\alpha_{x} x_{t+2, t}+\alpha_{z} z_{t+3, t} \\
= & \left(1+\alpha_{x} \beta_{r}\right) \pi_{t+1, t}+\alpha_{x} \beta_{x} x_{t}+\alpha_{x} \beta_{z} z_{t+1, t}+\alpha_{z} z_{t+2, t}-\alpha_{x} \beta_{r}\left(i_{t}-\bar{r}\right) \\
& +\alpha_{x}\left[\left(1+\alpha_{x} \beta_{r}+\beta_{x}\right) \beta_{r} \pi_{t+1, t}+\left(\alpha_{x} \beta_{r}+\beta_{x}\right) \beta_{x} x_{t}\right] \\
& +\alpha_{x}\left[\left(\alpha_{x} \beta_{r}+\beta_{x}\right) \beta_{z} z_{t+1, t}+\left(\alpha_{z} \beta_{r}+\beta_{z}\right) z_{t+2, t}\right]+\alpha_{z} z_{t+3, t} \\
& -\alpha_{x}\left[\left(\alpha_{x} \beta_{r}+\beta_{x}\right) \beta_{r}\left(i_{t}-\bar{r}\right)+\beta_{r}\left(i_{t+1, t}-\bar{r}\right)\right] \\
= & {\left[1+\alpha_{x}\left(2+\alpha_{x} \beta_{r}+\beta_{x}\right) \beta_{r}\right] \pi_{t+1, t}+\alpha_{x}\left(1+\alpha_{x} \beta_{r}+\beta_{x}\right) \beta_{x} x_{t} } \\
& +\alpha_{x}\left(1+\alpha_{x} \beta_{r}+\beta_{x}\right) \beta_{z} z_{t+1, t}+\left[\alpha_{x}\left(\alpha_{z} \beta_{r}+\beta_{z}\right)+\alpha_{z}\right] z_{t+2, t}+\alpha_{z} z_{t+3, t} \\
& -\alpha_{x}\left(1+\alpha_{x} \beta_{r}+\beta_{x}\right) \beta_{r}\left(i_{t}-\bar{r}\right)-\alpha_{x} \beta_{r}\left(i_{t+1, t}-\bar{r}\right) .
\end{aligned}
$$

Consider the constant interest rate, $i_{t}=i_{t+1, t}$, for which $\pi_{t+3, t}=\pi^{*}$. This implies the equation,

$$
\begin{aligned}
\pi^{*}= & {\left[1+\alpha_{x}\left(2+\alpha_{x} \beta_{r}+\beta_{x}\right) \beta_{r}\right] \pi_{t+1, t}+\alpha_{x}\left(1+\alpha_{x} \beta_{r}+\beta_{x}\right) \beta_{x} x_{t} } \\
& +\alpha_{x}\left(1+\alpha_{x} \beta_{r}+\beta_{x}\right) \beta_{z} z_{t+1, t}+\left[\alpha_{x}\left(\beta_{r} \alpha_{z}+\beta_{z}\right)+\alpha_{z}\right] z_{t+2, t}+\alpha_{z} z_{t+3, t} \\
& -\alpha_{x}\left(2+\alpha_{x} \beta_{r}+\beta_{x}\right) \beta_{r}\left(i_{t}-\bar{r}\right) .
\end{aligned}
$$

Solving for $i_{t}$ gives the reaction function

$$
i_{t}=\bar{r}+\pi^{*}+f_{\pi}\left(\pi_{t+1, t}-\pi^{*}\right)+f_{x} x_{t}+f_{z 1} z_{t+1, t}+f_{z 2} z_{t+2, t}+f_{z 3} z_{t+3, t},
$$


where

$$
\begin{aligned}
f_{\pi} & \equiv \frac{1+\alpha_{x}\left(2+\alpha_{x} \beta_{r}+\beta_{x}\right) \beta_{r}}{\alpha_{x}\left(2+\alpha_{x} \beta_{r}+\beta_{x}\right) \beta_{r}}>1, \\
f_{x} & \equiv \frac{\left(1+\alpha_{x} \beta_{r}+\beta_{x}\right) \beta_{x}}{\left(2+\alpha_{x} \beta_{r}+\beta_{x}\right) \beta_{r}}>0, \\
f_{z 1} & \equiv \frac{\left(1+\alpha_{x} \beta_{r}+\beta_{x}\right) \beta_{z}}{\left(2+\alpha_{x} \beta_{r}+\beta_{x}\right) \beta_{r}} \\
f_{z 2} & =\frac{\alpha_{x}\left(\beta_{r} \alpha_{z}+\beta_{z}\right)+\alpha_{z}}{\alpha_{x}\left(2+\alpha_{x} \beta_{r}+\beta_{x}\right) \beta_{r}}, \\
f_{z 3} & =\frac{\alpha_{z}}{\alpha_{x}\left(2+\alpha_{x} \beta_{r}+\beta_{x}\right) \beta_{r}} .
\end{aligned}
$$

\section{B The forward-looking model}

Consider the Lagrangian in period $t$ for the problem of minimizing (5.1) subject to (5.5),

$\mathfrak{L}_{t}=\sum_{\tau=0}^{\infty} \delta^{\tau}\left\{\frac{1}{2}\left[\left(\pi_{t+\tau, t}-\pi^{*}\right)^{2}+\lambda x_{t+\tau, t}^{2}\right]+\Xi_{t+\tau, t}\left[\delta\left(\pi_{t+1+\tau, t}-\pi\right)+\alpha_{x} x_{t+\tau, t}+\alpha_{z} z_{t+\tau, t}-\left(\pi_{t+\tau, t}-\pi\right)\right]\right\}$

where $\Xi_{t+\tau, t}$ is the Lagrange multiplier for the constraint (5.5) for period $t+\tau$, considered in period $t$. Differentiating with respect to $\pi_{t+\tau+1, t}$ and $x_{t+\tau+1, t}$ gives the first-order conditions

$$
\begin{aligned}
\pi_{t+\tau+1, t}-\pi^{*}-\Xi_{t+\tau+1, t}+\Xi_{t+\tau, t} & =0 \\
\lambda x_{t+\tau+1, t}+\alpha_{x} \Xi_{t+\tau+1, t} & =0
\end{aligned}
$$

for $\tau \geq 0$, together with the initial condition

$$
\Xi_{t, t}=0
$$

Eliminating the Lagrange multipliers leads to the consolidated first-order condition

$$
\pi_{t+\tau+1, t}-\pi^{*}+\frac{\lambda}{\alpha_{x}}\left(x_{t+\tau+1, t}-x_{t+\tau, t}\right)=0
$$

for $\tau \geq 1$ and

$$
\pi_{t+1, t}-\pi^{*}+\frac{\lambda}{\alpha_{x}} x_{t+1, t}=0
$$

for $\tau=0$. Thus, finding the optimal forecasts is reduced to the problem of finding $\pi^{t}, x^{t}$ and $\Xi^{t} \equiv\left\{\Xi_{t+\tau, t}\right\}_{\tau=1}^{\infty}$ that satisfy (5.5) and (B.2)-(B.4), or, equivalently, $\pi^{t}$ and $x^{t}$ that satisfy (5.5), (B.5) and (B.6).

By taking the unconditional mean of (B.5), it follows that there is no average inflation bias

$$
\mathrm{E}\left[\pi_{t+\tau, t}\right]=\pi^{*} .
$$

As noted in Woodford (1999a) and discussed in detail in Svensson and Woodford (2002a), these first-order conditions define a decision procedure that will not be time-consistent (under the case of flexible inflation targeting, $\lambda>0$ ). This can be seen from the fact that the initial condition (B.4) and the corresponding first-order condition for $\tau=1$, (B.6), are different from that for $\tau \geq 2$, (B.5). This results because, in deciding on $\pi_{t+1, t}$, the central bank takes the 
previous period's forecast $\pi_{t+1, t-1}$ as given, and lets $\pi_{t+1, t}$ deviate from it without assigning any specific cost to doing so. As a result, the forecasts in period $t$ are not generally consistent with the forecasts made in period $t-1$, even if no new information is received in period $t$.

To see this, suppose that the forecasts $\pi^{t-1}$ and $x^{t-1}$ were constructed in period $t-1$ so as to minimize the intertemporal loss function (5.1) with $t-1$ substituted for $t$. The same procedure in period $t-1$ as above then resulted in the same first-order conditions (B.5) and (B.6), although with $t-1$ substituted for $t$. Thus, in period $t-1$, the first-order condition for $\tau=2$ was

$$
\pi_{t+1, t-1}-\pi^{*}+\frac{\lambda}{\alpha_{x}}\left(x_{t+1, t-1}-x_{t, t-1}\right)=0 .
$$

Without any new information in period $t$ relative to period $t-1$, we should have $\pi_{t+1, t}=\pi_{t+1, t-1}$ and $x_{t+1, t}=x_{t+1, t-1}$ for intertemporal consistency. From (B.6) and (B.8) it is apparent that this will not be the case, unless by chance $x_{t, t-1}=0$.

As discussed in Svensson and Woodford (2002a), time-consistency is ensured under optimization "in a timeless perspective," which corresponds to imposing the initial condition

$$
\Xi_{t, t}=\Xi_{t, t-1}
$$

for the Lagrange multiplier $\Xi_{t, t}$. That is, the multiplier $\Xi_{t, t}$ is set equal to the shadow cost of the one-period-ahead inflation forecast from the previous period.

Equivalently, (B.6) is replaced by

$$
\pi_{t+1, t}-\pi^{*}+\frac{\lambda}{\alpha_{x}}\left(x_{t+1, t}-x_{t, t-1}\right)=0,
$$

where $x_{t, t-1}$ is the one-period-ahead output-gap forecast from the previous period. Equivalently, we can let (B.5) apply for $\tau \geq 0$ instead of $\tau \geq 1$, with the initial condition

$$
x_{t, t}=x_{t, t-1}
$$

imposed. That is, in the first-order condition (B.5), $x_{t, t}$ does not denote the current output gap, $x_{t}$, but the forecast one period ago of the current output gap, $x_{t, t-1}$.

For the case of flexible inflation targeting $(\lambda>0)$, substituting (B.5) into (5.5) leads to the difference equation

$$
x_{t+\tau+2, t}-2 a x_{t+\tau+1, t}+\frac{1}{\delta} x_{t+\tau, t}=\frac{\alpha_{x}}{\delta \lambda} \alpha_{z} z_{t+\tau+1, t}
$$

for $\tau \geq 0$, where

$$
2 a=1+\frac{1}{\delta}+\frac{\alpha_{x}^{2}}{\delta \lambda}
$$

(note that (B.11) is similar to (A.7) except that the last term differs). (Since $x_{t, t}$ is given (by B.10), it is natural to express the difference equation in terms of the output-gap forecasts.)

By standard methods, it can be shown that the solution to the difference equation, the optimal output-gap forecast, fulfills

$$
\begin{aligned}
x_{t+\tau+1, t} & =c x_{t+\tau, t}-\frac{\alpha_{x} c}{\lambda} \sum_{s=0}^{\infty}(\delta c)^{s} \alpha_{z} z_{t+\tau+1+s, t} \\
& =c x_{t+\tau, t}-\frac{\alpha_{x} c}{\lambda} \alpha_{z} \tilde{z}_{t+\tau+1, t}
\end{aligned}
$$


where $\tilde{z}_{t+\tau+1, t}$ is defined as in $(3.2)$ and $c(0 \leq c<1)$ is the smaller root of the characteristic equation (A.9) and hence again is given by (A.10) (but with $a$ given by (B.11)), is an increasing function $c(\lambda)$ of $\lambda$, and fulfills $c(0)=0, c(\infty)=1 .^{61}$

The optimal inflation forecast then fulfills, by (B.5),

$$
\pi_{t+\tau+1, t}-\pi^{*}=\frac{\lambda}{\alpha_{x}}(1-c) x_{t+\tau, t}+c \alpha_{z} \tilde{z}_{t+\tau+1, t} .
$$

The optimal interest-rate path will by (5.5) and (B.5) follow

$$
\begin{aligned}
i_{t+\tau+1, t} & =r_{t+\tau+1, t}^{*}+\pi^{*}+\left(\pi_{t+\tau+2, t}-\pi^{*}\right)+\frac{1}{\beta_{r}}\left(x_{t+\tau+2, t}-x_{t+\tau+1, t}\right)+\frac{\beta_{z}}{\beta_{r}} z_{t+\tau+1, t} \\
& =r_{t+\tau+1, t}^{*}+\pi^{*}+\left(1-\frac{\alpha_{x}}{\lambda \beta_{r}}\right)\left(\pi_{t+\tau+2, t}-\pi^{*}\right)+\frac{\beta_{z}}{\beta_{r}} z_{t+\tau+1, t} \\
& =r_{t+\tau+1, t}^{*}+\pi^{*}+\left(1-\frac{\alpha_{x}}{\lambda \beta_{r}}\right) \frac{\lambda}{\alpha_{x}}(1-c) x_{t+\tau+1, t}+\left(1-\frac{\alpha_{x}}{\lambda \beta_{r}}\right) c \alpha_{z} \tilde{z}_{t+\tau+2, t}+\frac{\beta_{z}}{\beta_{r}} z_{t+\tau+1, t} .
\end{aligned}
$$

The optimal interest-rate decision in period $t$ for the interest rate in period $t+1$ is then given by (note the loose relation to "forecast-based" instrument rules)

$$
\begin{aligned}
i_{t+1, t}= & r_{t+1, t}^{*}+\pi^{*}+\left(1-\frac{\alpha_{x}}{\lambda \beta_{r}}\right)\left(\pi_{t+2, t}-\pi^{*}\right)+\frac{\beta_{z}}{\beta_{r}} z_{t+1, t} \\
= & r_{t+1, t}^{*}+\pi^{*}+\left(1-\frac{\alpha_{x}}{\lambda \beta_{r}}\right) \frac{\lambda}{\alpha_{x}} c(1-c) x_{t, t} \\
& +\frac{\beta_{z}}{\beta_{r}} z_{t+1, t}+\left(1-\frac{\alpha_{x}}{\lambda \beta_{r}}\right) c\left\{[1-\delta c(1-c)] \alpha_{z} \tilde{z}_{t+2, t}-(1-c) \alpha_{z} z_{t+1, t}\right\},
\end{aligned}
$$

where we use that the two-period-ahead inflation forecast is given by

$$
\begin{aligned}
\pi_{t+2, t}-\pi^{*} & =\frac{\lambda}{\alpha_{x}}(1-c) x_{t+1, t}+c \alpha_{z} \tilde{z}_{t+2, t} \\
& =\frac{\lambda}{\alpha_{x}}(1-c)\left[c x_{t, t}-\frac{\alpha_{x} c}{\lambda} \alpha_{z} \tilde{z}_{t+1, t}\right]+c \alpha_{z} \tilde{z}_{t+2, t} \\
& =\frac{\lambda}{\alpha_{x}}(1-c) c x_{t, t}-c(1-c)\left(\alpha_{z} z_{t+1, t}+\delta c \alpha_{z} \tilde{z}_{t+2, t}\right)+c \alpha_{z} \tilde{z}_{t+2, t} \\
& =\frac{\lambda}{\alpha_{x}} c(1-c) x_{t, t}+c\left\{[1-\delta c(1-c)] \alpha_{z} \tilde{z}_{t+2, t}-(1-c) \alpha_{z} z_{t+1, t}\right\}
\end{aligned}
$$

where I have used that

$$
\tilde{z}_{t+1, t} \equiv \sum_{s=0}^{\infty}(\delta c)^{s} z_{t+1+s, t} \equiv \delta c \tilde{z}_{t+2, t}+z_{t+1, t} .
$$

Note that, by (B.12),

$$
\begin{aligned}
x_{t, t} & =x_{t, t-1} \\
& =c x_{t-1, t-2}-\frac{\alpha_{x} c}{\lambda} \alpha_{z} \tilde{z}_{t, t-1} \\
& =-\frac{\alpha_{x} c}{\lambda} \sum_{j=0}^{\infty} c^{j} \alpha_{z} \tilde{z}_{t-j, t-1-j} .
\end{aligned}
$$

\footnotetext{
${ }^{61}$ If the smaller root of (A.9) with (A.7) as a function of $\lambda$ is denoted $\hat{c}(\lambda)$, the smaller root of (A.9) with (B.11) is obviously $\hat{c}(\delta \lambda)$, for fixed $\delta$.
} 
For the case of strict inflation targeting $(\lambda=0)$, we have

$$
\pi_{t+\tau+1, t}-\pi^{*}=0
$$

for $\tau \geq 0$ from (B.5). From (5.5) then follows

$$
\alpha_{x} x_{t+\tau+1, t}+\alpha_{z} z_{t+\tau+1, t}=0
$$

and

$$
x_{t+\tau+1, t}=-\frac{\alpha_{z}}{\alpha_{x}} z_{t+\tau+1, t} .
$$

The optimal instrument-rate decision in period $t$ is then given by

$$
\begin{aligned}
i_{t+1, t} & =r_{t+1, t}^{*}+\pi^{*}+\frac{1}{\beta_{r}}\left(x_{t+2, t}-x_{t+1, t}\right)+\frac{\beta_{z}}{\beta_{r}} z_{t+1, t} \\
& =r_{t+1, t}^{*}+\pi^{*}+\frac{\beta_{z}}{\beta_{r}} z_{t+1, t}-\frac{\alpha_{z}}{\alpha_{x} \beta_{r}}\left(z_{t+2, t}-z_{t+1, t}\right) .
\end{aligned}
$$

\section{B.1 The discretion case}

As discussed in Svensson and Woodford (2002a), the first-order condition under discretion is

$$
\pi_{t+\tau+1}-\pi^{*}=-\frac{\lambda}{\alpha_{x}} x_{t+\tau+1, t}
$$

for $\tau \geq 0$. Combining (B.18) with (5.2) gives the difference equation

$$
-\frac{\lambda}{\alpha_{x}} x_{t+\tau+1, t}=-\frac{\delta \lambda}{\alpha_{x}} x_{t+\tau+2, t}+\alpha_{x} x_{t+\tau+1, t}+\alpha_{z} z_{t+\tau+1, t} .
$$

The solution will fulfill

$$
\begin{aligned}
x_{t+\tau+1, t} & =\delta \tilde{c} x_{t+\tau+2, t}-\frac{\alpha_{x} \tilde{c}}{\lambda} \alpha_{z} z_{t+\tau+1, t} \\
& =-\frac{\alpha_{x} \tilde{c}}{\lambda} \alpha_{z} \tilde{z}_{t+\tau+1, t}
\end{aligned}
$$

and

$$
\pi_{t+\tau+1, t}-\pi^{*}=\tilde{c} \alpha_{z} \tilde{z}_{t+\tau+1, t}
$$

where $\tilde{z}_{t+\tau+1, t}$ is defined as in (3.2) (with $\tilde{c}$ replacing $c$ ), and

$$
0 \leq \tilde{c}=\tilde{c}(\lambda) \equiv \frac{\lambda}{\lambda+\alpha_{x}^{2}}<1
$$

The corresponding reaction function is

$$
\begin{aligned}
i_{t+1, t} & =r_{t+1, t}^{*}+\pi_{t+2, t}+\frac{1}{\beta_{r}}\left(x_{t+2, t}-x_{t+1, t}\right)+\frac{\beta_{z}}{\beta_{r}} z_{t+1, t} \\
& =r_{t+1, t}^{*}+\pi^{*}+\left(\pi_{t+2, t}-\pi^{*}\right)+\frac{1}{\beta_{r}}\left(x_{t+2, t}-x_{t+1, t}\right)+\frac{\beta_{z}}{\beta_{r}} z_{t+1, t} \\
& =r_{t+1, t}^{*}+\pi^{*}+\tilde{c} \alpha_{z} \tilde{z}_{t+2, t}-\frac{1}{\beta_{r}} \frac{\alpha_{x} \tilde{c}}{\lambda} \alpha_{z}\left(\tilde{z}_{t+2, t}-\tilde{z}_{t+1, t}\right)+\frac{\beta_{z}}{\beta_{r}} z_{t+1, t} \\
& =r_{t+1, t}^{*}+\pi^{*}+\tilde{c} \alpha_{z} \tilde{z}_{t+2, t}-\frac{1}{\beta_{r}} \frac{\alpha_{x}}{\lambda} \tilde{c} \alpha_{z}\left(\tilde{z}_{t+2, t}-\delta \tilde{c} \tilde{z}_{t+2, t}-z_{t+1, t}\right)+\frac{\beta_{z}}{\beta_{r}} z_{t+1, t} \\
& =r_{t+1, t}^{*}+\pi^{*}+\frac{\tilde{c}}{\beta_{r} \lambda}\left[\beta_{r} \lambda-\alpha_{x}(1-\delta \tilde{c})\right] \alpha_{z} \tilde{z}_{t+2, t}+\frac{\alpha_{x} \tilde{c} \alpha_{z} z_{t+1, t}+\lambda \beta_{z} z_{t+1, t}}{\beta_{r} \lambda}
\end{aligned}
$$




\section{B.2 A constant-interest-rate inflation forecast}

As explained in the appendix of the working-paper version of Svensson (1999b), constructing constant-interest-rate forecasts in a forward-looking model requires some special considerations (see also Leitemo 2000). Basically, some assumptions must be made about future policy in order to construct determinate forecasts. The forecasts will not be rational-expectations forecasts, in that the constant-interest-rate path will not materialize even in the absence of new information or new judgment.

Here is an example:

In period $t$, impose the conditions that the interest rate is constant 3 periods ahead,

$$
i_{t+1, t}=i_{t+2, t}=i_{t+3, t}
$$

Furthermore, assume that we like to find the constant interest rate (for the next 3 periods) for which the corresponding 3-period-ahead inflation forecast is on target,

$$
\pi_{t+3, t}=\pi^{*}
$$

We must make some assumptions about the economy after period 3 in order to have a determinate solution. Assume, for instance, that policy is optimal from $(t+4, t)$ onwards (where $(t+\tau, t)$ denotes period $t+\tau$ seen from the forecasting done in period $t)$. Then $\pi_{t+4, t}, x_{t+4, t}$ and $i_{t+4, t}$ are given by (B.13), (B.12) and (B.14), respectively. In particular, they depend on $x_{t+3, t}$, which remains to be determined.

By (5.5) for $(t+3, t)$, given that $\pi_{t+4, t}$ is a function of $x_{t+3, t}$, and given (B.23) and $z_{t+3, t}$, we can solve for $x_{t+3, t}$. Then $\pi_{t+4, t}$ and $x_{t+4, t}$ are determined.

By (5.6) for $(t+3, t)$, given $x_{t+4, t}, x_{t+3, t}, \pi_{t+4, t}$, and $z_{t+3, t}$, we get $i_{t+3, t}$ and, by (B.22), also $i_{t+1, t}$ and $i_{t+2, t}$. From now on, we can exploit the simple recursivity of the forward-looking model:

By (5.6) for $(t+2, t)$, given $x_{t+3, t},(\mathrm{~B} .23), z_{t+2, t}$, and $i_{t+2, t}$, we get $x_{t+2, t}$.

By (5.5) for $(t+2, t)$, given (B.23), $x_{t+3, t}$ and $z_{t+3, t}$ we get $\pi_{t+2, t}$.

By (5.6) for $(t+1, t)$, given $x_{t+2, t}, \pi_{t+2, t}, z_{t+2, t}$, and $i_{t+1, t}$, we get $x_{t+1, t}$.

By (5.5) for $(t+1, t)$, given $\pi_{t+2, t}, x_{t+1, t}$ and $z_{t+1, t}$ we get $\pi_{t+1, t}$.

Thus, we have found $\left(\pi^{t}, x^{t}, i^{t}\right)$ for which (B.23) and (B.22) holds.

Suppose this procedure is followed each period $t$ and $i_{t+1, t}$ is implemented in each period $t+1$. In period $t+1$, even in the absence of any new information (any change in the judgment), the resulting $i_{t+2, t+1}$ will differ from $i_{t+2, t}$, since in period $t+1$ (B.23) is replaced by $\pi_{t+4, t+1}=\pi^{*}$. Thus, we will have $\pi_{t+2, t+1}$ and $x_{t+2, t+1}$ differing from $\pi_{t+2, t}$ and $x_{t+2, t}$. In particular, rational plans by the private sector will incorporate rational interest-rate expectations of the time-varying interest rate, so $i_{t+2 \mid t}=\mathrm{E}\left[i_{t+2, t+1} \mid I_{t}\right] \neq i_{t+1, t}$. Consequently, the private-sector plans $\pi_{t+1 \mid t}$ and $x_{t+1 \mid t}$ will differ from the constant-interest-rate forecasts $\pi_{t+1, t}$ and $x_{t+1, t}$.

This will typically not fulfill (B.5) and not be optimal. This may not even be close to optimal. Leitemo (2000) provides more details. Kohn (2000) provides a more general discussion of constant-interest-rate forecasts.

\section{An optimal reaction function with response to forecasts for an unchanged interest rate}

This appendix shows how a forecast-based instrument rule involving precisely defined unchangedinterest-rate rather than equilibrium forecasts can be derived from the optimal targeting rule. 


\section{C.1 The backward-looking model}

For the backward-looking forward-looking model, let $\left(\hat{\pi}^{t}, \hat{x}^{t}, \hat{\imath}^{t}\right)$ be the optimal equilibrium forecasts and instrument-rate path. For a given $i$, let $\left[\bar{\pi}^{t}(i), \bar{x}^{t}(i), \bar{\imath}^{t}(i)\right]$ correspond to an equilibrium where $i_{t, t}=i$ but $i_{t+\tau, t}$ is optimal for $\tau \geq 1$ (conditional on $i_{t, t}=i$ ). Then, for $\bar{\imath}^{t}(i)$, (A.5) will be fulfilled for $\tau \geq 1$, but not for $\tau=0$ (except if $i=\hat{\imath}_{t, t}$ ). An unchanged interest rate in period $t$ then corresponds to $i=i_{t-1}$. We realize that we have

$$
\begin{aligned}
& \hat{\pi}_{t+2, t}=\bar{\pi}_{t+2, t}\left(i_{t-1}\right)-a\left(\hat{\imath}_{t, t}-i_{t-1}\right), \\
& \hat{x}_{t+1, t}=\bar{x}_{t+1, t}\left(i_{t-1}\right)-b\left(\hat{\imath}_{t, t}-i_{t-1}\right), \\
& \hat{x}_{t+2, t}=\bar{x}_{t+2, t}\left(i_{t-1}\right)-d\left(\hat{\imath}_{t, t}-i_{t-1}\right),
\end{aligned}
$$

where $a \equiv-\partial \bar{\pi}_{t+2, t}\left(i_{t-1}\right) / \partial i$ and $b \equiv-\partial \bar{x}_{t+1, t}\left(i_{t-1}\right) / \partial i$ and $d \equiv-\partial \bar{x}_{t+2, t}\left(i_{t-1}\right) / \partial i$ are the derivatives of $\pi_{t+2, t}$ and $x_{t+1, t}$ with respect to $i$ at the equilibrium $\left(\bar{\pi}^{t}\left(i_{t-1}\right), \bar{x}^{t}\left(i_{t-1}\right), \bar{\imath}^{t}\left(i_{t-1}\right)\right)$. The coefficients $a, b$ and $c$ are endogenously determined in the equilibrium, but once determined, they are constant, due to the linearity of the model. Since $\hat{\pi}_{t+2, t}, \hat{x}_{t+2, t}$ and $\hat{x}_{t+1, t}$ fulfill (A.5) for $\tau=1$, we have

$$
\left[\bar{\pi}_{t+2, t}\left(i_{t-1}\right)-\pi^{*}-a\left(\hat{\imath}_{t, t}-i_{t-1}\right)\right]+\frac{\lambda}{\delta \alpha_{x}}\left\{\left[\bar{x}_{t+1, t}\left(i_{t-1}\right)-b\left(\hat{\imath}_{t, t}-i_{t-1}\right)\right]-\delta\left[\bar{x}_{t+2, t}\left(i_{t-1}\right)-d\left(\hat{\imath}_{t, t}-i_{t-1}\right)\right]\right\}=0 .
$$

It follows that we can write

$$
\begin{aligned}
\hat{\imath}_{t, t}-i_{t-1}= & \frac{1}{a+\lambda(b-\delta d) / \delta \alpha_{x}}\left[\bar{\pi}_{t+2, t}\left(i_{t-1}\right)-\pi^{*}\right] \\
& -\frac{\lambda / \alpha_{x}}{a+\lambda(b-\delta d) / \delta \alpha_{x}}\left[\delta \bar{x}_{t+2, t}\left(i_{t-1}\right)-\bar{x}_{t+1, t}\left(i_{t-1}\right)\right] .
\end{aligned}
$$

It follows that the optimal change in the interest rate from period $t-1$ to $t, \hat{\imath}_{t, t}-i_{t-1}$, can be seen as a linear response to the deviation of a two-period-ahead forecast from the inflation target, $\bar{\pi}_{t+2, t}\left(i_{t-1}\right)-\pi^{*}$, and to the two-period-ahead forecast of the modified change in the output gap, $\delta \bar{x}_{t+2, t}\left(i_{t-1}\right)-\bar{x}_{t+1, t}\left(i_{t-1}\right)$.

\section{C.2 The forward-looking model}

For the forward-looking model, let $\left(\hat{\pi}^{t}, \hat{x}^{t}, \hat{\imath}^{t}\right)$ be the optimal equilibrium forecasts and instrumentrate path. Recall that in the forward-looking model, the relevant decision in period $t$ concerns $i_{t+1, t}$. For a given $i$, let $\left[\bar{\pi}^{t}(i), \bar{x}^{t}(i), \bar{t}^{t}(i)\right]$ correspond to an equilibrium where $i_{t+1, t}=i$ but $i_{t+\tau, t}$ is optimal for $\tau \geq 2$ (conditional on $i_{t+1, t}=i$ ). Then, for $\bar{\imath}^{t}(i)$, (B.5) will be fulfilled for $\tau \geq 2$, but not for $\tau=1$ (except if $i=\hat{\imath}_{t+1, t}$ ). Now, a decision in period $t$ of an unchanged interest rate corresponds to $i=i_{t}$. We realize that we have

$$
\begin{aligned}
& \hat{\pi}_{t+1, t}=\bar{\pi}_{t+1, t}\left(i_{t}\right)-a\left(\hat{\imath}_{t+1, t}-i_{t}\right) \\
& \hat{x}_{t+1, t}=\bar{x}_{t+1, t}\left(i_{t}\right)-b\left(\hat{\imath}_{t+1, t}-i_{t}\right),
\end{aligned}
$$

where $a \equiv-\partial \bar{\pi}_{t+1, t}\left(i_{t}\right) / \partial i$ and $b \equiv-\partial \bar{x}_{t+1, t}\left(i_{t}\right) / \partial i$ are the derivatives of $\pi_{t+1, t}$ and $x_{t+1, t}$ with respect to $i$ at the equilibrium $\left[\bar{\pi}^{t}(i), \bar{x}^{t}(i), \bar{\imath}^{t}(i)\right]$. (Note that $x_{t, t}=x_{t, t-1}$ is the previous optimal forecast in period $t-1$ and is not affected by $i$.) Again, the coefficients $a, b$ and $c$ are endogenously determined in the equilibrium but constant, once determined, because of the linearity of the model. Since $\hat{\pi}_{t+1, t}$ and $\hat{x}_{t+1, t}$ fulfill (B.5) for $\tau=1$, we have

$$
\left[\bar{\pi}_{t+1, t}\left(i_{t}\right)-\pi^{*}-a\left(\hat{\imath}_{t+1, t}-i_{t}\right)\right]+\frac{\lambda}{\alpha_{x}}\left[\bar{x}_{t+1, t}\left(i_{t}\right)-b\left(\hat{\imath}_{t+1, t}-i_{t}\right)-x_{t, t-1}\right] .
$$


It follows that we can write

$$
\hat{\imath}_{t+1, t}-i_{t}=\frac{1}{a+\lambda b / \alpha_{x}}\left[\bar{\pi}_{t+1, t}\left(i_{t}\right)-\pi^{*}\right]+\frac{\lambda / \alpha_{x}}{a+\lambda b / \alpha_{x}}\left[\bar{x}_{t+1, t}\left(i_{t}\right)-x_{t, t-1}\right] .
$$

It follows that the optimal change in the interest rate from period $t$ to $t+1, \hat{\imath}_{t+1, t}-i_{t}$, can be seen as a linear response to the one-period-ahead forecast of the inflation gap, $\bar{\pi}_{t+1, t}\left(i_{t}\right)-\pi^{*}$, and the change in the forecast of output gap, $\bar{x}_{t+1, t}\left(i_{t)}-x_{t-1, t}\right.$ (relative not to the previous unchanged-interest-rate forecast $\bar{x}_{t, t-1}\left(i_{t-1}\right)$ but to the previous optimal forecast, $\left.x_{t, t-1}\right)$, where both forecasts for period $t+1$ are conditional on an unchanged instrument rate, $i_{t+1, t}=i_{t}$. 


\section{References}

Ball, Laurence. 1994. "Credible Disinflation with Staggered Price Setting," Amer. Econ. Rev. 84, pp. 282-289.

Ball, Laurence. 1999. "Efficient Rules for Monetary Policy," Int. Finance 2:2, pp. 63-64.

Barro, Robert and David Gordon. 1983. "A Positive Theory of Monetary Policy in a Natural Rate Model," J Polit. Economy 91, pp. 589-610.

Batini, Nicoletta and Andrew G. Haldane. 1999. "Forward-Looking Rules for Monetary Policy," in Monetary Policy Rules. John B. Taylor, ed. Chicago: Chicago U. Press.

Benhabib, Jess; Stephanie Schmitt-Grohé and Martín Uribe. 2001. "Monetary Policy and Multiple Equilibria," Amer. Econ. Rev. 91, pp. 167-186.

Berg, Claes. 1999. "Inflation Forecast Targeting: The Swedish Experience," Sveriges Riksbank Econ. Rev. 3/1999, pp. 40-66.

Bernanke, Ben S.; Thomas Laubach, Frederic S. Mishkin, and Adam S. Posen. 1999. Inflation Targeting: Lessons from the International Experience. Princeton: Princeton U. Press.

Bernanke, Ben S. and Frederic S. Mishkin. 1997. "Inflation Targeting: A New Framework for Monetary Policy?" J. Econ. Perspect. 11, pp. 97-116.

Black, Richard; Vincenzo Cassino, Aaron Drew, Eric Hansen, Benjamin Hunt, David Rose, and Alasdair Scott. 1997. "The Forecasting and Policy System: The Core Model," Research Paper No. 43, Reserve Bank of New Zealand, Wellington.

Black, Richard; Tiff Macklem and David Rose. 1997. "On Policy Rules for Price Stability," in Price Stability, Inflation Targets, and Monetary Policy. Tiff Macklem, ed. Ottawa: Bank of Canada, pp. 411-461.

Blinder, Alan S. 1998. Central Banking in Theory and Practice. Cambridge: MIT Press.

Blix, Mårten and Peter Sellin. 1998. "Uncertainty Bands for Inflation Forecasts," Sveriges Riksbank Working Paper Series No. 65.

Brash, Donald T. 2001. "Making Monetary Policy: A Look behind the Curtains," speech in Christchurch, New Zealand, January 26, 2001.

Britton, Erik; Paul Fisher and John Whitley. 1998. "The Inflation Report Projections: Understanding the Fan Chart," Bank Engl. Quart. Bull. 38, pp. 30-37.

Bryant, Ralph C.; Peter Hooper and Catherine L. Mann, eds. 1993. Evaluating Policy Regimes: New Research in Empirical Macroeconomics. Washington D.C.: The Brookings Institution.

Budd, Alan. 1998. "Economic Policy, with and without Forecasts," Bank Engl. Quart. Bull. 38 , pp. $379-384$.

Calvo, Guillermo A. 1983. "Staggered Prices in a Utility-Maximizing Framework," J. Monet. Econ. 12, pp. 383-398. 
Carlstrom, Charles T. and Timothy S. Fuerst. 2000. "Forward-Looking Versus BackwardLooking Taylor Rules" Federal Reserve Bank of Cleveland Working Paper 00-09.

Cecchetti, Stephen G. 1998. "Central Bank Policy Rules: Conceptual Issues and Practical Considerations," in Current Issues in Monetary Economics. Helmut Wagner, ed. Heidelberg: Physica-Verlag, pp. 121-140.

Cecchetti, Stephen G. 2000. "Making Monetary Policy: Objectives and Rules," Oxford Rev. Econ. Pol. 16:4, pp. 43-59.

Chow, Gregory C. 1975. Analysis and Control of Dynamic Economic Systems. New York: John Wiley \& Sons.

Christian, James W. 1968. "A Further Analysis of the Objectives of American Monetary Policy," J. Finance 23, 465-477.

Christiano, Lawrence J. and Christopher J. Gust. 1999. "Taylor Rules in a Limited Participation Model," NBER Working Paper 7017.

Clarida, Richard; Jordi Galí and Mark Gertler. 1998. "Monetary Policy Rules in Practice: Some International Evidence," Europ. Econ. Rev. 42, pp. 1033-1067.

Clarida, Richard; Jordi Galí and Mark Gertler. 1999. "The Science of Monetary Policy: A New Keynesian Perspective," J. Econ. Lit. 37, pp. 1661-1707.

Coletti, Donald; Benjamin Hunt, David Rose and Robert Tetlow. 1996. "Bank of Canada's New Quarterly Projection Model. Part 3, The Dynamic Model: QPM," Technical Report No. 75, Bank of Canada, Ottawa.

Currie, David and Paul Levine. 1993. Rules, Reputation and Macroeconomic Policy Coordination. Cambridge: Cambridge U. Press.

Dewald, William G. and Harry G. Johnson. 1963. "An Objective Analysis of the Objectives of American Monetary Policy, 1952-61," in Banking and Monetary Studies. Deane Carson, ed. Homewood: Richard D. Irwin, pp. 171-189.

Faust, Jon W. and Lars E.O. Svensson. 2000. "Credibility and Transparency: Monetary Policy with Unobservable Goals," Int. Econ. Rev., forthcoming.

Federal Reserve Bank of Kansas City. 1996. Achieving Price Stability. Kansas City: Federal Reserve Bank of Kansas City.

Federal Reserve Bank of Kansas City. 1999. New Challenges for Monetary Policy. Kansas City: Federal Reserve Bank of Kansas City.

Federal Reserve Bank of Kansas City. 2002. Rethinking Stabilization Policy. Kansas City: Federal Reserve Bank of Kansas City, forthcoming.

Federal Reserve Board. 1995. Federal Open Market Committee Transcripts, FOMC Meeting January 31-February 1, 1995, www.federalreserve.gov/fomc/transcripts.

Friedman, Milton. 1969. The Optimal Quantity of Money and Other Essays. New York: Aldine De Gruyter. 
Gerlach, Stefan and Gert Schnabel. 1998. "The Taylor Rule and Average Interest Rates in the EMU-11 Area: A Note," working paper, Bank for International Settlements.

Giannoni, Marc P. 2000. "Optimal Interest-Rates Rules in a Forward-Looking Model, and Inflation Stabilization versus Price-Level Stabilization," working paper, Federal Reserve Bank of New York.

Giannoni, Marc P. and Michael Woodford. 2002a. "Optimal Interest-Rate Rules: I. General Theory," working paper.

Giannoni, Marc P. and Michael Woodford. 2002b. "Optimal Interest-Rate Rules: II. Applications," working paper.

Goodhart, Charles A.E. 2000. "The Inflation Forecast," working paper, London School of Economics.

Greenspan, Alan. 1994. "Discussion," in The Future of Central Banking. Forrest Capie, Charles Goodhart, Stanley Fischer and Norbert Schnadt eds. Cambridge: Cambridge U. Press.

Hansen, Lars Peter and Thomas J. Sargent. 1998. "Alternative Representation of Discounted Robust Linear Quadratic Control," working paper.

Hart, Oliver. 1995. Firms, Contracts, and Financial Structure. Oxford: Oxford U. Press.

Henderson, Dale W. and Warwick J. McKibbin. 1993. "A Comparison of Some Basic Monetary Policy Regimes for Open Economies: Implications of Different Degrees of Instrument Adjustment and Wage Persistence," Carnegie-Rochester Conf. Ser. Public Pol. 39, pp. $221-317$.

Heikensten, Lars. 1999. "The Riksbank's Inflation Target-Clarification and Evaluation," Sveriges Riksbank Quart. Rev. 1/1999, pp. 5-17.

Heikensten, Lars and Anders Vredin. 1998. "Inflation Targeting and Swedish Monetary Policy-Experience and Problems," Sveriges Riksbank Quart. Rev. 4/1998, 5-33.

Hetzel, Robert L. 2000. "The Taylor Rule: Is It a Useful Guide to Understanding Monetary Policy?" Fed. Reserve Bank Richmond Econ. Quart. 86:2, pp. 1-33.

Jansson, Per and Anders Vredin. 2000. "Forecast-Based Monetary Policy in Sweden 1992 1998: A View from Within," working paper, Sveriges Riksbank.

Judd, John P. and Glenn D. Rudebusch. 1998. "Taylor's Rule and the Fed: 1970-1997," Fed. Reserve Bank of San Francisco Econ. Rev. 1998:3, pp. 3-16.

King, Mervyn A. 1994. "Monetary Policy in the UK," Fiscal Studies 15, No. 3, pp. 109-128.

King, Mervyn A. 1997. "The Inflation Target Five Years On," Bank Engl. Quart. Bull. 37(4), $434-442$.

King, Mervyn A. 1999. "Challenges for Monetary Policy: New and Old," in New Challenges for Monetary Policy. Kansas City: Federal Reserve Bank of Kansas City, pp. 11-57. 
Kohn, Donald L. 2000. "Report to the Non-Executive Directors of the Court of the Bank of England on Monetary Policy Processes and the Work of Monetary Analysis," Federal Reserve Board, October 18, 2000. Reprinted in Bank Engl. Quart. Bull. 41, pp. 35-49.

Kozicki, Sharon. 1999. "How Useful Are Taylor Rules for Monetary Policy?" Fed. Reserve Bank Kansas City Econ. Rev., 1999:2, pp. 5-33.

Kydland, Finn and Edward Prescott. 1977. "Rules Rather Than Discretion: The Inconsistency of Optimal Plans," J Polit. Economy 85, pp. 473-490.

Leeper, Eric M. and Tao Zha. 1999. "Identification and Forecasting: Joint Inputs to Policy Analysis," working paper.

Leitemo, Kai. 2000. "Targeting Inflation by Constant-Interest-Rate Forecasts," working paper, Norges Bank.

Levin, Andrew, Volker Wieland and John C. Williams. 1999. "Robustness of Simple Monetary Policy Rules under Model Uncertainty," in Monetary Policy Rules. John B. Taylor ed. Chicago: Chicago U. Press.

Levin, Andrew; Volker Wieland and John C. Williams. 2001. "The Performance of ForecastBased Monetary Policy Rules," working paper, Federal Reserve Board.

Lucas, Robert E., Jr. 1976. "Econometric Policy Evaluation: A Critique," Carnegie-Rochester Conf. Ser. Public Pol. 1, pp. 19-46.

Macklem, Tiff, ed. 1997. Price Stability, Inflation Targets, and Monetary Policy. Ottawa: Bank of Canada.

Mankiw, N. Gregory. 2001. "The Inexorable and Mysterious Tradeoff Between Inflation and Unemployment," Econ. J. 111, pp. 45-61.

Marcet, Albert and Ramon Marimon. 1999. "Recursive Contracts," working paper, Universitat Pompeu Fabra, Barcelona.

McCallum, Bennett T. 1988. "Robustness Properties of a Rule for Monetary Policy," CarnegieRochester Conf. Ser. Public Pol. 29, pp. 173-204.

McCallum, Bennett T. 1997. "Crucial Issues Concerning Central Bank Independence," J. Monet. Econ. 39, pp. 99-112.

McCallum, Bennett T. 1999. "Issues in the Design of Monetary Policy Rules," in Handbook of Macroeconomics. John B. Taylor and Michael Woodford, eds. Amsterdam: NorthHolland.

McCallum, Bennett T. 2000 "The Present and Future of Monetary Policy Rules," Int. Finance 3, pp. 273-286.

McCallum, Bennett T. and Edward Nelson. 2000 "Timeless Perspective vs. Discretionary Monetary Policy in Forward-Looking Models," working paper.

Meltzer, Allan H. 1987. "Limits of Short-Run Stabilization Policy," Econ. Inquiry 25, pp. $1-13$. 
Merriam-Webster. 1996. Webster's Tenth New Collegiate Dictionary, Springfield: MerriamWebster.

Onatski, Alexei and James H. Stock. 2000. "Robust Monetary Policy Under Model Uncertainty in a Small Model of the U.S. Economy," NBER Working Paper No. 7490.

Peersman, Gert and Frank Smets. 1998. "Uncertainty and the Taylor Rule in a Simple Model of the Euro-Area Economy," working paper.

Persson, Torsten and Guido Tabellini. 1993. "Designing Institutions for Monetary Stability," Carnegie-Rochester Conf. Ser. Public Pol. 39, pp. 53-84.

Reifschneider, David L.; David J. Stockton and David W. Wilcox. 1997. "Econometric Models and the Monetary Policy Process," Carnegie-Rochester Conf. Ser. Public Pol. 47, pp. $1-37$.

Rogoff, Kenneth. 1985. "The Optimal Degree of Commitment to an Intermediate Monetary Target," Quart. J. Econ. 100, pp. 1169-1189.

Rotemberg, Julio J. and Michael Woodford. 1997. "An Optimization-Based Econometric Framework for the Evaluation of Monetary Policy," NBER Macroeconomics Annual 1997, pp. 297-346.

Rudebusch, Glenn D. 2002a. "Assessing Nominal Income Rules for Monetary Policy with Model and Data Uncertainty," Econ. J. 112, pp. 402-432.

Rudebusch, Glenn D. 2002b. "Term Structure Evidence on Interest Rate Smoothing and Monetary Policy Inertia," J. Monet. Econ. 49, pp. 1161-1187.

Rudebusch, Glenn D. and Lars E.O. Svensson. 1999. "Policy Rules for Inflation Targeting," in Monetary Policy Rules. John B. Taylor, ed. Chicago: Chicago U. Press, pp. 203-246.

Sack, Brian and Volker Wieland. 1999. "Interest-Rate Smoothing and Optimal Monetary Policy: A Review of Recent Empirical Evidence," working paper, Federal Reserve Board.

Sims, Christopher A. 1980. "Macroeconomics and Reality," Econometrica 48, pp. 1-48.

Sims, Christopher A. 2001. "A Review of Monetary Policy Rules," J. Econ. Lit. 39, pp. $562-566$.

Smets, Frank. 2000. "What Horizon for Price Stability," ECB Working Paper No. 24.

Söderlind, Paul. 1999. "Solution and Estimation of RE Macromodels with Optimal Policy," Europ. Econ. Rev. 43, pp. 813-823.

Strotz, Robert H. 1955-56. "Myopia and Inconsistency in Dynamic Utility Maximization," Rev. Econ. Stud. 23, pp. 165-180.

Svensson, Lars E.O. 1997a. "Inflation Forecast Targeting: Implementing and Monitoring Inflation Targets," Europ. Econ. Rev. 41, pp. 1111-1146.

Svensson, Lars E.O. 1997b. "Optimal Inflation Targets, 'Conservative' Central Banks, and Linear Inflation Contracts," Amer. Econ. Rev. 87, pp. 98-114. 
Svensson, Lars E.O. 1999a. "How Should Monetary Policy Be Conducted in an Era of Price Stability?" in New Challenges for Monetary Policy. Federal Reserve Bank of Kansas City ,Kansas City: Federal Reserve Bank of Kansas City, pp. 195-259.

Svensson, Lars E.O. 1999b. "Inflation Targeting as a Monetary Policy Rule," J. Monet. Econ. 43, pp. 607-654. Working-paper version with unabridged appendix available at www.princeton.edu $\backslash$ svensson.

Svensson, Lars E.O. 1999c. "Price Level Targeting vs. Inflation Targeting: A Free Lunch?" J. Money, Credit, Banking 31, pp. 277-295.

Svensson, Lars E.O. 2000. "Open-Economy Inflation Targeting," J. Int. Econ. 50, pp. 155183.

Svensson, Lars E.O. 2001a. "Independent Review of the Operation of Monetary Policy: Report

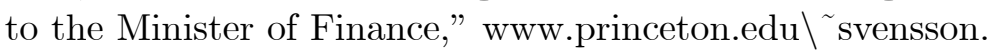

Svensson, Lars E.O. 2001b. "The Inflation Forecast and the Loss Function," in Central Banking, Monetary Theory and Practice: Essays in Honour of Charles Goodhart. Paul Mizen, ed., Edward Elgar, forthcoming.

Svensson, Lars E.O. 2001c. "Price Stability as a Target for Monetary Policy: Defining and Maintaining Price Stability," in The Monetary Transmission Process: Recent Developments and Lessons for Europe. Deutsche Bundesbank, ed. New York: Palgrave, pp. 60-102.

Svensson, Lars E.O. 2001d. "Requiem for Forecast-Based Instrument Rules," working paper.

Svensson, Lars E.O. 2002a. "Monetary Policy and Real Stabilization", in New Challenges for Monetary Policy. Federal Reserve Bank of Kansas City. Kansas City: Federal Reserve Bank of Kansas City.

Svensson, Lars E.O. and Michael Woodford. 2002a. "Implementing Optimal Policy through Inflation-Forecast Targeting," working paper.

Svensson, Lars E.O. and Michael Woodford. 2002b. "Indicator Variables for Optimal Policy," J. Monet. Econ., forthcoming.

Sveriges Riksbank. 2001. Inflation Report 1/2001.

Taylor, John B. 1979. "Estimation and Control of A Macroeconomic Model with Rational Expectations," Econometrica 47, pp. 1267-1286.

Taylor, John B. 1993. "Discretion versus Policy Rules in Practice," Carnegie-Rochester Conf. Ser. Public Pol. 39, 195-214.

Taylor, John B. 1999a. "Introduction," in Monetary Policy Rules. John B.Taylor, ed. Chicago: Chicago U. Press.

Taylor, John B. 1999b. "A Historical Analysis of Monetary Policy Rules," in Monetary Policy Rules. John B. Taylor, ed. Chicago: Chicago U. Press.

Taylor, John B., ed. 1999c. Monetary Policy Rules. Chicago: Chicago U. Press. 
Taylor, John B. 1999d. "The Robustness and Efficiency of Monetary Policy Rules as Guidelines for Interest Rate Setting by the European Central Bank," J. Monet. Econ. 43, pp. 655679 .

Taylor, John B. 2000. "Using Monetary Policy Rules in Emerging Market Economies," in Stabilization and Monetary Policy: The International Experience, Bank of Mexico, pp. 441-457.

Tinbergen, Jan. 1952. On the Theory of Economic Policy. Amsterdam:North-Holland.

Tirole, Jean. 1999. "Incomplete Contracts: Where Do We Stand?" Econometrica 67, pp. $741-781$.

Vestin, David. 2000. "Price-Level Targeting versus Inflation Targeting in a Forward-Looking Model," working paper.

Vestin, David. 2001. "The Size of the Commitment Problem", working paper.

Walsh, Carl. 1995. "Optimal Contracts for Independent Central Bankers," Amer. Econ. Rev. 85, pp. 150-167.

Walsh, Carl E. 1998. Monetary Theory and Policy. Cambridge: MIT Press.

Wicksell, Knut. 1898. Geldzins und Güterprise. Jena: Gustav Fischer. English translation 1936: Interest and Prices. Reprinted 1965. New York: Augustus M. Kelley, Bookseller.

Woodford, Michael. 1999a. "Commentary: How Should Monetary Policy Be Conducted in an Era of Price Stability?" in New Challenges for Monetary Policy.Federal Reserve Bank of Kansas City, Kansas City: Federal Reserve Bank of Kansas City, pp. 277-316.

Woodford, Michael. 1999b. "Inflation Stabilization and Welfare," working paper.

Woodford, Michael. 1999c. "Optimal Monetary Policy Inertia," NBER Working Paper No. 7261.

Woodford, Michael. 2000a. "Pitfalls of Forward-Looking Monetary Policy," Amer. Econ. Rev.: Papers and Proceedings 90, pp. 100-104.

Woodford, Michael. 2000b. "A Neo-Wicksellian Framework for the Analysis of Monetary Policy," working paper.

Woodford, Michael. 2001. "The Taylor Rule and Optimal Monetary Policy," Amer. Econ. Rev.: Papers and Proceedings 91, pp. 232-237.

Yun, Tack. 1996. "Nominal Price Rigidity, Money Supply Endogeneity, and Business Cycles," J. Monet. Econ. 37, pp. 345-370. 